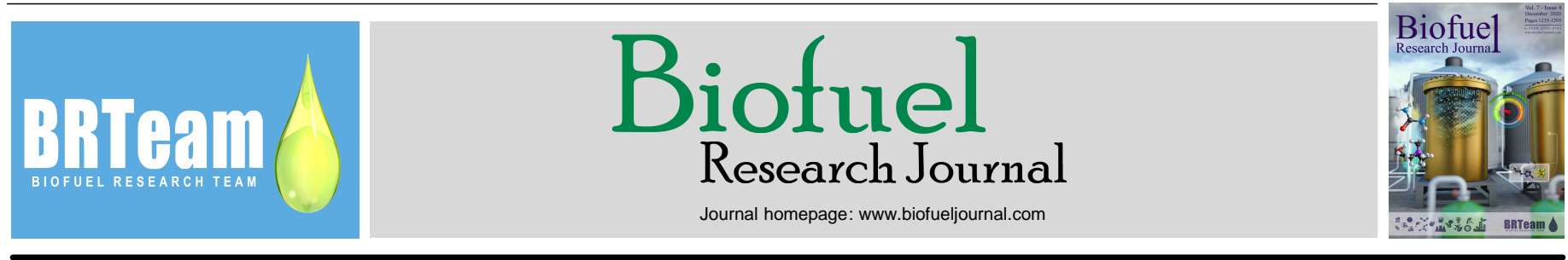

Review Paper

\title{
Recent advances in bioethanol production from lignocelluloses: a comprehensive review with a focus on enzyme engineering and designer biocatalysts
}

\author{
Yogita Lugani ${ }^{1,}$, Rohit Rai ${ }^{2,}$, Ashish A. Prabhu ${ }^{3}$, Poonam Maan ${ }^{4}$, Meenu Hans ${ }^{5}$, Vinod Kumar ${ }^{3}$, Sachin Kumar ${ }^{5} *$, Anuj \\ K. Chandel ${ }^{6}$, R.S. Sengar ${ }^{4}$
}

${ }^{1}$ Department of Biotechnology, Punjabi University, Patiala-147002, Punjab, India.

${ }^{2}$ Faculty of Applied Medical Sciences, Lovely Professional University, Phagwara-144411, Punjab, India.

${ }^{3}$ School of Water, Energy and Environment, Cranfield University, Cranfield MK43 OAL, UK.

${ }^{4}$ Sardar Vallabhbhai Patel University of Agriculture and Technology, Meerut, India.

${ }^{5}$ Biochemical Conversion Division, Sardar Swaran Singh National Institute of Bio-Energy, Kapurthala-144601, India.

${ }^{6}$ Department of Biotechnology, Engineering School of Lorena (EEL), University of São Paulo, Lorena-SP-12606452, Brazil.

\section{HIGHLIGHTS}

$>$ Recent advances in pretreatment of lignocellulosic biomass are reviewed and discussed.

$>$ Use of green solvents, including ionic liquids and deep eutectic solvents, is presented.

$>$ Strain improvement strategies to develop hyperproducing lignocellulolytic strains are compared. $>$ Advanced techniques for fermentation of mixed sugars in lignocellulosic hydrolysates are presented. $>$ Integration approaches for efficient biomass utilization and improved ethanol yields and productivity are discussed.

\section{GRAPHICAL ABSTRACT}

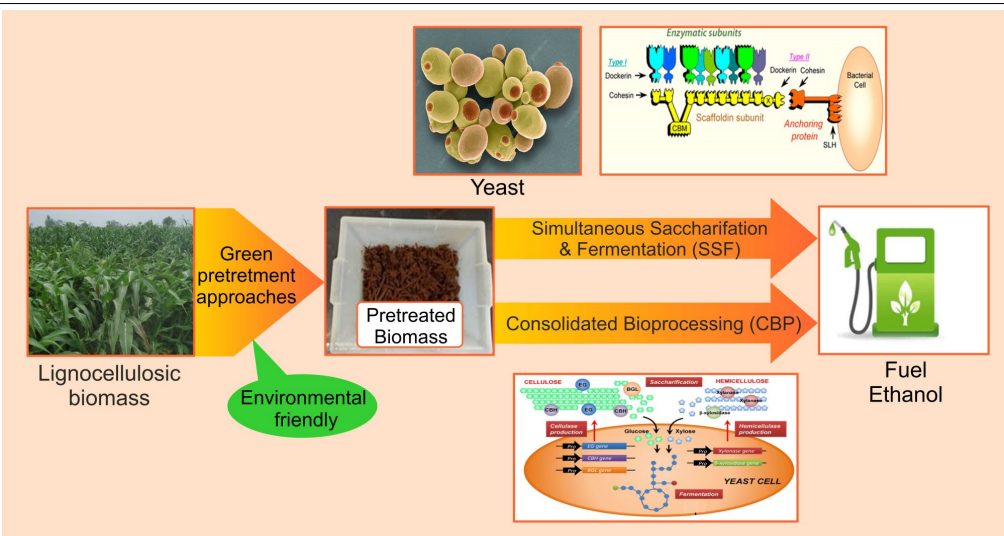

\section{ARTICLE INFO}

Article history:

Received 28 June 2020

Received in revised form 12 September 2020

Accepted 17 October 2020

Available online 1 December 2020

\section{Keywords:}

Pretreatment

Enzymatic saccharification

Auxiliary proteins

Pathway engineering

Transporter engineering

Integrated fermentation

\begin{abstract}
Many countries have their biofuel policy programs in place as part of their overall strategy to achieve sustainable development. Among biofuels, bioethanol as a promising alternative to gasoline is of substantial interest. However, there is limited availability of a sufficient quantity of bioethanol to meet demands due to bottlenecks in the present technologies to convert non-edible feedstocks, including lignocelluloses. This review article presents and critically discusses the recent advances in the pretreatment of lignocellulosic biomass, with a focus on the use of green solvents, including ionic liquids and deep eutectic solvents, followed by enzymatic saccharification using auxiliary proteins for the efficient saccharification of pretreated biomass. Different techniques used in strain improvement strategies to develop hyper-producing deregulated lignocellulolytic strains are also compared and discussed. The advanced techniques employed for fermentation of mixed sugars contained in lignocellulosic hydrolysates for maximizing bioethanol production are summarized with an emphasis on pathway and transporters engineering for xylose assimilation. Further, the integration of different steps is suggested and discussed for efficient biomass utilization and improved ethanol yields and productivity.
\end{abstract}

(c) 2020 BRTeam. All rights reserved.

Corresponding authors at: Tel.: +91 1822507415

E-mail address: sachin.biotech@gmail.com, sachin.kumar20@gov.in

t. These authors contributed equally

Please cite this article as: Lugani Y., Rai R., Prabhu A.A., Maan P., Hans M., Kumar V., Kumar S., Chandel A.K., Sengar R.S. Recent advances in bioethanol production from lignocelluloses: a comprehensive review with a focus on enzyme engineering and designer biocatalysts. Biofuel Research Journal 28 (2020) 1267-1295. DOI: $10.18331 / \mathrm{BRJ} 2020.7 .4 .5$ 


\section{Contents}

1. Introduction

2. Pretreatment.

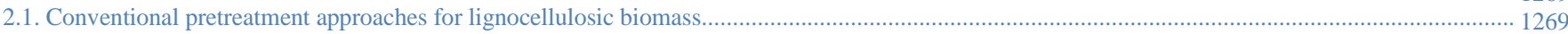

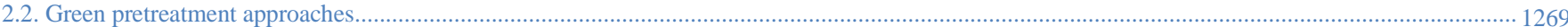

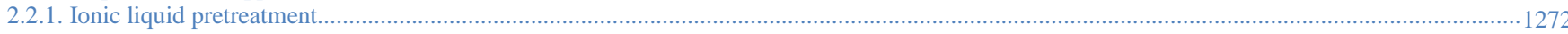

2.2.2. Deep eutectic solvent pretreatment

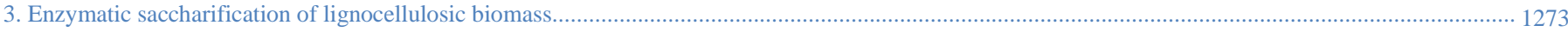

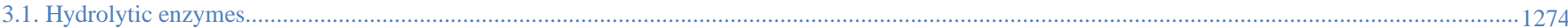

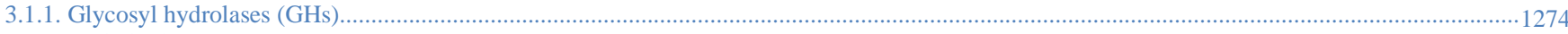

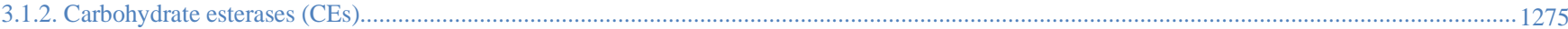

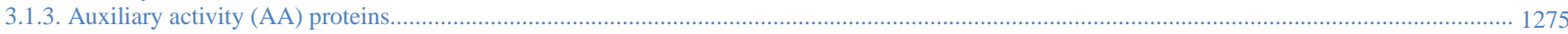

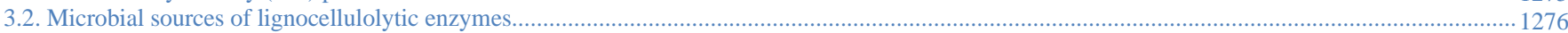

3.3. Strain improvement strategies for hyper-producing deregulated lignocellulolytic strains

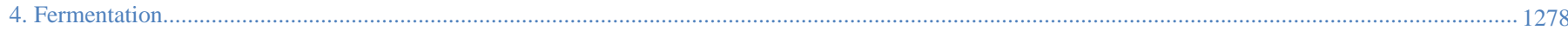

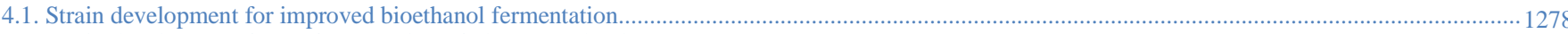

4.2. Strain development for co-fermentation of glucose and xylose

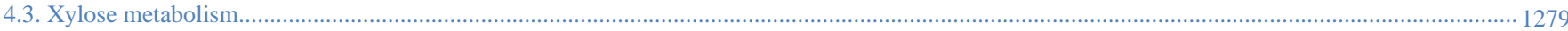

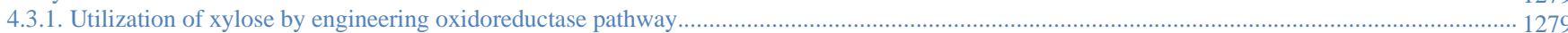

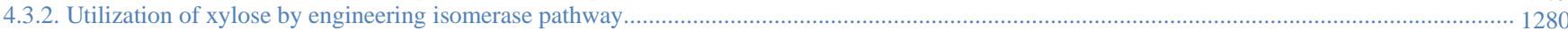

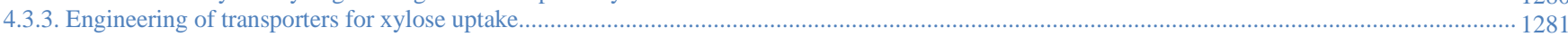

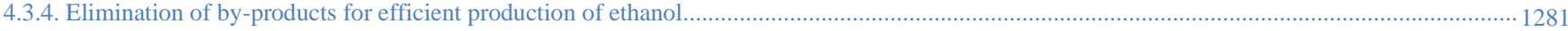

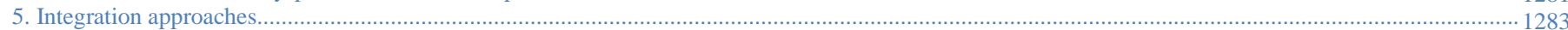

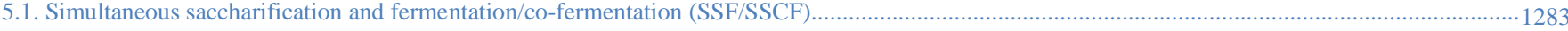

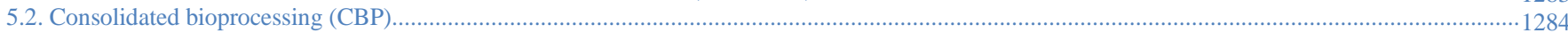

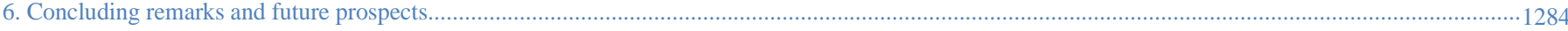

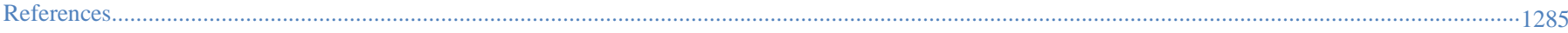

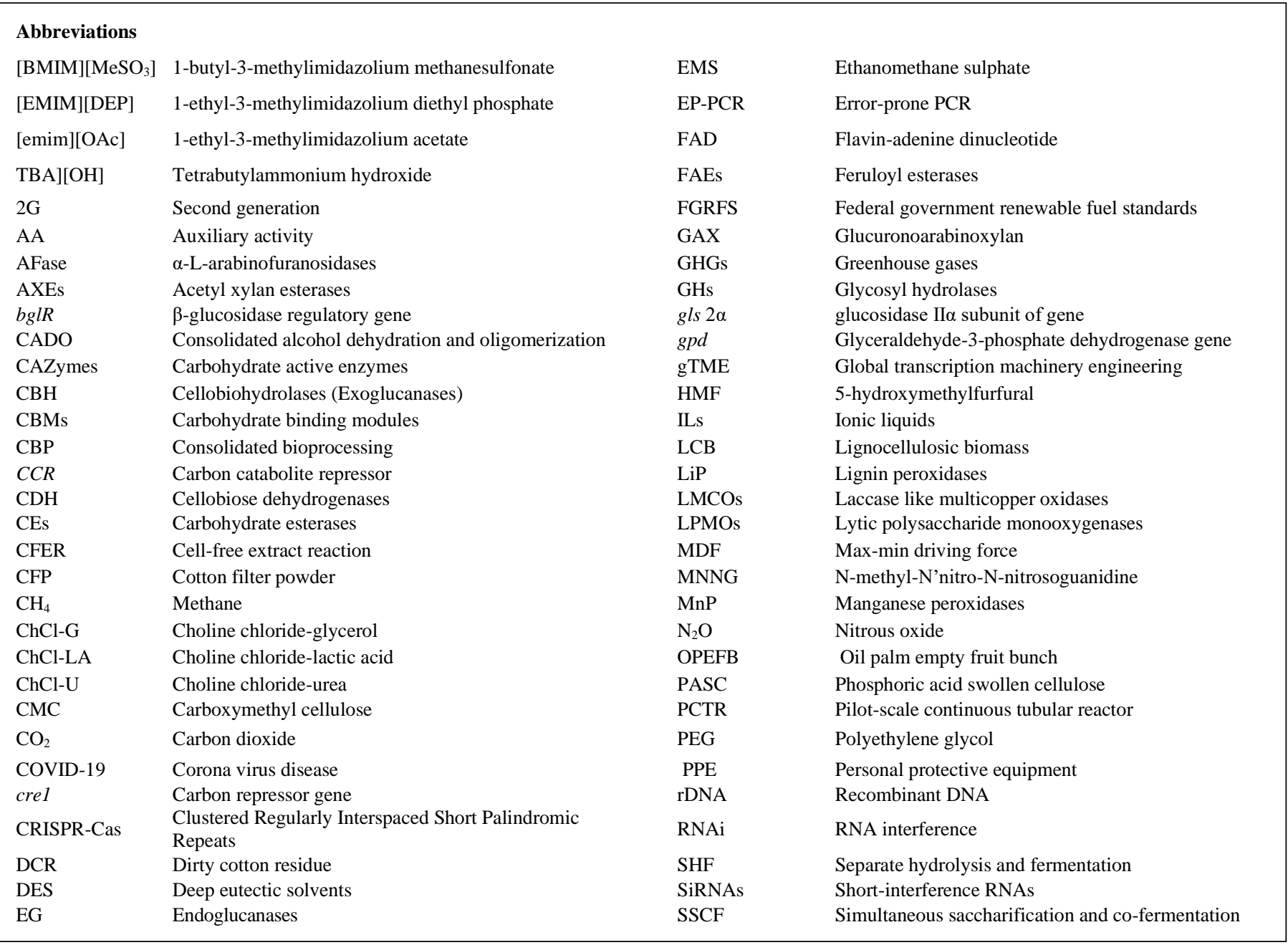




\begin{tabular}{|llll|}
\hline Abbreviations & & & \\
$\mathrm{SSF}$ & Simultaneous saccharification and fermentation & XI & Xylose isomerase \\
$\mathrm{t}_{1 / 2}$ & Half-life & XK & Xylulokinase \\
$\mathrm{VP}$ & Versatile peroxidases & XR & Xylose reductase \\
WHO & World Health Organization & $\beta \mathrm{G}$ & $\beta$-glucosidases \\
$\mathrm{XDH}$ & Xylitol dehydrogenase & & \\
\hline
\end{tabular}

\section{Introduction}

The ever-increasing demands for energy due to rapid increase of global population, industrialization, and geopolitical factors have called for the search for alternative and carbon neutral sources of energy (Souza et al., 2017; Chandel et al., 2020). For many years, the primary sources of energy have been non-renewable fossil fuels, oil, natural gas, and coal. However, these energy sources are inadequate to fulfil today`s most significant requirements of the societies in particular from the environmental and public health perspectives. More specifically, the widespread application of conventional energy resources has contributed to serious challenges, including global warming and climate change by releasing greenhouse gases (GHGs) like carbon dioxide $\left(\mathrm{CO}_{2}\right)$, methane $\left(\mathrm{CH}_{4}\right)$, nitrous oxide $\left(\mathrm{N}_{2} \mathrm{O}\right)$, and chlorofluorocarbons (Kiran et al, 2014). In fact, these adverse impacts have overshadowed the previous justifications used, including burgeoning petroleum prices, finite nature of fossil fuels, and have encourage the government and non-government agencies to find environmentally friendly, renewable, and sustainable energy resources for transportation, heating, and electricity generation (Nikolić et al., 2016).

Among these alternative energy carriers, ethanol has attracted a great deal of attention. It should be noted that ethanol is also widely used in a number of other industries and sectors among which the healthcare sector is largely highlighted due to the current COVID-19 pandemic and the recommendations by the World Health Organization (WHO) on the use of disinfectants containing alcohols like ethanol and isopropanol for adequate inactivation of coronavirus (Kratzel et al., 2020). This has for sure intensified the global demands for this valuable commodity and hence, a larger magnitude of production is required which in turns imposes more pressure on the already limited feedstocks available, i.e., first-generation feedstocks such as sugars and starch.

Given the above, lignocellulosic biomass (LCB) used as economic, widelyavailable non-edible feedstock for second-generation (2G) biofuels are highlighted more than ever (Kuila et al., 2016; Branco et al., 2019). If reaching their full potentials, LCB-derived liquid biofuels can cover approximately $40 \%$ of the total energy consumption of the world (Meher et al., 2006; Gielen et al., 2019). LCB of different origins such as banana plant waste (Ingale et al., 2014; Jahid et al., 2018; Khaliq et al., 2020), barley straw (Lara-Serrano et al., 2018), corn stover (Zakir et al., 2016; Dhiman et al., 2017), cotton stalk (Nikolić et al., 2016), and sugarcane bagasse (Wong and Sanggari, 2014; Zakir et al., 2016; Cheng et al., 2019) have been utilized for bioethanol production previously.

Three major steps are involved in LCB conversion into fuel ethanol, viz., pretreatment, saccharification, fermentation and distillation. Lignocelluloses are composed of complex polysaccharides, which are highly resistant to degradation by chemical and enzymatic methods, due to closed packing within recalcitrant lignin structure (Haldar and Purkait, 2020). Hence, in spite of their high availability and cost-effectiveness, the production of fuel ethanol and other high value-added products with high yield and productivity is a challenge (Kumar et al., 2008). The pretreatment process is performed to remove or redistribute the lignin, to reduce the cellulose crystallinity, and to increase the porosity significantly (McMillan, 1994). Subsequent saccharification or hydrolysis is done by acids or enzymes to hydrolyze the polymeric cellulose and hemicellulose into fermentable monomeric sugars (hexoses and pentoses). Enzymatic hydrolysis is preferred over acid hydrolysis due to lower energy requirements and reduced by-products formation. Nevertheless, enzymatic hydrolysis is influenced by several factors such as accessible surface area, cellulose crystallinity and degree of polymerization, lignin content, and enzyme synergy and effectiveness (Myat and Ryu, 2016; Lugani and Sooch, 2018; Cheng et al., 2019; Kucharska et al., 2020). Following pretreatment and hydrolysis, fermentation of monomeric sugars is accomplished via microbial action to produce ethanol.
The selection of microorganisms for industrial bioethanol production depends upon their ability to utilize a wide range of substrates, being resistance against various inhibitory products, and tolerance to high sugar and ethanol concentrations (Hans et al., 2019). The yield and productivity of ethanol is much less with wild microbial strains, hence, developing genetically-modified microbial strains capable of meeting these requirements at industrial scale has been a primary focus. In light of these, the aim of the present article is to review and critically discuss the advanced approaches used for the pretreatment of LCB, enzymatic saccharification, development of modified microbial strains to improve bioethanol yield, and different action mechanisms for bioethanol production using wild and genetically-modified strains. It also provides a summary of various integration approaches used for fermentative production of bioethanol. The review articles published in last five years in this domain are tabulated in Table 1 .

\section{Pretreatment}

As mentioned earlier, pretreatment is a necessary step to unwind the complex structure of LCB composing mainly of cellulose, hemicellulose, and lignin (Kassaye et al., 2017). A suitable pretreatment method is key in breaking down/redistribute the recalcitrant lignin structure leading to the accessibility of polysaccharides towards hydrolytic enzymes for their conversion into monosaccharides. In fact, an efficient pretreatment method largely facilitates the hydrolysis process leading to improved yields of monomeric sugars, reduced degradation of carbohydrates, and reduced formation of inhibitory by-products (Procentese et al., 2017). Therefore, finding an effective biomass pretreatment which is at the same time convenient to perform, environment friendly, and economically feasible, is highly critical (Ravindran et al., 2018). A variety of pretreatment methods have been developed for LCB conversion over the past few decades; however, there is no single strategy available so far that could be suitable for all types of feedstocks.

\subsection{Conventional pretreatment approaches for lignocellulosic biomass}

The most commonly used pretreatment technologies for LCB conversion include physical, (thermo)chemical, physicochemical, and biological methods (Behera et al., 2014; Kumar and Sharma, 2017; Baruah et al., 2018; Gabhane et al., 2020; Hans et al., 2020). These are extensively studied methods but are associated with a variety of limitations such as low yield, high processing cost, and negative environmental impacts, and therefore, more efficient green technologies are being explored continuously to overcome these challenges (Capolupo and Faraco, 2016). Figure 1 shows the different pretreatment approaches along with their pros and cons.

\subsection{Green pretreatment approaches}

Recently, the "Green Chemistry" concept has gained attention with a possible solution to the challenges of negative environmental impacts associated with the conventionally used pretreatment methods for LCB, involving the use of hazardous chemicals. Ionic liquids (ILs)- and deep eutectic solvents (DES)-based pretreatments are among the most promising alternative methods owing to their ability to pretreat and selectively dissolve the constituents of biomass in a non-hazardous manner. 
Table 1.

Recent review articles (2015-2020) on bioethanol production through the utilization of lignocellulosic biomass.

\begin{tabular}{ll}
\hline S. No. & Review title \\
\hline 1 & $\begin{array}{l}\text { Lignocellulosic agriculture wastes as biomass } \\
\text { feedstocks for second-generation bioethanol } \\
\text { production: Concepts and recent developments }\end{array}$ \\
2 & $\begin{array}{l}\text { Recent advances in pretreatment technologies for } \\
\text { efficient hydrolysis of lignocellulosic biomass }\end{array}$
\end{tabular}

Lignocellulosic biomass: A sustainable platform for 3 the production of bio-based chemicals and polymers

$4 \quad$ Lignocelluloses: An economical and ecological resource for bio-ethanol production- A review

Consolidated briefing biochemical ethanol production from lignocellulosic biomass

6 Utilization of agricultural waste for bioethanol production- A review

Recent progresses in bioethanol production from lignocellulosic materials: A review

Bioethanol production from lignocellulosic wasteA review

A prospective of bioethanol production from biomass ass alternative fuel for spark ignition engine

A review on current technological advancement of lignocellulosic bioethanol production

A review on second and third generation bioethanol production

Fuel ethanol production from lignocellulosic biomass: An overview on feedstocks and technological approaches

13

Current status and strategies for second generation biofuel production using microbial systems lignocellulosic biomass

15

A review on the pretreatment of lignocellulose for high-value chemicals

Recent updates on different methods of

16 pretreatment of lignocellulosic feedstocks: A review

17 Recent status on enzymatic saccharification of lignocellulosic biomass for bioethanol production

8 Review on pretreatment methods and ethanol production from cellulosic water hyacinth

19 Harnessing the potential of bio-ethanol production from lignocellulosic biomass in Nigeria- A review

Recent trends in the pretreatment of lignocellulosic biomass for value-added products

Engineering ligninolytic consortium for

21 bioconversion of lignocelluloses to ethanol and chemicals
Coverage of review

Reference

Different LCB as feedstock and their structural compositions; different pretreatment methods;

fermentation of sugars into ethanol; product recovery; optimization of saccharification and fermentation Saini et al. (2015) bioprocess; economic considerations for cellulosic ethanol production

Composition of LCB, effective parameters limiting the hydrolysis of lignocelluloses; pretreatment technologies for LCB to obtain fermentable sugars for ethanol production

Akhtar et a $(2016$

Structure and sources of LCB; production of valuable chemicals from LCB; existing, planned, and under construction facilities to produce bioethanol from LCB

Isikgor and Becer (2015)

Potential sources and composition of LCB; microorganisms and their lignolytic enzymes; overview on LCB conversion into bioethanol; pretreatment methods; hydrolysis of pretreated biomass; fermentation; methods used to improve fungal enzyme production, activity, and/or stability

Current status of global bioethanol production; sources and composition of LCB; processing routes to bioethanol including pretreatment, hydrolysis, and fermentation; recent issues in bioethanol production including gap between biotech research and commercialization and bioethanol-based economy

Classification of agricultural wastes; conversion of agricultural waste to ethanol; hydrolysis of cellulose contained in LCB; fermentation of sugar to ethanol; pretreatment technologies for agricultural wastes along with advantages and disadvantages of each method

Lignocellulosic and algal feedstocks for bioethanol production; different pretreatment and hydrolysis methods for LCB; fermentation methods including integrated approaches (SHF, SSF, SSCF, SSFF, $\mathrm{CBP}$ ); ethanol recovery; LCB biorefinery

Different pretreatment methods for agricultural wastes including wheat straw, rice straw, corn straw, and bagasse; enzymatic hydrolysis; fermentation

Feedstocks used for different generations of biofuels; process for conversion of biomass to bioethanol; fuel properties of bioethanol; engine performance and emission characteristics using bioethanol and its blends

Production of bioethanol from LCB including pretreatment, hydrolysis, and fermentation; integrated approaches (SHF, SSF, CBP) used in fermentation with a special emphasis on SSF; yeast genetic engineering; ethanol production from different thermotolerant yeasts

Different generations of biofuels with their feedstocks; processes for production of second and third generation bioethanol; cogeneration of energy from sugarcane; life cycle assessment of ethanol and gasoline

Sources and composition of LCB; conversion of LCB into ethanol using pretreatment, detoxification, hydrolysis, fermentation, and product recovery; strategies used to overcome inhibitor problems during ethanol production; integration processes used for bioethanol production; role of microorganisms in pretreatment, detoxification, hydrolysis, and fermentation

LCB pretreatment methods; $2 \mathrm{G}$ biofuel production from biomass using microbes; different approaches to enhance biofuel production; current production status of bioethanol

An overview on biochemical routes including different processes for bioethanol production; challenges, advantages, and recent developments in different pretreatment processes; quantitative comparison of leading pretreatment technologies; process integration to establish commercial systems

Structure of LCB; pretreatment methods with their action mechanisms for extraction of sugars (pentoses and hexoses) from LCB; existing challenges in pretreatment of $\mathrm{LCB}$

Composition of common LCB, different pretreatment processes along with their advantages and limitations; production of value-added products, i.e., biofuels and chemicals from pretreated LCB

An overview of different processes used in conversion of LCB into ethanol; enzymes used for LCB hydrolysis; production of cellulose and hemicellulose by microorganisms; various factors affecting enzymatic hydrolysis

Composition of LCB; cell wall composition of water hyacinth (WH); pretreatment methods along with their advantages and disadvantages; sugar production from $\mathrm{WH}$; fermentation and ethanol production considering the latest studies on ethanol production from $\mathrm{WH}$

Potential LCB feedstocks in Nigeria; bioethanol production from sugarcane bagasse, corn cobs, mang peels, sorghum straw, and rice husks; cellulosic biomass capacity for bioethanol production in Nigeria pathways to bioethanol production; challenges of LCB conversion to bioethanol; commercialization of biomass to bioethanol processes

Structure and composition of LCB; different pretreatment methods for extraction of reducing sugars for production of biofuels including bioethanol, biogas, aldehydes, phenols, and organic acids

Allen et al. (2016)

Spyridon and

Willem Euverink

$(2016$

Nwosu-Obieogu et al. (2016)

Haq et al. (2016)

Mohanty and Abdullahi (2016)

Sebayang et a

(2016)

Sharma et a

(2016b)

Teixeira et al.

(2016)

Zabed et al. (2016)

Bhatia et al

(2017)

Bhutto et al (2017)

Chen et al. (2017)

Kumar and

Sharma (2017)

Madadi et al.

(2017)

Rezania et al. $(2017)$

Awoyale and Lokhat (2019)

Baruah et al. (2018)

Engineering of ligninolytic armory; enzymatic hydrolysis and fermentation; strategies for improving lignocellulosic ethanol production; lignocellulose-derived platform chemicals 
Table 1.

Continued.

\begin{tabular}{ll}
\hline S. No. & Review title \\
\hline 22 & $\begin{array}{l}\text { Effects of organosolv pretreatment conditions for } \\
\text { lignocellulosic biomass in biorefinery applications: } \\
\text { A review }\end{array}$ \\
23 & $\begin{array}{l}\text { Second generation bioethanol production: On the } \\
\text { use of pulp and paper industry wastes as feedstock }\end{array}$ \\
24 & $\begin{array}{l}\text { Bioethanol production from renewable raw } \\
\text { materials and its separation and purification: A } \\
\text { review }\end{array}$ \\
& $\begin{array}{l}\text { Emerging role of nanobiocatalysts in hydrolysis of } \\
\text { lignocellulosic biomass leading to sustainable } \\
\text { bioethanol production }\end{array}$
\end{tabular}

bioethanol production

\section{Coverage of review}

Organosolv pretreatment method with advantages and disadvantages; optimal pretreatment conditions for effective delignification and enzymatic conversion; organosolv-based biorefineries

LCB composition; production of $2 \mathrm{G}$ bioethanol through pretreatment, hydrolysis/ saccharification, fermentation, recovery, and dehydration; bioethanol production from kraft pulp, spent sulfite liquor, an paper and pulp sludge; conversion of paper and pulp mills into biorefineries

Biorefinery and bioethanol production; raw materials and their pretreatment for bioethanol production; bioethanol production from raw materials containing sugar, starch, and LCB; bioethanol separation and purification

Conventional methods for hydrolysis of LCB; role of nanobiocatalysts in hydrolysis; different nanomaterials used in nanobiocatalysis; synthesis of nanocellulose; toxicity concerns of nanoparticles,

Bioethanol production from LCB; bioethanol production using molecular tools and genetically modified organisms

Types of bioethanol generations; composition of LCB; conversion of LCB into ethanol using differen types of pretreatment, enzymatic hydrolysis, and fermentation methods (SHF, SSF, SSCF, CBP); pentose fermentation and xylose metabolism; recombinant fermentative microbes; distillation and dehydration for ethanol recovery; latest improvements in ethanol production from LCB

Composition of LCB; overall bioconversion process of LCB into ethanol; comparison of conventional and developing pretreatment methods (1996 to 2018) for different LCB along with the advantages and limitations of each method; SSCF process for bioethanol production

Composition of LCB; whole process of bioethanol production including pretreatment, hydrolysis, fermentation, and distillation; advantages and disadvantages of various physical, physico-chemical, and biological pretreatment methods; challenges faced in pretreatment of LCB; integrated approaches for bioethanol production (SHF, SSF, SSCF, CBP)

Composition of various types of LCB; pretreatment techniques for LCB; ethanol recovery from different feedstocks

Sources and composition of LCB; bioethanol production steps including pretreatment, hydrolysis, and fermentation; integrated processes in bioethanol production

Production of cellulosic ethanol in a step-wise manner; production of different inhibitors during enzymatic hydrolysis and fermentation and their impacts; opportunities to produce bio-based chemicals alongside cellulosic ethanol; technology readiness level (TRL) of chemicals which have reached commercial-scale production

Different generations and types of biofuels; structure of LCB; biomass recalcitrance and pretreatment; hydrolysis of pretreated biomass; obstacles in enzymatic hydrolysis of LCB and the role of pretreatment; comparison of IL, concentrate phosphoric acid (CPA), and N-methylmorpholine-N-oxide (NMMO) pretreatment methods

Overview on different steps for production of first, second, third, and fourth generation biofuels; details on production of fourth generation biofuels including cultivation and accumulation of carbohydrates, harvesting, recycling of water, and nutrients after cultivation; saccharification and fermentation; distillation, concentration, transportation and use of bioethanol; comparison of bioethanol productivities from plants and microalgae

Physico-chemical properties of bioethanol; steps involved in bioethanol production; feedstocks for bioethanol production; fermentation process and mechanism; types of fermentation in bioethanol production (SHF, SSF, BF, FBF, CF, SoSF, NSSF, SSCF, SSFF, CBP); advantages of CBP

Chemical composition of different LCB; comparison of different pretreatment methods; factors affecting biological pretreatments; delignification using bacteria, fungi, and their enzymes along with their action mechanisms; hydrolysis of polysaccharides contained in LCB; fermentation; lignocellulose fuel economy

Structure and composition of LCB; processes for conversion of LCB into ethanol; processes used in different pretreatment methods with their advantages and disadvantages; integrated fermentation approaches (SHF, SSF, SSCF) for ethanol production along with advantages and disadvantages of each process; effect of different pretreatment and hydrolysis methods and conditions, and fermentation conditions on ethanol yield; use of bioethanol as an alternative fuel

Composition of corncob; contemporary pretreatment strategies; formation of inhibitory by-products and minimizing their effects; chemical hydrolysis

Different LCB and their compositions; conventional and advanced pretreatment technologies with advantages and limitations of each method

\section{Reference}

Borand and

Karaosmanoğlu (2018)

Branco et al (2019)

Bušić et al. (2018)

Rai et al. (2019a)

Rastogi and Shrivastava (2018)

Robak and Balcerek (2018)

Singh and Satapathy (2018)

Singh and Satapathy (2018)

Tayyab et al. (2018)

Abo et al. (2019)

Rosales-Calderon and Arantes (2019)

Satari et al. (2019)

Silva and

Bertucco (2019)

Toor et al. (2020)

Tsegaye et al

Abdu Yusuf and L Inambao (2019)

Arumugam et al. (2020)

Cheah et al. (2020) 
Table 1.

Continued

\begin{tabular}{|c|c|c|c|}
\hline S. No. & Review title & Coverage of review & Reference \\
\hline 40 & $\begin{array}{l}\text { Lignocellulosic bioethanol production: Prospects of } \\
\text { emerging membrane technologies to improve the } \\
\text { process- A critical review }\end{array}$ & $\begin{array}{l}\text { Existing processes of lignocellulosic bioethanol production; conventional fermentation technology to } \\
\text { produce bioethanol; conventional separation processes and their limitations; emerging membrane-based } \\
\text { processes for lignocellulosic bioethanol production; advanced membrane-based enzymatic } \\
\text { saccharification and fermentation for bioethanol production; advanced SSFF strategy for lignocellulosic } \\
\text { bioethanol production; advanced membrane separation processes for recovery of bioethanol; status of } \\
\text { lignocellulosic bioethanol production at international and national levels; economic aspects of } \\
\text { lignocellulosic bioethanol production }\end{array}$ & Dey et al. (2020) \\
\hline 41 & $\begin{array}{l}\text { Different pretreatment technologies of } \\
\text { lignocellulosic biomass for bioethanol production: } \\
\text { An overview }\end{array}$ & $\begin{array}{l}\text { LCB structure; steps for conversion of LCB into ethanol; pretreatment methods with merits and } \\
\text { demerits of each method; efficiency of different pretreatment methods for conversion of LCB into } \\
\text { ethanol; ethanol yield of different raw materials using different pretreatment combinations }\end{array}$ & $\begin{array}{l}\text { Rezania et al. } \\
(2020)\end{array}$ \\
\hline 42 & $\begin{array}{l}\text { Current state-of-the art in ethanol production from } \\
\text { lignocellulosic feedstocks }\end{array}$ & $\begin{array}{l}\text { Structure of LCB; pretreatment strategies for removal of lignin and xylan; detoxification of } \\
\text { lignocellulosic hydrolysates by various methods; enzymatic hydrolysis; fermentation; distillation and } \\
\text { dehydration }\end{array}$ & $\begin{array}{l}\text { Robak and } \\
\text { Balcerek (2020) }\end{array}$ \\
\hline 43 & $\begin{array}{l}\text { Recent advances in bioethanol production from } \\
\text { lignocelluloses: A comprehensive review with a } \\
\text { focus on enzyme engineering and designer } \\
\text { biocatalysts }\end{array}$ & $\begin{array}{l}\text { Green pretreatment approaches including the use of ILs and DES for pretreatment of LCB; enzymatic } \\
\text { saccharification of LCB; microbial sources of lignocellulolytic enzymes; strain improvement strategies } \\
\text { to achieve hyper-producing lignocellulolytic strains; fermentation and integrated approaches for ethanol } \\
\text { production; strain development for co-fermentation of xylose and glucose; pathways and genes } \\
\text { involved in xylose metabolism; utilization of xylose through engineering the xylose isomerase pathway; } \\
\text { engineering of transporters for improved xylose uptake }\end{array}$ & Present review \\
\hline
\end{tabular}

\section{Lignocellulosic Biomass}

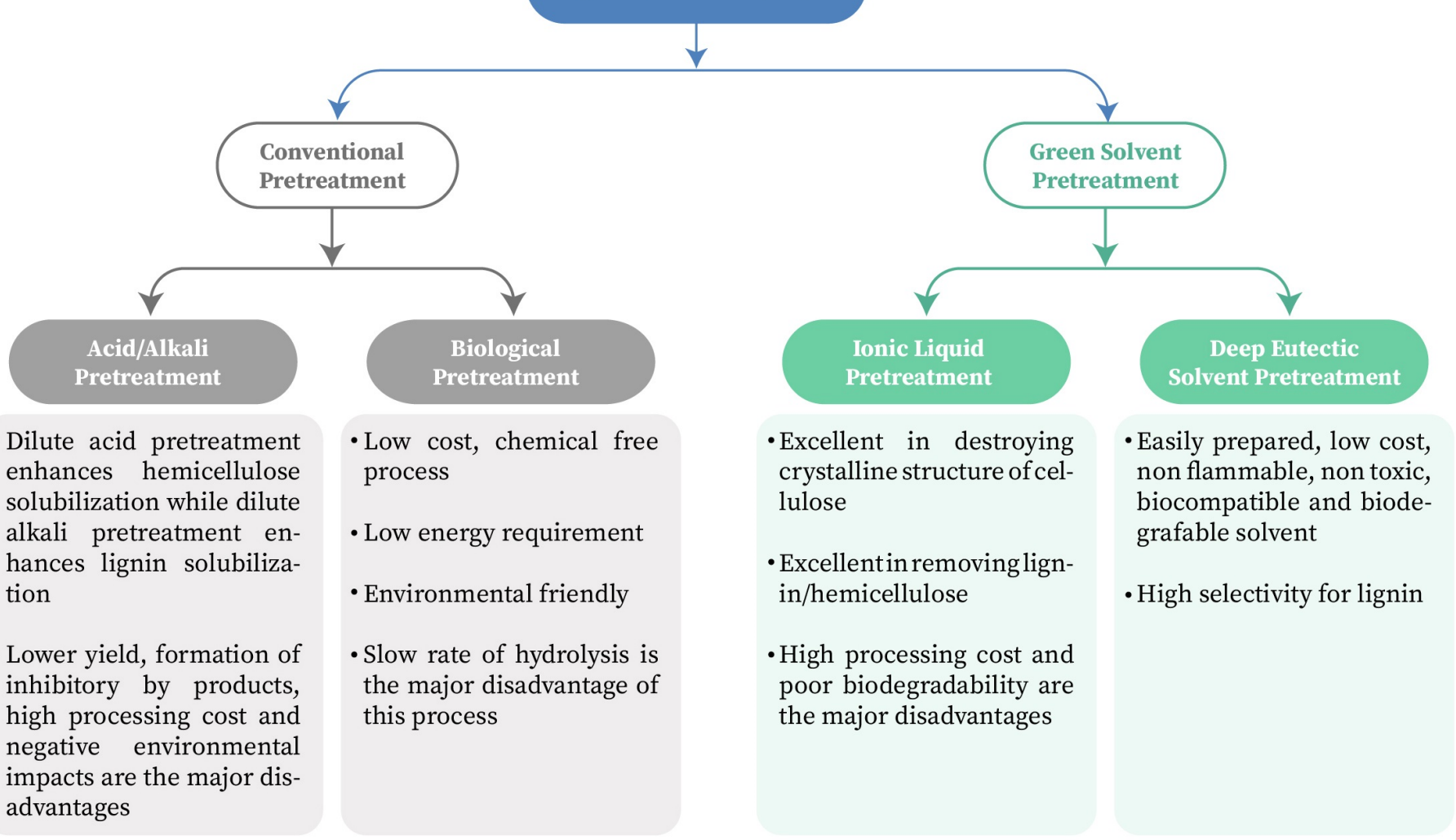

Fig. 1. Different pretreatment approaches, along with their pros and cons.

\subsubsection{Ionic liquid pretreatment}

ILs are known as "green solvents" due to their higher thermal and chemical stability, low vapor pressure, and non-flammable nature (Wu et al., 2014; Wahlström and Suurnäkki, 2015). ILs are liquids composed of ions with strong

electrostatic bonding, making them less volatile, and electrochemicallystable (Socha et al., 2014). Moreover, ILs` characteristic could be designed by altering the combination of cations and anions. The cations contained in ILs are organic, while the anions could be either inorganic or organic (Brandt et al., 2011). 
Table 2.

A summary of the studies on the effects of ionic liquid pretreatment on LCB conversion.

\begin{tabular}{|c|c|c|c|c|c|}
\hline S. No. & Biomass type & Ionic liquid & Pretreatment conditions & Effect on saccharification & Reference \\
\hline 1 & $\begin{array}{l}\text { Dirty cotton residue } \\
\text { (DCR) and cotton filter } \\
\text { powder (CFP) }\end{array}$ & $\begin{array}{l}\text { 1-ethyl-3- } \\
\text { methylimidazolium acetate }\end{array}$ & $\begin{array}{l}140{ }^{\circ} \mathrm{C}, 2 \mathrm{~h} \text {, solid-to liquid } \\
\text { ratio }(1: 9 \mathrm{w} / \mathrm{v})\end{array}$ & $\begin{array}{l}\text { For DCR: Glucan to } \\
\text { Glucose yield: } 78 \% \text {, xylose yield: } 94.9 \% \text {, } \\
\text { delignification: } 45.5 \% \\
\text { For CFP: Glucan to glucose yield: } 75.8 \% \text {, Xylan } \\
\text { to xylose yield: } 95.7 \% \text {, delignification: } 16 \%\end{array}$ & $\begin{array}{l}\text { Fockink et al. } \\
(2020)\end{array}$ \\
\hline 2 & Rice straw & $\begin{array}{l}\text { 1-H-3-methylmorpholinium } \\
\text { chloride }\end{array}$ & $\begin{array}{l}120^{\circ} \mathrm{C}, 5 \mathrm{~h} \text {, solid loading }(5 \% \mathrm{w} / \mathrm{w}) \text {, } \\
50 \% \text { water }\end{array}$ & Hydrolysis yield increased from $33.2 \%$ to $70.1 \%$ & $\begin{array}{l}\text { Mohammadi et al. } \\
\text { (2019) }\end{array}$ \\
\hline 3 & Eucalyptus & Tetrabutylammonium hydroxide & $\begin{array}{l}60^{\circ} \mathrm{C}, 30 \mathrm{~min} \text {, solid loading }(10 \% \text {, } \\
\mathrm{w} / \mathrm{v})\end{array}$ & Reducing sugar yield of $426.6 \mathrm{mg} / \mathrm{g}$ & Wang et al. (2018) \\
\hline 4 & Bamboo biomass & $\begin{array}{l}\text { 1-butyl 3-methylimidazolium } \\
\text { chloride }\end{array}$ & $\begin{array}{l}120^{\circ} \mathrm{C}, 6 \mathrm{~h} \text {, solid loading }(20 \% \text {, } \\
\mathrm{w} / \mathrm{v})\end{array}$ & Reducing sugar yield of $80 \%$ & $\begin{array}{l}\text { Kassaye et al. } \\
\text { (2017) }\end{array}$ \\
\hline 5 & Oil palm frond biomass & $\begin{array}{l}\text { 1-ethyl-3-methylimidazolium } \\
\text { diethyl phosphate }\end{array}$ & $\begin{array}{l}100^{\circ} \mathrm{C}, 4 \mathrm{~h}, \text { solid-to liquid } \\
\text { ratio }(1: 10, \mathrm{w} / \mathrm{v})\end{array}$ & $\begin{array}{l}\text { Lignin reduction by } 55 \% \text {; no enzymatic reaction } \\
\text { performed }\end{array}$ & $\begin{array}{l}\text { Financie et al. } \\
(2016)\end{array}$ \\
\hline 6 & Switchgrass & $\begin{array}{l}\text { 1-butyl-3-methylimidazolium } \\
\text { methanesulfonate }\end{array}$ & $110^{\circ} \mathrm{C}, 4 \mathrm{~h}$, solid loading $(5 \%, \mathrm{w} / \mathrm{v})$ & $\begin{array}{l}23 \% \text { reduction in cellulose crystallinity; } 12 \mathrm{~g} / \mathrm{L} \\
\text { glucose recovery by employing } 2 \% \text { pretreated } \\
\text { switch grass }\end{array}$ & Xia et al. (2014) \\
\hline 7 & Rice straw & Cholinium lysine & $\begin{array}{l}90^{\circ} \mathrm{C}, 5 \mathrm{~h} \text {, biomass loading }(5 \% \text {, } \\
\mathrm{w} / \mathrm{w})\end{array}$ & Glucose yield: $84.0 \%$, Xylose yield: $42.1 \%$ & Hou et al. (2012) \\
\hline 8 & Switchgrass & $\begin{array}{l}\text { 1-ethyl-3-methylimidazolium } \\
\text { acetate }\end{array}$ & $\begin{array}{l}160^{\circ} \mathrm{C}, 3 \mathrm{~h} \text {, biomass loading ( } 3 \% \text {, } \\
\mathrm{w} / \mathrm{w})\end{array}$ & Reduced saccharification time from $72 \mathrm{~h}$ to $12 \mathrm{~h}$ & Li et al. (2010) \\
\hline
\end{tabular}

Many studies have revealed that ILs-pretreated LCB exhibited increased surface area with reduced lignin content and cellulose crystallinity (Wu et al., 2011; Li et al., 2010; Kassaye et al., 2017). The developments made in the utilization and characterization of LCB using ILs over the past decade are reviewed and represented in Table 2. Xia et al. (2014) evaluated that switchgrass (Panicum virgatum) pretreated with 1-butyl-3-methylimidazolium methanesulfonate ([BMIM] $\left.\left[\mathrm{MeSO}_{3}\right]\right)$ at $110^{\circ} \mathrm{C}$ for $4 \mathrm{~h}$ resulted in much higher enzymatic hydrolysis and glucose yields. Financie et al. (2016) observed that oil palm frond biomass pretreated with 1-ethyl-3-methylimidazolium diethyl phosphate [EMIM][DEP] at $110^{\circ} \mathrm{C}$ for $1 \mathrm{~h}$ showed an enhancement in cellulose content from $45.7 \%$ to $68.5 .1 \%$ while a reduction of $8.5 \%$ and $12.1 \%$ was also observed in lignin and hemicellulose contents, respectively. Wang et al. (2018) investigated an ultrasound-assisted aqueous IL pretreatment approach (tetrabutylammonium hydroxide $([\mathrm{TBA}][\mathrm{OH}]))$ for eucalyptus. They argued that the pretreated sample showed a marked enhancement in the initial enzymatic rate of cellulose $(79.39 \mathrm{mg} / \mathrm{g} / \mathrm{h})$ as compared to the untreated sample $(17.63 \mathrm{mg} / \mathrm{g} / \mathrm{h})$. Recently, Fockink et al. (2020) observed the effect of 1-ethyl3-methylimidazolium acetate [emim][OAc] during the pretreatment of dirty cotton residue (DCR) and cotton filter powder (CFP) at $140^{\circ} \mathrm{C}$ for $2 \mathrm{~h}$. DCR yielded a high glucose yield of $78 \%$, xylose yield of $94.9 \%$, and delignification level of $45.5 \%$, while CFP provided a glucose yield of $75.8 \%$, xylose yield of $95.7 \%$, and $16 \%$ of delignification.

Although as reported in the studies, ILs pretreatment approaches are environment friendly but the high cost of these strategies may limit their use in large scale biorefineries (Hou et al., 2013).

\subsubsection{Deep eutectic solvent pretreatment}

Abbott et al. (2003) attracted the attention of the scientific community towards a nascent class of green and designer solvents known as deep eutectic solvent (DES) as an alternative to ILs. DESs are a mixture of organic compounds having a hydrogen-bond acceptor, typically a quaternary ammonium halide salt and a hydrogen-bond donor such as amino acids, urea, amines, carboxylic acid, or carbohydrates (Francisco et al., 2012; Zhang et al., 2016). DESs are promising alternative to ILs in terms of cost, nontoxicity, and biodegradability. The use of DESs has been explored as extraction solvents (García et al., 2016; Jenkin et al., 2016), reaction media, and electrolytes (Jhong et al., 2009; Alonso et al., 2016). These compounds have also been used extensively in recent years in the pretreatment of LCB for achieving high hydrolysis and fermentation yields as tabulated in Table 3 .

Several studies have reported DES as a reasonable reaction media for enzymatic reactions as compared to conventional organic media (Gill and Vulfson, 1994; Erbeldinger et al., 1998). DESs are also promising solvents for dissolving a considerable proportion of the lignin contained in LCB (Kandanelli et al., 2018; Kim et al., 2018). Francisco et al. (2012) observed that choline chloride-lactic acid (ChCl-LA) in a molar ratio of $1: 10$ at $60^{\circ} \mathrm{C}$ for $24 \mathrm{~h}$ dissolved a high amount of lignin (11.82\%) from wheat straw, while cellulose was intact. An et al. (2015) studied the pretreatment of grasses with cholinium-arginate, and observed $>69 \%$ lignin extraction. Pretreatment of rice straw with ChCl-LA was reported in a different study leading to a lignin dissolution of $68 \pm 4 \mathrm{mg} / \mathrm{g}$ (Kumar et al., 2016). Solubilization of lignin and hemicellulose with cellulose digestibility of $>90 \%$ have been reported when corn stover and corncobs were pretreated by using DESs (Xu et al., 2016; Zhang et al., 2016; Hou et al., 2017). Loow et al. (2018) reported that the pretreatment of oil palm empty fruit bunch (OPEFB) with a mixture of choline chloride-urea (ChCl-U) $(1: 2)\left(120{ }^{\circ} \mathrm{C}\right.$ $4 \mathrm{~h})$ and $0.4 \mathrm{~mol} / \mathrm{L} \mathrm{CuCl}_{2}\left(120^{\circ} \mathrm{C}, 30 \mathrm{~min}\right)$ resulted in high delignification, and a xylose concentration of $14.76 \mathrm{~g} / \mathrm{L}$ in hydrolysate (Loow et al., 2018). Another report showed similar results for DES-pretreated food wastes (pretreatment conditions: $150^{\circ} \mathrm{C}$ for $16 \mathrm{~h}$ ), such as apple residues, potato peels, and brewer's spent grains (Procentese et al., 2018). In this study, $\mathrm{ChCl}-\mathrm{U}$ pretreatment lowered the energy requirement by about $28 \%$ as compared to $\mathrm{NaOH}$ pretreatment.

The effect of three different DESs, namely, ChCl-LA, ChCl-U, and choline chloride-glycerol (ChCl-G), during the pretreatment of OPEFB at $120^{\circ} \mathrm{C}$ for $3 \mathrm{~h}$ with the solid-to-liquid ratio of $1: 10(\mathrm{w} / \mathrm{v})$ was studied and compared to acid and alkaline solvents (Thi and Lee, 2019). ChCl-LA (1:2) showed the highest reducing sugars yield $(20.7 \%)$ and was found more effective than acid and alkaline solvents in preventing sugars loss and exposing the cellulose fraction to enzymatic saccharification.

\section{Enzymatic saccharification of lignocellulosic biomass}

Conversion of LCB into pentose/hexose sugars with industrially desired yields is one of the major bottlenecks in the production of $2 \mathrm{G}$ biofuels since there are several challenges associated with achieving high process 
Table 3 .

A summary of the studies on the effects of DES pretreatment on LCB conversion.

\begin{tabular}{|c|c|c|c|c|}
\hline Biomass & Deep eutectic solvent & Pretreatment conditions & Effect on saccharification & Reference \\
\hline Oil palm empty fruit bunch & Choline chloride-lactic acid & $120^{\circ} \mathrm{C}, 3 \mathrm{~h}$, solid to liquid ratio $(1: 10, \mathrm{w} / \mathrm{v})$ & Reducing sugars yield: $20.7 \%$ & Thi and Lee (2019) \\
\hline Eucalyptus saw dust & Choline chloride-lactic acid & $110^{\circ} \mathrm{C}, 6 \mathrm{~h}$, solid loading $(10 \%, \mathrm{w} / \mathrm{v})$ & $\begin{array}{l}\text { Hydrolysis yield: } 94.3 \% \\
\text { Delignification } 80 \%\end{array}$ & Shen et al. (2019) \\
\hline $\begin{array}{l}\text { Rice straw, rice husk, and } \\
\text { wheat straw }\end{array}$ & Choline chloride-Oxalic acid-n butanol & $120^{\circ} \mathrm{C}, 1 \mathrm{~h}$, solid loading $(15 \%, \mathrm{w} / \mathrm{v})$ & Delignification:50\% & Kandanelli et al. (2018) \\
\hline Switchgrass & Choline chloride- p-coumaric acid & $160^{\circ} \mathrm{C}, 3 \mathrm{~h}$ & $\begin{array}{l}\text { Glucose yield: } 85.7 \% \\
\text { Xylose yield: } 28.8 \% \text {, } \\
\text { Delignification: } 60.8 \%\end{array}$ & Kim et al. (2018) \\
\hline Oil palm fronds & Choline chloride-Urea- $\mathrm{CuCl}_{2}$ & $120^{\circ} \mathrm{C}, 30 \mathrm{~min}$, solid loading $(10 \%, \mathrm{w} / \mathrm{v})$ & Xylose yield: $14.76 \mathrm{~g} / \mathrm{L}$ & Loow et al. (2018) \\
\hline Lettuce residue & Choline chloride-glycerol & $150^{\circ} \mathrm{C}, 16 \mathrm{~h}$, solid:liquid ratio $(1: 16, \mathrm{w} / \mathrm{v})$ & $\begin{array}{l}\text { Glucose yield: } 94.9 \% \\
\text { Xylose yield: } 75.0 \%\end{array}$ & Procentese et al. (2017) \\
\hline Oil palm empty fruit bunch & Choline chloride-Urea & $110^{\circ} \mathrm{C}, 1 \mathrm{~h}$, solid to liquid ratio $(1: 5, \mathrm{w} / \mathrm{v})$ & Glucose yield: $66.33 \mathrm{mg} / \mathrm{mL}$ & Nor et al. (2015) \\
\hline Corn stover & Choline chloride-Formic acid & $130^{\circ} \mathrm{C}, 2 \mathrm{~h}$, solid loading $(5 \% \mathrm{w} / \mathrm{v})$ & $\begin{array}{l}\text { Glucose yield: } 99 \% \\
\text { Lignin removal: } 23.8 \%\end{array}$ & Xu et al. (2016) \\
\hline Corncob & Choline chloride-Imidazole & $115^{\circ} \mathrm{C}, 15 \mathrm{~h}$, solid to liquid ratio $(1: 16, \mathrm{w} / \mathrm{v})$ & $\begin{array}{l}\text { Glucose yield: } 94 \% \\
\text { Xylose yield: } 84 \%\end{array}$ & Procentese et al. (2015) \\
\hline Rice husk & Ethylene glycol -choline chloride & $160^{\circ} \mathrm{C}, 4 \mathrm{~h}$, solid loading $(4 \%, \mathrm{w} / \mathrm{v})$ & Reducing sugar yield: $0.74 \mathrm{mg} / \mathrm{mL}$ & $\begin{array}{l}\text { Nagoor Gunny et al. } \\
\text { (2014) }\end{array}$ \\
\hline Rice straw & Potassium carbonate-glycerol & $140^{\circ} \mathrm{C}, 100 \mathrm{~min}$, solid to liquid ratio $(1: 10, \mathrm{w} / \mathrm{v})$ & Enhanced delignification & Lim et al. (2019a) \\
\hline
\end{tabular}

efficacies. Acid hydrolysis is the most convenient and widely employed method for hydrolysis of polysaccharides into monomers via breakdown of hydrogen bonds between cellulose chains and converting its crystalline form into entirely amorphous state. However, its corrosive nature, degradation of released sugars, difficulties in sugar and acid recovery from the mixture, high energy requirements, formation of fermentation inhibitors, and several environment-related issues increase the process cost, and hence, limit its use (Sun and Cheng, 2002; Harmsen et al., 2010; Binod et al., 2011; Al-Battashi et al., 2019). On the other hand, enzymatic saccharification of LCB is a suitable alternative as it is a mild and eco-friendly approach with lower energy requirements (Rai et al., 2016b; Al-Battashi et al., 2019; Ummalyma et al., 2019).

The enzymes required for efficient deconstruction of polysaccharides into monomeric sugars include modular and non-modular glycosyl hydrolases (GHs) comprising of cellulases and hemicellulases, carbohydrate esterases (CEs), and auxiliary activity (AA) proteins (Chylenski et al., 2017; Ezeilo et al., 2017). The techno-economic analysis of the enzyme-mediated $2 \mathrm{G}$ biofuel production processes remain a much-debated topic owing to limited information of enzyme costs available in public domains. The enzyme costs reported in literature related to $2 \mathrm{G}$ ethanol production vary significantly, e.g., USD 0.10/gal (Aden and Foust, 2009), 0.30/gal (Lynd et al., 2008), 0.32/gal (Dutta et al., 2010) and 0.40/gal (Kazi et al., 2010). Such an inconsistency in cost estimation hinders robust techno-economic analysis of $2 \mathrm{G}$ ethanol production.

\subsection{Hydrolytic enzymes}

\subsubsection{Glycosyl hydrolases (GHs)}

GHs mediate the cleavage of glycosidic bonds that connect two or more sugars or one sugar and one non-sugar moiety within oligosaccharides (Sathya and Khan, 2014; Ezeilo et al., 2017). A total of 115 GH families comprising modular and non-modular cellulases and hemicellulases have been identified so far. These families of enzymes have been classified on the basis of their amino acid sequences and modes of action (Rai et al., 2016a and b; Ezeilo et al., 2017). The catalytic activity of GH family enzymes is achieved either through inversion or retention mechanisms resulting in products with a stereochemistry opposite and identical to the substrate, respectively (Davies and Henrissat, 1995; Jayasekara and Ratnayake, 2019). The mode of action of lignocellulolytic enzymes is shown in Figure 2.

Cellulases are the dynamic constituents of GH enzymes that hydrolyze the most dominant polysaccharide on the earth, cellulose, to yield hexose sugars (mainly glucose) (Mandels and Weber, 1969; Bayer et al., 1998; Patel et al., 2019). The obtained sugars can then be fermented into ethanol, and additional valued products (Rai et al., 2016b). Cellulases include three main hydrolytic enzymes: endoglucanases (E.C.3.2.1.4; EG), exoglucanases (E.C.3.2.1.174 and E.C.3.2.1.91; cellobiohydrolases $(\mathrm{CBH})$ ), and $\beta$-glucosidases (E.C.3.2.1.21; $\beta \mathrm{G}$ ). EGs have been reported from the GH families 5, 6, 7, 8, 9, 12, 44, 45, 48, 51, 74, and 124, and act randomly on $\beta-1,4$ glycosidic bonds of amorphous cellulose (Sweeney and Xu, 2012; Ezeilo et al., 2017). Among the identified families, the EGs belonging to $\mathrm{GH} 6,9$, and 48 follow the inversion mechanism, whereas, the rest act through the retention mechanism (Mingardon et al., 2007; Miotto et al., 2014). The catalytic action of these enzymes yield long-chain oligomers (with varying degrees of polymerization) possessing reducing and non-reducing ends which are subsequently processed by exoglucanases to form cellobiose (catalyzed by $\mathrm{CBH}$ ) and/or glucose (catalyzed by $\beta \mathrm{G}$ ) in a processive manner (Sweeney and $\mathrm{Xu}, 2012$; Ezeilo et al., 2017). CBH belonging to $\mathrm{GH}$ families 5, 6, 7, 9, 48 and 74, act either from reducing (CBH I) or non-reducing (CBH II) ends of cellulose to produce short-chain oligosaccharides (Poidevin et al., 2013). Finally, $\beta$ Gs catalyze the hydrolysis of cellobiose and short cellodextrins yielding glucose as the final product (Poidevin et al., 2013; Ezeilo et al., 2017; Patel et al., 2019). $\beta G$ enzymes are broadly classified as members of GH family $1,3,5,9,30$, and 116; however, the majority of the $\beta G$ enzymes reported from fungi belong to the GH family 3 (Singhania et al., 2013).

Hemicellulases, another group of GHs, mediate depolymerization of hemicellulosic fraction of LCB (Ezeilo et al., 2017). Owing to its heterogenous structure, hemicellulose degradation requires a large suite of enzymes comprising endoxylanase (E.C.3.2.1.8), $\beta$-xylosidase (E.C.3.2.1.37), $\alpha$-arabinofuranosidase (E.C.3.2.1.55), $\alpha$-glucuronidase (E.C.3.2.1.139), acetyl xylan esterase (E.C.3.1.1.72), arabinase (E.C.3.2.1.99), and feruloyl xylan esterase (E.C.3.1.1.73) (Juturu and Wu, 2013; Bhattacharya et al., 2015; Ezeilo et al., 2017). Among diverse hemicellulases, endoxylanases and $\beta$-xylosidases, collectively known as xylanases, are the most extensively studied enzymes. Endoxylanases have 

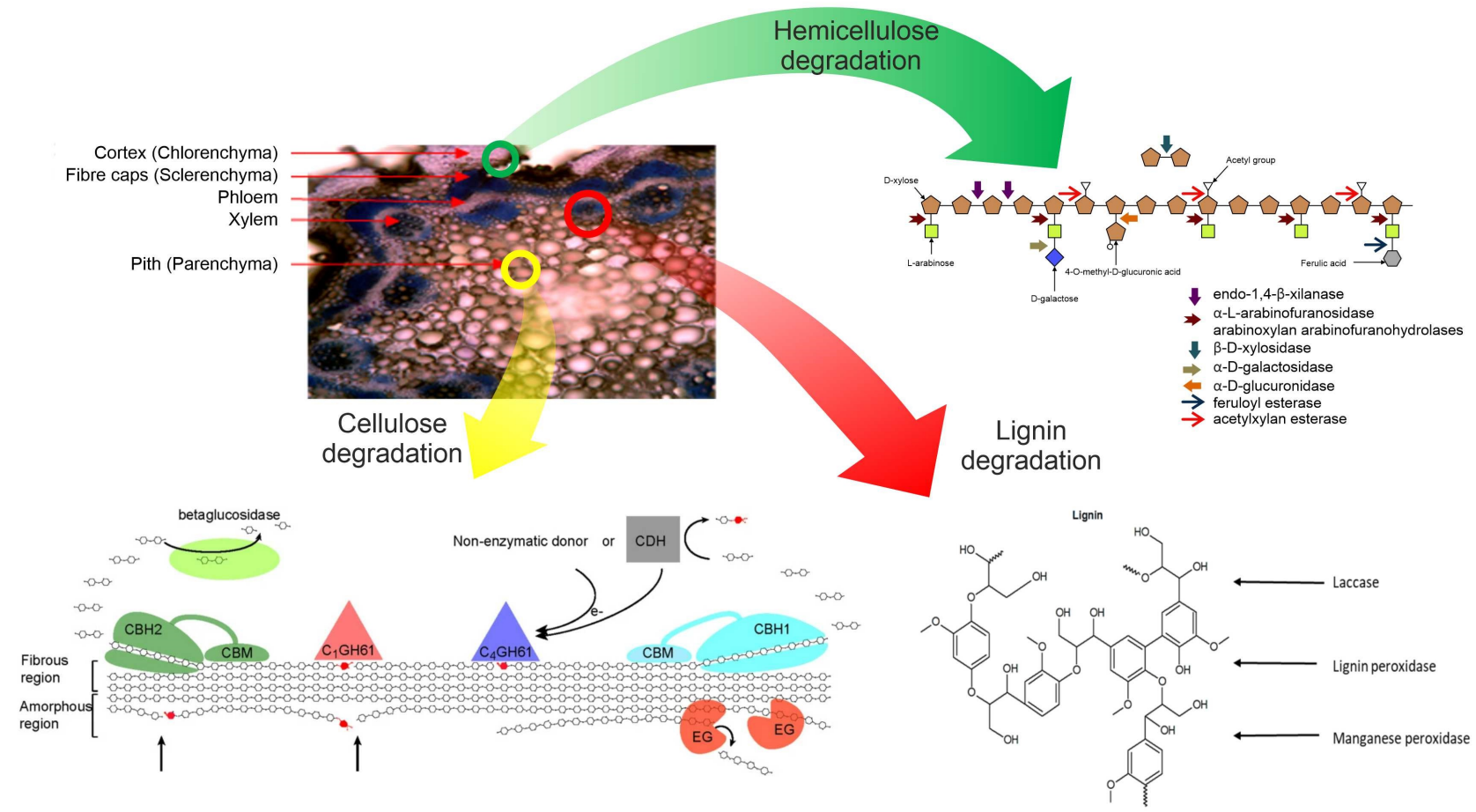

Fig. 2. Lignocellulolytic enzymes in action on plant cell wall.

been identified primarily from $\mathrm{GH}$ families $5,8,10,11$, and 43 , and are known to cleave $\beta$-xylosidic linkages that hold 2-D-xylopyranosyl residues together in the xylan backbone (Lombard et al., 2014; Bhattacharya et al., 2015; Ezeilo et al., 2017). Endoxylanases belonging to GH family 8 and 43 operate through the inversion mechanism, whereas, those which belong to GH 5, 10, and 11 operate via the retention mechanism.

$\beta$-xylosidase, another essential component of hemicellulases, hydrolyze xylobiose and other short-chain xylo-oligosaccharides by attacking their $\beta-1,4$ linkages. The majority of the identified $\beta$-xylosidases have been reported from GH families 3, 39, 43, 52, and 54 (Shallom and Shoham, 2003; Knob and Carmona, 2009; Bhattacharya et al., 2015). Both inversion (GH 43) and retention ( $\mathrm{GH} 3$ and 54) mechanism of actions can be observed in $\beta$-xylosidases (Shallom and Shoham, 2003; Knob and Carmona, 2009). Further, $\alpha$-Larabinofuranosidases (AFase) and $\alpha$-L-arabinases (collectively belonging to GH 3, 43, 51, 54, and 62) constitute another class of hemicellulases that is important for removal of arabinose residues from xylan backbone, which could have a synergistic effect on xylan hydrolysis. The arabinose substituted xylose residues inhibit the hydrolysis of glycosidic bonds in xylan backbone, and synergistic action of endoxylanases with these enzymes relieves this inhibition (Numan and Bhosle, 2006).

$\beta$-mannanases (GH 5 and 26) and $\beta$-mannosidases (GH 1, 2, and 5) degrade hemicelluloses made up of mannans into short manno-oligomers and subsequently into monomeric mannose (Shallom and Shoham, 2003).

\subsubsection{Carbohydrate esterases (CEs)}

Carbohydrate esterases formulate a distinct class of hydrolytic enzymes that are involved in the removal of ester flags from carbohydrates (Cantarel et al., 2009; Nakamura et al., 2017). These enzymes have been classified into $16 \mathrm{CE}$ families ranging from CE1 to CE16; however, CE family 10 has been abolished since most of the members corresponding to this family were found to be active against non-carbohydrate substrates (Nakamura et al., 2017). There are diverse biotechnological applications assigned to CE proteins where the majority of the enzymes catalyze the elimination of ester-based alterations form mono, oligo, and polysaccharides. Therefore, CE-mediated removal of acetylated moieties of polysaccharides could hasten up degradation of carbohydrates by facilitating $\mathrm{GH}$ proteins in accessing their target sites within biomass. The number of CEs analyzed for their enzymatic function is very low $(0.6 \%)$ with acetyl xylan esterases (AXEs) and feruloyl esterases (FAEs) being the most studied enzymes (Ulaganathan et al., 2015; Nakamura et al., 2017). Both AXEs and FAEs are the hemicellulolytic esterases where the former group hydrolyse acetyl substitutions on xylose fractions, and the latter group mediate hydrolysis of ester linkages holding ferulic acid and arabinose substituents together (Ulaganathan et al., 2015; Nakamura et al., 2017).

\subsubsection{Auxiliary activity $(A A)$ proteins}

The conventional hydrolytic model for degradation of lignocelluloses has been updated with the discovery of a novel class of oxidative enzymes. These enzymes are capable of triggering the cleavage of glycosidic bonds within the glucose polymers through oxidative route and are referred to as AA proteins (Ezeilo et al., 2017; Filiatrault-Chastel et al., 2019). The AA category encompasses a large class of carbohydrate active enzymes (CAZymes) that assist $\mathrm{GH}$ and $\mathrm{CE}$ enzymes acting on carbohydrates in LCB (Levasseur et al., 2013; Ezeilo et al., 2017). Currently, AA category constitutes 9 families of lignin-degrading enzymes and 6 families of lytic polysaccharide monooxygenases (LPMOs) (Levasseur et al., 2013). Different AA families involved in the degradation of LCB are briefly described below.

AA1 family circumscribes multicopper oxidases with potential to utilize diphenols related compounds and oxygen as electron donor and acceptor, respectively (Levasseur et al., 2013). Laccases (EC 1.10.3.2), form a subfamily within AA1 family, is known to degrade LCB either by attacking lignin directly or eliminating inhibitors produced during pretreatment (Levasseur et al., 2013; Rai et al., 2019b). Laccase like multicopper oxidases (LMCOs; EC 1.10.3.2) constitutes another subfamily of AA1 proteins which shows involvement in delignification (Levasseur et al., 2013; Berni et al., 2019).

AA2 family encompasses another group of lignin-modifying enzymes, also known as class II peroxidases (Levasseur et al., 2013). Lignin peroxidases (LiP; EC 1.11.1.14), manganese peroxidases (MnP; EC 1.11.1.13), and versatile peroxidases (VP; EC1.11.1.16) are the main enzymes of AA2 family where LiPs mediate oxidation of several aromatic phenolic compounds and a variety of non-phenolic lignin model 
compounds. On the other hand, VPs act as hybrid models of both LiPs and MnPs which consolidate their catalytic properties and oxidize phenolic, nonphenolic, and $\mathrm{Mn}^{2+}$ substrates (Levasseur et al., 2013; Janusz et al., 2017).

AA3 family comprises flavoproteins having flavin-adenine dinucleotide (FAD) binding domain. Cellobiose dehydrogenases (CDH; EC 1.1.99.18), the secreted hemoflavoenzymes produced by lignocellulolytic fungi under cellulolytic culture conditions, constitute a major proportion of this family (Levasseur et al., 2013; Bodenheimer et al., 2018). Another family of CAZymes, AA8 contain CDH enzymes that have cytochrome domains of spectral class b in their structural organization (Levasseur et al., 2013; Ma et al., 2017). Cellobiose dehydrogenases bind cellulose to mediate oxidation of cellodextrins, maltodextrins, and lactose; and inhibit repolymerization of cellulose post cleavage (Henriksson et al., 2000; Langston et al., 2011; Wang and Lu, 2016).

Lytic polysaccharide monooxygenases (LPMOs), previously known as GH61 proteins, have shown enormous potential to assist with the hydrolysis of LCB in recent years (Levasseur et al., 2013; Basotra et al., 2019). To date, LPMOs are classified as members of AA family 9, 10,11, and 13, where, LPMO9s (AA9), LPMO11s (AA11), and LPMO13s (AA13) have been reported only from fungi (Levasseur et al., 2013; Loose et al., 2016). The presence of copper ion in the active site of LPMOs stimulates hydroxylation of either $\mathrm{C} 1$ or $\mathrm{C} 4$ in polysaccharide substrates forming aldonic acid or 4-keto sugars, respectively (Beeson et al., 2012; Walton and Davies, 2016; Müller et al., 2017). LPMOs require reducing equivalents to trigger their catalytic activity, and these equivalents are generated by functional electron donors like ascorbic acid or gallic acid (Vaaje-Kolstad et al., 2010; Quinlan et al., 2011) and lignin content in LCB (Walton and Davies, 2016). Several studies have shown that redox active proteins viz. CDH act as natural consort for LPMOs (Wymelenberg et al., 2010; Phillips et al., 2011; Yakovlev et al., 2012; Rai et al., 2020). Further, co-expressions of LPMOs and CDHs have also been reported in various fungi when cultured using plant biomass as a carbon source (Phillips et al., 2011; Wang and Lu, 2016).

Another set of oxidative enzymes, previously known as carbohydratebinding modules 33 (CBM33), has been recently reclassified as AA10 family proteins (Levasseur et al., 2013). CBMs are non-catalytic modules and possess carbohydrate-binding activity. The lignocellulolytic enzymes are inefficient in degrading insoluble polysaccharides since they are unable to access target sites on substrates during catalysis. Therefore, cellulases/ hemicellulases are equipped with $\mathrm{CBMs}$ which bind cell wall polymers and increase their accessibility to lignocellulolytic enzymes (Levasseur et al., 2013; Ezeilo et al., 2017). It has been shown that AA family 9 and 10 proteins act synergistically on the crystalline portion of cellulose, and provide new ends for recognition and action of cellulases (Morgenstern et al., 2014; Vermaas et al., 2015). Therefore, these enzymes can be used for boosting the efficiency of lignocellulolytic GHs.

\subsection{Microbial sources of lignocellulolytic enzymes}

The microbial lignocellulolytic enzymes (cellulase, hemicellulases, and auxiliary) have been reported from diverse ecological niches including forests, compost piles, composting soils, rumens, wood-processing plants, and sewage sludge (McDonald et al., 2012; Rai et al., 2016b; Patel et al., 2019). There are two most prominent lignocellulolytic systems: (i) extracellular enzymes in filamentous fungi and aerobic bacteria and (ii) enzyme complexes called as cellulosomes in anaerobic bacterial and fungal strains (Mathew et al., 2008; Arora et al., 2015b; Ezeilo et al., 2017). The complexed cellulolytic systems (cellulosomes) have been reported from several anaerobic microbes, e.g., Acetivibrio, Bacteroides, Clostidium, Ruminococcus, Nocallimastix, Piromyces, and Orpinomyces (Doi and Kosugi, 2004; Fontes and Gilbert, 2010; Sadhu and Maiti, 2013; Blumer-Schuette et al., 2014). The interaction of cellulosome with cellulose is shown in Figure 3. The non-complexed enzyme system is more common and has been widely exploited for numerous industrial applications. Several aerobic bacteria, including Cellvibrio, Cellulomonas, Microspora, Thermobispora, Thermomonospora sp., Pseudomonas sp., Bacillus sp., Nocardia sp., Streptomyces sp., Erwinia chrysanthemi, Thermobifida fusca, Geobacillus sp. strain WSUCF1, Paenibacillus sp., Aeromonas sp., and Aureobasidium pullulans LB 83 have exhibited significant cellulase, hemicellulase, and auxiliary activities (Sadhu and Maiti, 2013; Pang et al., 2017; Chadha et al., 2019; Islam and Roy, 2019; Rai et al., 2019b). Bacteroides luti and Oricola cellulosilytica are the examples of novel cellulolytic bacteria that have been isolated from methanogenic sludge and surface of seashore, respectively (Shinoda et al., 2012; Hameed et al., 2015; Chadha et al., 2019).

Although different microbial genera capable of producing lignocellulolytic enzymes, fungi have turned out to be the major role players (Marjamaa et al., 2013; Rai et al., 2016b; Patel et al., 2019). Humicola grisea, H. insolens, Chaetomium thermophilum, Sporotrichum thermophila, Talaromyces emersonii, Myceliophthora thermophila, Thermoascus auranticus, Melanocarpus albomyces, Aspergillus sp. Trichoderma reesei, Acremonium cellulolyticus, Penicillium sp., and Trametes versicolor are among the most potent lignocellulolytic fung reported over the past couple of decades (Jatinder et al., 2006; Zambare and Christopher, 2010; Liu et al., 2013; Marjamaa et al., 2013; Phitsuwan et al., 2013; Rai et al., 2016b; Basotra et al., 2019; Sun et al., 2019). Among diverse lignocellulolytic fungi, T. reesei and Aspergillus sp. have been extensively exploited as lignocellulolytic strains at commercial scale (Gusakov, 2011; Chekushina et al., 2013; Rai et al., 2016b). However, recent trends have shown a paradigm shift towards other fungal strains, i.e., $P$. decumbens, A. cellulolyticus, and $M$. thermophila, which exhibit better hydrolytic potential as compared to $T$. reesei at equal protein loadings (Chekushina et al., 2013; Marjamaa et al., 2013). These fungal strains are also being used at commercial scale for lignocellulolytic enzymes production (Fujii et al., 2009; Gusakov, 2011; Liu et al., 2013). In addition, $P$. funiculosum, $P$. oxalicum, Penicillium sp. Dal5, and $P$. oxalicum $114-2$ RE-10 are potent Penicillium strains that have been tested and validated for efficient degradation of different pretreated biomass (Huang et al., 2015; Yao et al., 2015; Rai et al., 2016b; Saini et al., 2016).

\subsection{Strain improvement strategies for hyper-producing deregulated lignocellulolytic strains}

The cost of lignocellulolytic enzymes is one of the limiting factors in biorefineries; therefore, continuous efforts are being made to (i) minimize the cost of enzymes and (ii) increase overall yields of the enzymes with desired productivity. For making the concept of biorefineries economically feasible, several approaches such as random mutagenesis, site-directed mutagenesis, heterologous expression of proteins, clustered regularly interspaced short palindromic repeats (CRISPR-Cas) system, and genome and metabolic engineering have been used in recent years to improve the enzymatic expression by microbial strains (Fujii et al., 2018; Basotra et al. 2019; Lim et al., 2019b; Misra et al., 2019; Wen et al., 2020).

Random mutagenesis is the simplest tool that has been extensively used for inducing genetic and functional modifications in microorganisms. Several reports of cyclic mutagenesis employing physical agents such as UV radiations, chemical agents like $\mathrm{N}$-methyl-N'nitro-N-nitrosoguanidine (MNNG), acriflavin, and ethanomethane sulphate (EMS), and combination of both physical and chemical mutagens have been published in the past decade (Chadha et al., 2005; Adsul et al., 2007; Fang et al., 2009; Liu et al., 2013; Kaur et al., 2014; Ottenheim et al., 2015; Lim et al., 2019b). Reportedly, the benchmark of hypercellulolytic fungal strains has been developed through cyclic mutagenesis. The rationale behind cyclic mutagenesis is to mutate carbon catabolite repressor $(C C R)$ gene in a nonspecific manner that will deregulate the expression of cellulases and some hemicellulases (Amore et al., 2013; Brown et al., 2013). The alterations in carbon repressor gene crel, glucosidase II $\alpha$ subunit of $g l s 2 \alpha$ gene and $\beta$ glucosidase regulatory gene $b g l R$ have been reported for upregulating cellulolytic genes (Ilmén et al., 1996; Geysens et al., 2005; Nitta et al., 2012; Fujii et al., 2013). Fujii et al. (2013) reported the upregulation of cellulases and xylanase in Acremonium cellulolyticus by disruption of creA gene.

Site-directed mutagenesis is also a highly accepted technique that induces specific alterations in the known DNA sequences. Error-prone PCR (EP-PCR) applied in tandem with site-directed mutagenesis has been reported to increase EG activity (by up to 7.93 folds) in Bacillus amyloliquefaciens DL-3, and enhance alkaline tolerance of EGIII in $T$. reesei (Wang et al., 2005; Vu and Kim, 2012). A study has suggested that the product of $b g l 2$ gene catalyzes conversion of cellobiose into glucose, which in turn inhibits the expression of cellulases through feedback inhibition of $\mathrm{crel}$ gene. Also, cellobiose acts as an inducer for transcription factor $\operatorname{clr} B$, which activates the expression of cellulases. Therefore, 


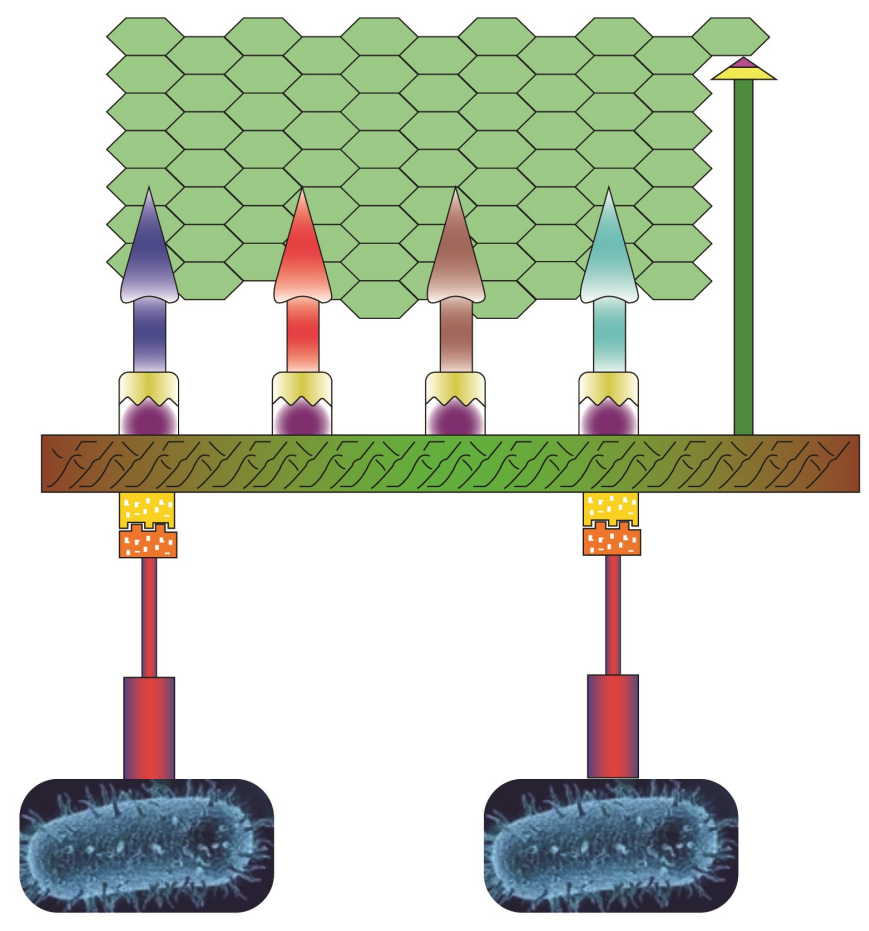

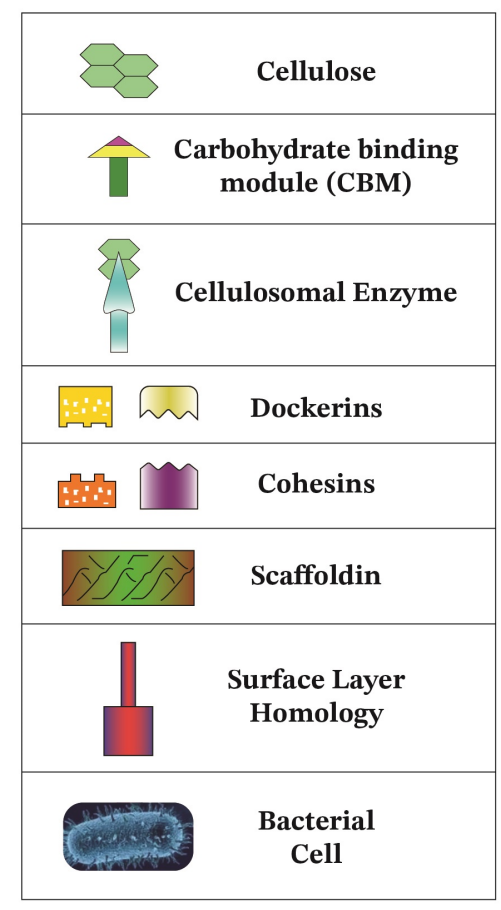

Fig. 3. Cellulosome in action for saccharification of cellulose. Modified from Arora et al. (2015b).

mutations in bgl2 and cre 1 genes could significantly enhance the production of cellulases through cellobiose-mediated upregulation of $\operatorname{clr} B$ gene (Yao et al., 2015).

Protoplast fusion is another technique where protoplasts isolated from two genotypically versatile somatic cells are fused into hybrid protoplast cells harboring genetic modifications. This technique is relatively inexpensive and simple, and shows enormous potential for developing industrially-competent hypercellulase strains without causing many disturbances in their physiology (Savitha et al., 2010; Kaur et al., 2013; Adeleye et al., 2019). This technique works schematically by (i) isolating protoplasts through carbohydrase (chitinase, glucanase, lysozymes, Novozyme 234) mediated digestion of cell wall, (ii) fusing isolated protoplasts (at interspecific, intraspecific, and intergeneric level) employing electrofusion or chemicals like polyethylene glycol (PEG), calcium ions, and sodium nitrate, (iii) regenerating transformed protoplasts, and (iv) screening regenerated transformants (Kordowska-Wiater et al., 2012; Kaur et al., 2013; Adeleye et al., 2019). Protoplast fusion has been used for increasing the production of cellulases in T. reesei (Prabavathy et al., 2006), increasing fumaric acid production from glycerol in Rhizopus microspores (Kordowska-Wiater et al., 2012), developing heterokaryons of two cellulolytic strains Aspergillus tubingensis and A. nidulans (Kaur et al., 2013), and improving amylase titers of two amylolytic species of Aspergillus (Adeleye et al., 2019). Further, protoplast transformation technique provides another excellent platform for improving yields of cellulases and hemicellulases through RNA interference (RNAi) of crel/creA gene expression. A study investigated the role of crel gene in M. thermophila ATCC42464 where silencing of $\mathrm{crel}$ gene through RNA interference resulted in C88 strain exhibiting up to 5.59 folds increase in cellulase activities when compared to the parent strain (Yang et al., 2015). Another study reported the transformation of Verticillium dahliae protoplasts with different shortinterference RNAs (SiRNAs) targeting gfp gene. The resultant transformant SiRNA-gfp4 exhibited significant gene silencing (up to 100\%) lasting for minimum of $72 \mathrm{~h}$ (Rehman et al., 2016).

Genetic engineering is also regarded as a powerful tool for putting together multiple traits of interest in a single organism. Therefore, this technique could be very useful in (i) increasing enzyme titer, (ii) reducing the production cost of enzymes, and (iii) developing process-specific enzymes (Singh et al., 2017;
Phillips, 2019). Methodologically, genetic engineering involves isolation of gene of interest from the target organism, insertion of the isolated gene into a suitable vector to form recombinant DNA (rDNA), and transfer of rDNA to the expression host (Singh et al., 2017; Basotra et al., 2019; Rai et al., 2019b). Moreover, there are several reports where recombinant strategies have been utilized for efficient bioconversion of LCB into fermentable sugars through heterologous expression of the functional cellulase, hemicellulase, and auxiliary activity proteins (Poidevin et al., 2013; Fang and Xia, 2015; Basotra et al., 2019; Rai et al., 2019b). A B-glucosidase from B. circulans and multiple copies of bifunctional endo/exoglucanase from Bacillus sp. DO4 were integrated into the chromosomal DNA of Saccharomyces cerevisiae, and the resultant strain was reported to reduce the requirement for addition of commercial cellulases in a solid-state fermentation process (Cho et al., 1999). A recombinant strain of $S$. cerevisiae was developed through expression of endoglucanase 11 and cellobiohydrolase 11 (T. reesei) together with $\beta$-glucosidase (A. aculeatus) in the form of fusion proteins attached to the cell surface (Fujita et al., 2004). The developed strain was reported to produce $\sim 3 \mathrm{~g} / \mathrm{L}$ ethanol from amorphous cellulose. In a different investigation, a developed strain of $S$. cerevisiae co-expressing fungal endoglucanase EG1 (T. reesei) and $\beta$ glucosidase of the yeast (Saccharomycopsis fibuligera) has been reported as the first yeast strain capable of growing on cellulose (phosphoric acid swollen cellulose; PASC) as a sole carbohydrate source, yielding $1 \mathrm{~g} / \mathrm{L}$ ethanol (Den Haan et al., 2007).

The three cellulases PaCel6A, PaCelB, and PaCel6C (Podospora anserine) functionally expressed in Pichia pastoris were reported to hydrolyze amorphous and crystalline celluloses but were found to be inactive against hydroxyethyl cellulose, mannan, galactomannan, xyloglucan, arabinoxylan, arabinan, xylan, and pectin (Poidevin et al., 2013). A study has reported the expression and production of CBH II from $T$. reesei into $P$. pastoris, and its application has also been proved in the hydrolysis of corn stover and rice straw (Fang and Xia, 2015). The cloning and expression of GH11 xylanase gene from A. fumigatus MKU1 has been reported where two exons of the gene were amplified separately and fused using overlap extension PCR. The fused product was then cloned in pPICZB, and expressed in P. pastoris under the control of AOX1 promoter 
(Jeya et al., 2009). Gong et al. (2013) reported cloning of aufaeA, a gene encoding for type-A feruloyl esterase, in A. usamii E001. The gene was expressed in a heterologous host $P$. pastoris GS115. One of the transformants, $P$. pastoris GSFaeA4-8 showed high expression of the recombinant auFae A with an enzyme activity of $10.76 \mathrm{U} / \mathrm{ml}$. A gene encoding CDH was cloned from Neurospora crassa strain FGSC 2489 and successfully expressed in a heterologous host $P$. pastoris under the control of AOX1 methanol inducible promoter (Zhang et al., 2011). A novel laccase gene pclac2 was cloned from Phytophthora capsici using pPIC9K expression vector and expressed in $P$. pastoris host system (Feng and Li, 2014). A thermo-alkali stable laccase was cloned from B. licheniformis and expressed in P. pastoris. The expressed protein showed remarkable stability at $70^{\circ} \mathrm{C}$ with a half-life $\left(\mathrm{t}_{1 / 2}\right)$ of $6.9 \mathrm{~h}(\mathrm{Lu}$ et al., 2013). The cloning of a novel LPMO (PMO9A_MALCI) from thermophilic fungus Malbranchea cinnamomea and its expression in $P$. pastoris has been recently reported where the expressed AA9 protein was capable of hydrolysis of both cellulose and pure xylan (Basotra et al., 2019).

In case of bacteria, more reports concern introduction of cellulase and hemicellulase genes into strains of Escherichia coli. There is a report on the cloning of first functional gene from Paecilomyces thermophila where a 681bp xylanase gene (Pt $x y n A)$ was expressed in E. coli BL21, and the recombinant protein was purified using nickel- nitrilotriacetic acid (Ni-NTA) and Sephadex G50 columns. The characterization of the recombinant xylanase indicated that the enzyme is thermostable and has a great potential in various industries (Zhang et al., 2010). A novel endo-1,4- $\beta$-D-glucanase (EG) was cloned from T. virens ZY-01 (Zeng et al., 2016), a cellobiohydrolase B (cbhB) was cloned from A. niger ATCC 10574 (Woon et al., 2015), soluble flavin domain of Phanerochaete chrysosporium $\mathrm{CDH}$, and genes coding for $\beta$-xylosidase, endoxylanase, and laccase were cloned from Geobacillus sp. WSUCF1 through pRham N-His SUMO Kan Vector (Bhalla et al., 2014a and b; Rai et al., 2019b) and expressed in E. coli and/or in genetically modified E. coli based cells. Epigenetics could be a handy technique when it comes to regulating gene expression. There are several factors like methylation, acetylation, and post transcriptional modifications that control expression of genes without incorporating any changes in the gene sequence (Gibney and Nolan, 2010; Mello-de-Sousa et al., 2016; Druzhinina and Kubicek, 2017). Although there is a big research gap in the area of epigenetics-based strain improvement, this technique in combination with other genetic tools could be a windfall in developing industrially competent cellulase producers.

CRISPR-Cas9 is another powerful technique that has revolutionized the genetic engineering domain and is being employed successfully in several yeasts and fungi; however, its applicability is yet to be validated in case of thermophilic fungi. Liu et al. (2015) have reported the application of the CRISPR/Cas9 technology for simultaneous editing of multiple genes through co-transformation of in vitro synthesized gRNAs and donor DNA in T. reesei to enhance lignocellulose degradation. Another study conducted by Shi et al. (2016) on S cerevisiae has envisioned that CRISPR technology could be a potential industrial approach for metabolic engineering.

\section{Fermentation}

Fermentation is a critical step for the production of industrially important fuels and chemicals where monomeric sugars released by hydrolysis of feedstock are converted into these products by the microbial action. The wildtypes of microorganisms tested in the ethanol fermentation are Calonectria brassicae, Candida (Scheffersomyces) shehatae, E. coli, S. cerevisiae, Mucorindicus, Pachysolen tannophilus, Pichia (Scheffersomyces) stipitis, and Zymomonas mobilis (Sanchez and Cardona, 2008). There are many factors affecting fermentation process for bioethanol production such as temperature, $\mathrm{pH}$, aeration rate, salt concentration, carbohydrate concentration, and ethanol concentration (Arora et al., 2017; Selim et al., 2018; Ding et al., 2020). There are three major modes of fermentation for ethanol production: batch, fed-batch, and continuous fermentation, and each process has its own advantages and limitations. Batch fermentation is the most traditional type of fermentation where high concentration of initial substrate is converted into high concentration of product, and a fresh batch is run after the end of each batch (Olsson and Hahn-Hägerdal, 1996). A modification of batch fermentation is repeated batch fermentation in which immobilized microbial cells are used instead of free ones to make the system more efficient (Jain and Chaurasia, 2014). Fed-batch method is another type of fermentation, which is a combination of batch and continuous mode, with intermittent additions of fresh substrates without removing products. This type of fermentation is more economical compared to batch type method due to shorter fermentation time, higher ethanol productivity, higher dissolved oxygen in media, and less toxicity of media components (Cheng et al., 2009). There is a constant addition of substrate and nutrients with continuous removal of products from bioreactor in the continuous type of fermentation. Continuous fermentation is the most common type of fermentation, which has been used for industrial bioethanol production due to easy process control, elimination of unproductive time required for cleaning, less investment cost, and less labor-intensive process (Sanchez and Cardona, 2008; Kumar et al., 2015)

Techno-economic analysis of a pilot-scale production of bioethanol with high yields using $Z$. mobilis, revealed that ethanol production using this bacterium could save the cellulosic ethanol production facility by $\$ 2$ million/yr (Kremer et al., 2015). Another study on pilot-scale production of bioethanol from dilute sulphuric acid-pretreated wheat straw by using recombinant $E$. coli FBR5 in a simultaneous saccharification and fermentation (SSF) system achieved an improved ethanol yield $(0.29 \mathrm{~g} / \mathrm{g})$, and productivity $(0.43 \mathrm{~g} / \mathrm{L} / \mathrm{h})$ (Saha et al., 2015). The consolidated alcohol dehydration and oligomerization (CADO) approach, a one-step conversion process, is estimated to reduce the operating plus annual capital costs from $\$ 2.00 / \mathrm{GJ}$ to $\$ 1.44 / \mathrm{GJ}$, i.e., $28 \%$ reduction in the conversion of wet ethanol to fungible blend-stocks. This approach has enhanced the liquid hydrocarbon yield (36\% of theoretical), decreased ethanol conversion cost (12-fold), and scaled up the process by 300 -fold (Hannon et al., 2020). A recent study proved an enhanced bioethanol production of $20.6 \mathrm{~g} / \mathrm{L}$ with volumetric productivity of $1.0 \mathrm{~g} / \mathrm{L} / \mathrm{h}$ from food waste in a SSF system using the mixed culture of $F$. oxysporum F3 and $S$. cerevisiae. The supplementation of glucoamylase into the mixed culture resulted in further enhancement of ethanol production and productivity by $30.3 \mathrm{~g} / \mathrm{L}$ and 1.4 $\mathrm{g} / \mathrm{L} / \mathrm{h}$, respectively, and hence, proved the feasibility of on-site production of multienzyme system and bioethanol production from food waste (Prasoulas et al., 2020). Similarly, a pilot-scale continuous tubular reactor (PCTR) technology is expected to achieve a high ethanol yield of 11.0 to $11.3 \mathrm{~kg}$ of ethanol per $100 \mathrm{Kg}$ of untreated biomass by overcoming the challenges related to biomass recalcitrance (Pérez-Pimienta et al., 2020).

To achieve maximum yield and productivity in bioethanol production, the selected microbial strain should have some unique features such as a broad range of substrate utilization, ability to withstand high concentrations of sugar, ethanol, and by-products produced during pretreatment step, and minimum by-products formation (Lugani and Sooch, 2018). However, most of the naturally-occurring microbial strains employed for the alcoholic fermentation possess the ability to ferment hexose sugars only with very low ethanol yields and productivities. The wild pentose sugars fermenting microbial strains such as $P$. stipitis, $P$. tannophilus, and $C$. shehatae are sensitive to low $\mathrm{pH}$, high concentration of ethanol, and inhibitors (HahnHägerdal et al., 2007). Therefore, it is very difficult for wild microbial strains to fulfil the features, which are required for their selection as industrially important, and hence, over the last few years, the focus has been placed on the development of genetically modified microorganisms to ensure their use in industrial applications.

\subsection{Strain development for improved bioethanol fermentation}

There are various previous studies, which have been done using adaptive evolution to create mutant strains, which are resistant to high temperatures, salt concentrations, acetic acid concentrations, freeze-thawing, pentose sugars, and various stress inducers (Wati et al., 1996; Stanley et al., 2010 Abreu-Cavalheiro and Monteiro, 2013; Sharma et al., 2016a and 2017; Choe et al., 2019). The powerful tools used to develop industrially important fermenting microbial strains to meet the demands of alcoholic fuel are genetic engineering, recombinant DNA technology, metabolic engineering, cell surface engineering, protein engineering, protoplast fusion, and CRISPR-Cas9. The other techniques used for manipulating the microbial genes to improve the efficiency of saccharification and fermentation are adaptation, selection, mutation, and protoplast fusion. The tools used for selection of genetically modified ethanol resistant strains are deletion mutant library screening and transposon-mediated mutant collection (Teixeira et al., 2009; Zheng et al., 2011). 
The ethanol-resistant strains are produced by global transcription machinery engineering (gTME), which is a powerful tool for selection of mutant library (Yang et al., 2011). Many in-silico tools like dynamic flux balance model and dynamic simulations are used for analysis of bioethanol production by genetically modified microorganisms in co-culture fermentation (Parambil and Sarkar, 2015). The main focus of developing genetically modified microbial strains is on accelerating the rate of reaction, shifting the existing metabolic pathway towards production of useful products, enhancing substrate specificity, and altering enzyme activity for producing novel structures (Doğan et al., 2014). Many previous studies have already been reported on the production of enhanced bioethanol using recombinant microbial strains (Abreu-Cavalheiro and Monteiro, 2013; Doğan et al., 2014; Ge et al., 2014; Kricka et al., 2014; Sar et al., 2017; Ko et al., 2018). The recombinant bacterial strains named E. coli and Klebsiella oxytoca showed the ability to utilize a wide range of substrates with enhanced bioethanol production (Dien et al., 2003). Previously, it has been observed that $S$. cerevisiae mutant with disrupted ura7 or gal6 showed increased resistance to different kinds of stressors including ethanol. The mutant yeast strain also showed enhanced glucose consumption at low temperatures compared to wild strains (Yazawa et al., 2007). Both ethanol tolerance and fermentation capacity of sake yeast strains were enhanced by overexpression of $m s n 2$ (Watanabe et al., 2009). The enhanced effective and rapid ethanol production (with $90 \%$ of maximum theoretical yield) was achieved with Geobacillus thermoglucosidasius by up-regulating the expression of pyruvate dehydrogenase, and disruption of pyruvate formate lyase and lactate dehydrogenase genes (Cripps et al., 2009). The overexpression of sugar transporter (Hxt) in Fusarium oxysporum resulted in enhanced glucose and xylose transport capacity with 39\% increase in ethanol yield (Ali et al., 2013).

Cell surface engineering is an innovative tool in molecular breeding for displaying functional proteins on the surface of microorganisms used in consolidated bioprocessing (CBP) system. Cell display system is very useful for ethanol production from starch in CBP because various amylases are displayed on the yeast cell surface, which can utilize starch as the sole carbon source for ethanol production (Sakuragi et al., 2011). The recombinant thermophilic strain of Kluyveromyces marxianus has been developed using cell surface engineering, and the recombinant strain displayed both $\beta$-glucosidase and endoglucanase on cell surface. The recombinant strain was used for bioethanol production in a CBP system using $\beta$-glucan as substrate, and the improved bioethanol production of $0.47 \mathrm{~g} / \mathrm{g}$ of carbohydrate consumed, was observed at the end of fermentation (Hasunuma and Kondo, 2012). E. coli is considered as one of the important industrial bacteria, and is commonly used in most of the recombinant studies. Xylose metabolic pathway was introduced into Z. mobilis from E. coli for producing recombinant strain having GRAS (generally recognized as safe) status. The recombinant strain showed minimum nutrient requirements, and could tolerate high temperatures and low $\mathrm{pH}$ values (McEwen and Atsumi, 2012). Similarly, constitutive promoter substitution and xylose metabolic integration was done in $S$. cerevisiae for producing an engineered strain EBY101-X5CC, and the engineered yeast strain had the ability for co-fermentation of cellulose and either sucrose or xylose. The recombinant strain produced $4.3 \mathrm{~g} / \mathrm{L}$ ethanol from $10 \mathrm{~g} / \mathrm{L}$ carboxymethyl cellulose (CMC) in a CBP system ( $\mathrm{Li}$ et al., 2017). The engineering of both feedstock as well as microorganism has reportedly resulted in an enhanced bioethanol production. This strategy also provided the feasibility of ethanol production at commercial scale using lignocellulosic waste materials (Ko et al., 2018).

Safe and stable expression of cellulase gene (sestc) and glyceraldehyde-3phosphate dehydrogenase gene $(g p d)$ promoter was achieved using the CRISPR -Cas9 approach in S. cerevisiae chromosome using gRNA expression vector from Agaricus biporus. The recombinant yeast strain showed increased expression of endo-1,4- $\beta$-glucanase and exo-1,4- $\beta$-glucanase, and 37.7-fold improved ethanol production compared to its native strain (Yang et al., 2018). In a recent study, industrially engineered $S$. cerevisiae MF01-PHO4 was produced by protoplast formation and pho4 gene replacement, and the mutant strain was observed to be stable for up to 30 generations. An enhanced ethanol yield of $114.71 \mathrm{~g} / \mathrm{L}$ was achieved with the genetically engineered strain, accounting for $5.30 \%$ increase in ethanol yield and $12.5 \%$ decrease in fermentation time (Wu et al., 2020). There is no clear evidence on side effects of genetically modified microorganisms on environment; thus, there is still a need to take preventive measures to ensure environmental safety. Federal government renewable fuel standards (FGRFS) should be adapted before introducing genetically modified microorganisms into large scale bioethanol production.

\subsection{Strain development for co-fermentation of glucose and xylose}

The conversion of LCB into ethanol is associated with challenges such as co-utilization of pentose and hexose sugars, and presence of fermentative inhibitory compounds such as phenolic derivatives, acetic acid, and furfurans. However, only a few strains such as S. shehatae, S. stipitis, and $K$. marxianus have the ability to assimilate pentose sugars but the production of ethanol is not up to the industrial standards, and hence the cofermentation of pentose and hexose sugars is a major obstacle in efficient conversion of LCB to ethanol (Kim et al., 2012; Arora et al., 2015c; Moysés et al., 2016).

For instance, among the organisms capable of converting sugars into ethanol, $S$. cerevisiae is the most widely used at the industrial scale due to its versatile characteristics such as high tolerance to ethanol, ability to withstand low $\mathrm{pH}$ values, ability to ferment under anaerobic condition, tolerance to high osmotic pressures, and less prone to bacteriophage infections (Robak and Balcerek, 2018). However, the yeast S. cerevisiae exhibits weak expression of pentose pathway gene, and have poor/no xylose uptake ability.

Over the last few years, the considerable developments in genetic engineering has changed the metabolic engineering paradigm. Specialized tool boxes are currently available for pathway manipulation of microbial strains by overexpression and knock-out of genes targeting metabolic pathways, molecular transport capability, cellular tolerance, and catabolite sensing (Selim et al., 2018).

\subsection{Xylose metabolism}

The pentose sugar xylose is metabolized by microorganisms during xylose metabolism through two different pathways. In filamentous yeasts, the oxidoreductase pathway having two-step reaction is involved. In the initial step, xylose is reduced to xylitol through $\mathrm{NAD}(\mathrm{P}) \mathrm{H}-$ and/or $\mathrm{NADH}$ dependent xylose reductase (XR) (EC 1.1.1.30) encoded by $x y l 1, x y l l p$, and in the second step, xylitol is oxidized to xylulose by $\mathrm{NAD}^{+}$-dependent xylitol dehydrogenase (XDH) (EC 1.1.1.9) encoded by $x y l 2, x y l 2 p$. In case of bacteria, xylose is directly converted into 5-xylulose using xylose isomerase (XI) (EC 5.3.1.5) encoded by $x y l A$ without any co-factor usage The 5-xylulose is phosphorylated by xylulokinase (XK) (EC 2.7.1.17) to xylulose-5-phosphate, which is an intermediate for the phosphoketolase and non-oxidative pentose pathways. The pentose pathway can be further classified into two distinct pathways, namely non-oxidative and oxidative pentose phosphate pathways. Most of the yeasts use the non-oxidative pathway to metabolize xylulose-5-phosphate as a precursor for nucleic acid and amino acids production and also convert it to three, four, five, six, and seven atom carbon sources, which serves as intermediate to glycolysis. While the oxidative pathway is used as a defensive mechanism against oxidative stress and to generate NADPH, which is a major precursor for biomass formation, and is also a driving element of XR (Karhumaa et al. 2007; Kwak and Jin, 2017).

\subsubsection{Utilization of xylose by engineering oxidoreductase pathway}

Even though S. cerevisiae encodes for putative pentose pathway genes, the expression level of these genes is weak, and as a result, the microorganism is unable to assimilate xylose as sole carbon source. Hence, there is a requirement of heterologous complementation and significant metabolic engineering. Among the pentose-utilizing strains, $S$. stipitis is the most studied organism as its xylose pathway of converting pentose sugars to ethanol is well curated (Harner et al., 2015). Most of the heterologous expression genes related to the pentose pathway were used from S. stipitis as compared to other eukaryotic organisms. Kötter et al. (1990) isolated $x y l 1$ and $x y l 2$ genes encoding XR and XDH from S. stipitis genomic DNA, respectively, cloned them in $S$. cerevisiae for the first time, and showed oxidative utilization of xylose. Later, more work on expressing $x y l 1$ and $x y l 2$ genes from S. stipitis in S. cerevisiae was carried out (Ho et al., 1998 Toivari et al., 2001; Kim et al., 2013), and reported higher assimilation of xylose and ethanol production as compared to the engineered strain 
overexpressed with XI gene (Karhumaa et al., 2007; Li et al., 2016). The XR$\mathrm{XDH}$ is an oxidoreductases-based enzyme, and requires a balance for complete assimilation of xylose. Under anaerobic condition, the NADH cannot be reoxidized to $\mathrm{NAD}^{+}$using oxygen as terminal electron acceptor; hence, there is an excess accumulation of NADPH and reduced $\mathrm{NAD}^{+}$availability. Further the $\mathrm{XR}$ in $P$. stipitis has a higher affinity for $\mathrm{NADPH}\left(K_{m}=3.2 \mu \mathrm{mol} / \mathrm{L}\right)$ as compared to NADH $\left(K_{m}=40 \mu \mathrm{mol} / \mathrm{L}\right)$ and XDH completely relies on $\mathrm{NAD}^{+}$, which causes severe disparity in the redox balance, leading to excess xylitol and reduced ethanol production (Jeffries and Jin, 2004).

To overcome the xylitol accumulation due to the redox imbalance, several strategies were employed including addition of external electron acceptor such as acetoin, acetaldehyde, furfural, and 5-hydroxymethylfurfural (HMF). Addition of acetoin and furfural showed reduced xylitol accumulation and increased ethanol production from $0.62 \mathrm{~mol}$ ethanol $/ \mathrm{mol}$ xylose to $1.35 \mathrm{~mol}$ ethanol/mol xylose by decreasing the flux by oxidative pentose pathway as the reduction of acetoin and furfural required NADH (Wahlbom and HahnHägerdal, 2002). Almeida et al. (2009) reported that the overexpression of the gene encoding furaldehyde reductase as a co-factor used in HMF reduction, significantly influenced ethanol production. They reported that the NADHdependent reductase exhibited carbon conservation by reducing glycerol formation and enhancing $\mathrm{NAD}^{+}$availability for $\mathrm{XDH}$, which eased xylose uptake and reduced xylitol accumulation.

In $S$. cerevisiae, ammonium assimilation involves glutamate dehydrogenase. Basically, glutamate dehydrogenase catalyzes the synthesis of glutamate from ammonium and 2-ketoglutarate. Two glutamate dehydrogenases namely NADPH-dependent glutamate dehydrogenase and NADH dependent glutamate dehydrogenase are responsible for ammonium assimilation in S. cerevisiae. Cofactor imbalance in the recombinant $S$. cerevisiae can be reduced by modifying ammonium assimilation through the deletion of gdhl encoding NADPHdependent glutamate dehydrogenase (EC 1.4.1.4) and the overexpression of $g d h 2$ encoding NADH-dependent glutamate dehydrogenase (EC 1.4.1.2). This strategy was reported to improve ethanol yield from 0.43 to $0.51 \mathrm{cmol} / \mathrm{cmol}$ while reducing xylitol accumulation by $44 \%$ (Roca et al., 2003). The increase in ethanol production and reduced xylitol production was due to the increase in the $\mathrm{NAD}^{+}$availability for $\mathrm{XDH}$, which directed xylose towards product and biomass formation (Roca et al., 2003). The re-oxidation of NADH can be achieved by channelizing the carbon flux through recombinant phosphoketolase pathway. Overexpression of phosphotransacetylase and acetaldehyde dehydrogenase in combination with the native phosphoketolase in xylose-fermenting S. cerevisiae strain TMB3001c showed reduced glycerol and xylitol accumulation, while ethanol yield was increased by $25 \%$ (Sonderegger et al., 2004).

The accumulation of xylitol was reduced when glucose was used as a cosubstrate; however, this costs in reduced xylose assimilation due to the competition among the sugar transporters (Hallborn et al., 1994). A recombinant $S$. cerevisiae strain with an $\mathrm{XR}$ to $\mathrm{XDH}$ ratio of 0.06 showed no xylitol and acetic acid formation, and depicted a good ethanol yield as compared to the strain with a higher XR:XDH ratio (Walfridsson et al., 1997). Multicopy integration of $x y l 2$ gene encoding $\mathrm{XDH}$ in the recombinant $S$. cerevisiae strain elevated xylulose accumulation and reduced xylitol formation reflecting that the activity of XK inhibits the assimilation and utilization of xylose on such cells (Jeffries and Jin, 2004). Further inefficient XK activity will tend to accumulate excess xylulose, and reduce intracellular levels of ATP and the ATP/ADP ratio with the subsequent overexpression of XR, XDH, and XK substantially enhancing the production of ethanol in S. cerevisiae (Richard et al., 2000). The engineered $S$. cerevisiae strain consisting of XR isozyme for wild type, and mutant showed an ethanol yield of $0.47 \mathrm{~g} / \mathrm{g}$ emphasizing on the role of XR in increasing ethanol yield (Jo et al., 2017).

\subsubsection{Utilization of xylose by engineering isomerase pathway}

The XI pathway is evident in most of the bacterial species as compared to yeast and in contrast to oxidoreductase pathway, it does not require co-factor and convert xylose directly to xylulose. Most of the heterologous expression of $\mathrm{XI}$ in S. cerevisiae strain shows lower functionality; probably due to suboptimal internal $\mathrm{pH}$, absence of specific metal ion, post-translational modification and protein misfolding. Heterologous expression of XI from Piromyces sp. E2 (pirXI), an anaerobic fungus, increased the flux of xylose towards ethanol production; however, misfolding of the protein was evident which restrained the enzyme activity (Lee et al., 2017). Co-expression of cytoplasmic chaperonin complex Gro EL-Gro ES complex from E. coli in the recombinant $S$. cerevisiae cloned with XI from the bacterium Propionibacterium acidipropionici displayed proper folding of XI and efficiently converted xylose to ethanol with a yield of $0.44 \mathrm{~g}$ ethanol $/ \mathrm{g}$ xylose (Temer et al., 2017).

Walfridsson et al. (1996) expressed xylA gene encoding XI from Thermus thermophiles, which showed a high specific activity $(1.0 \mathrm{U} / \mathrm{mg}$ of protein) at $80^{\circ} \mathrm{C}$ but had a poor performance (with a specific activity of 0.04 $\mathrm{U} / \mathrm{mg}$ of protein) at $30^{\circ} \mathrm{C}$, and accumulated xylitol and acetate as byproduct. On the similar lines, Lönn et al. (2003) performed a study by overexpressing multicopy xylA gene from $T$. thermophiles and found xylitol formation by activity of non-specific endogenous aldose reductase (GRE3) which reduced the activity of non-oxidative pentose pathway and XK. The deletion of gre 3 and over-expression of an extra copy of XK in the recombinant strain improved ethanol productivity and reduced xylitol production. The bottleneck related to xylitol accumulation and increasing xylose flux was addressed by over-expressing enzymes such as xylulokinase (EC 2.7.1.17), ribulose 5-phosphate isomerase (EC 5.3.1.6), ribulose 5-phosphate epimerase (EC 5.3.1.1), transketolase (EC 2.2.1.1), and transaldolase (EC 2.2.1.2) with the deletion of GRE3. The engineered strain showed simultaneous uptake of glucose and xylose (Kuyper et al., 2005).

The affinity of XI from Ruminococcus flavefaciens towards xylose could be improved by adapting modifications to the 5 '-end of the gene, sitedirected mutagenesis, and codon optimization. The modified enzyme showed 4.8-fold higher activity as compared to the native enzyme with a $K_{m}=66.7 \mathrm{mM}$ and specific activity of $1.41 \mu \mathrm{mol} / \mathrm{min} / \mathrm{mg}$. The recombinant $S$. cerevisiae harboring the modified enzyme along with cellobiose phosphorylase, cellobiose transporters, the endogenous genes gal2 (encoding transporter gene) and $x k$ and disruption of the native phol3 (encoding p-nitrophenylphosphatase) and gre3 genes resulted in four-fold higher xylose consumption even in the presence of lignocellulosic inhibitors and showed higher ethanol concentration (Aeling et al., 2012). Likewise, the xylose consumption could be increased by overexpressing the heterologous sugar transporter (PSSUT1) and $x k$ in the engineered strain containing $x y l A$ from the fungus Orpinomyces, showing an ethanol yield of $0.48 \mathrm{~g} / \mathrm{g}$ and low xylitol yield of $0.04 \mathrm{~g} / \mathrm{g}$ when grown in a complex medium supplemented with 0.01M borate (Madhavan, et al., 2009).

Brat et al. (2009) compared the performance of XI isolated from anaerobic bacterium Clostridium phytofermentans and Piromyces sp., and reported low inhibition of xylitol in the strain cloned with $C$. phytofermentans XI with an ethanol yield of $0.43 \mathrm{~g} / \mathrm{g}$ and xylitol production of $0.18 \mathrm{~g} / \mathrm{g}$. Cloning and expression of XI gene (xylA) of Burkholderia cenocepacia in S. cerevisiae showed better co-consumption of glucose and xylose under anaerobic condition and also resulted in a higher ethanol yield of $0.45 \mathrm{~g} / \mathrm{g}$ without xylitol accumulation (Peng et al., 2015). Ota et al. (2013) showed that the cell surface display of $x y l A$ from $C$. cellulovorans with the over-expression of $x k$ resulted in $0.5 \mathrm{~g} / \mathrm{g}$ ethanol yield under anaerobic condition.

To overcome the challenges related to redox imbalance, some studies have been focused on altering NADH/NADPH ratio for efficient performance of the XR and XDH. Since NADPH co-factor is majorly generated through the oxidative pentose phosphate pathway, the deletion of $z w f 1$ (glucose-6-phosphate dehydrogenase, EC 1.1.1.49) and gndl (6phosphogluconate dehydrogenase, EC 1.1.1.44) genes reduced the xylitol production with a low $\mathrm{XR} / \mathrm{XDH}$ ratio. However, the mutant having $\Delta z w f 1$ and $\Delta g n d l$ also showed reduced growth rate due to a significant drop in NADPH levels. To subsidize the negative effect caused by deletion of $z w f 1$, over-expression of gpd 1 encoding $\mathrm{NADP}^{+}$-dependent glyceraldehyde-3phosphate dehydrogenase (Kluyveromyces lactis GPD 1, EC 1.2.1.13) was performed which resulted in 52\% alleviation in ethanol yield and $48 \%$ lower xylitol accumulation (Verho et al., 2003). The overexpression of water-forming NADH oxidase (EC 1.6.99.3) gene noxE from Lactococcus lactis in recombinant $S$. cerevisiae led to a significant decrease in glycerol and xylitol production, and hence, increased final ethanol production during xylose metabolism. The ethanol yields of $0.294 \mathrm{~g} / \mathrm{g}$ and $0.211 \mathrm{~g} / \mathrm{g}$, respectively, were observed with recombinant and control strains of $S$ cerevisiae, which clearly revealed the effect of co-factor imbalance on the production of by-products, i.e., ethanol and xylitol (Zhang et al., 2012). The 
Table 4.

A summary of the studies performed on the over-expression of heterologous pentose phosphate pathway genes for improving xylose consumption and ethanol yield.

\begin{tabular}{|c|c|c|c|c|c|}
\hline Strain & Gene over-expressed & Xylose consumption rate (g/g/h) & Ethanol yield (g/g) & Ethanol yield of wild type strain $(\mathrm{g} / \mathrm{g})$ & Reference \\
\hline Saccharomyces cerevisiae & $\mathrm{XR}^{*}, \mathrm{XDH}, \mathrm{XK}$ & - & 0.11 & 0.0 & Toivari et al. (2001) \\
\hline S. cerevisiae & XR, XDH, XK & 0.28 & 0.24 & 0.0 & Kim et al. (2013) \\
\hline S. cerevisiae & XR, XDH, XK & 0.76 & 0.4 & - & Cadete et al. (2016) \\
\hline S. cerevisiae & XR, XDH, XK & 0.129 & 0.378 & - & Li et al. (2016) \\
\hline S. cerevisiae & $\mathrm{XI}, \mathrm{XK}$ & - & 0.41 & 0.010 & Kuyper et al. (2005) \\
\hline S. cerevisiae & $\mathrm{XI}, \mathrm{XK}$ & 1.87 & 0.41 & - & Zhou et al. (2012) \\
\hline S. cerevisiae & $\mathrm{XI}, \mathrm{XK}$ & 0.98 & 0.45 & 0.025 & Lee et al. (2014) \\
\hline
\end{tabular}

* XR: xylose reductase; XDH: xylitol dehydrogenase; XI: xylose isomerase

improvement of xylose uptake and ethanol production by over-expression of oxidoreductase and xylose isomerase pathways is shown in Table 4.

\subsubsection{Engineering of transporters for xylose uptake}

Yeast shows an efficient transport system for the endogenous metabolism of hexose sugars but a limited exogenous xylose metabolism and a low affinity for xylose as it is dependent on the hexose transport system. Considerable efforts have been made to engineer the xylose transporters to improve the simultaneous uptake of hexose and pentose sugars (Sharma et al., 2018a). The strength of the xylose transporter can be improved by targeting and engineering the existing sugar transporters or searching for novel heterologous xylose affinity/glucose repressor-based transporters (Kwak and Jin, 2017). S. cerevisiae has 18 hexose transporters among which Hxt 1-17 and Gal2 are responsible for glucose permeation across the cell membrane, while Hxt 1-7 acts as glucose facilitator. Several hexose transporters such as Hxt1, Hxt2, Hxt4, Hxt5, Hxt7, and Gal2 facilitate xylose uptake in S. cerevisiae; however, these transporters have low affinities towards xylose in the presence of glucose and are inefficient in xylose transportation at lower concentrations (Hamacher et al., 2002; Saloheimo et al., 2007). Among the hexose transporters, Hxt7 and Gal2 show higher affinities for xylose, but in the presence of glucose, these transporters are repressed and xylose uptake rate is reduced.

To enhance the uptake of xylose in S. cerevisiae, Leandro and co-workers expressed $C$. intermedia PYCC 4715 transporter proteins (glucose/xylose symporter - Gxs1 and glucose/xylose facilitator - Gxf1) in S. cerevisiae. The recombinant strain exhibited a higher growth rate in a xylose-containing medium with $K_{m}=0.2 \mathrm{mM}$, but in the presence of glucose in the medium, the affinity towards xylose was significantly reduced. These results concluded that the activity of transporter proteins Gxs1 and Gxf1 is directly proportional to the glucose concentration (Leandro et al., 2006). Young et al. (2011) expressed $C$. intermedia Gxs1 and Gxf1 along with S. stipitis Xut1 and Xut2 in a hexose null mutant which barely showed any improvements on a xylose-containing medium. When Gxf1 was expressed in $S$. cerevisiae, the recombinant strain showed a higher xylose uptake at lower concentrations of xylose, but it was unchanged even at higher concentrations of xylose in aerobic condition. The strain also exhibited a higher ethanol production and xylose uptake under anaerobic condition (Runquist et al., 2009). Young et al. (2011) created a mutant of transporter protein $C$. intermedia Gxs1 and S. stipitis Xut1 through the directed evolution method and expressed these mutant genes in a hexosenull S. cerevisiae mutant. The recombinant strain showed a substantial growth and uptake of xylose in a glucose/xylose medium. Further improvement in $V_{\max }$ and $K_{m}$ was observed by point mutating amino acid, Phe40 in Gxs1 and Glu538 in Xut1. Similarly, the single nucleotide polymorphism was created by point mutating Phe79Ser in HXT7, which showed a co-utilization of glucose and xylose sugars with a higher xylose uptake ability with $V_{\max }=186.4$ $\mathrm{nmol} / \mathrm{mL} / \mathrm{min}$ as compared to the wild type with $V_{\max }=101.6 \mathrm{nmol} / \mathrm{mL} / \mathrm{min}$ (Apel et al., 2016). Based on the sequence similarity of Gxs1 with other xylose transporters, a conserved motif sequence G-G/F-XXX-G has been identified and successive mutation in the amino acids Phe38, Ile39, and Met40 showed a two-fold improvement in the xylose uptake rate (Young et al., 2014).
The presence of three sugar transporters Sut1, Sut2, and Sut3 in $P$. stipitis leads to a higher affinity towards glucose than xylose; however, Sut 1 has a higher $V_{\max }$ for xylose as compared to the other transporters. Overexpression of $P$. stipitis Sut1 in a recombinant $S$. cerevisiae harboring XR$\mathrm{XDH}-\mathrm{XK}$ genes showed a higher uptake of xylose in glucose/xylose fermentation with an ethanol yield of $0.44 \mathrm{~g} / \mathrm{g}$ sugar (Katahira et al., 2008) Goncalves et al. (2014) over-expressed Hxt1, Hxt2, Hxt5, and Hxt7

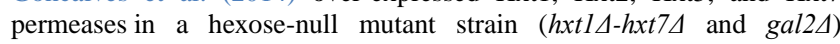
harboring $x y l 1, x y l 2$, and $x k$ genes. The results revealed that Hxt7 had a higher xylose consumption ability compared to the other transporters; however, the substrate affinity was 200 folds higher for glucose as compared to xylose in the medium containing glucose/xylose mixture making xylose the second choice even in the presence of low concentrations of glucose. While Hxt1 showed higher sugar uptake and ethanol productivity in co-fermentation of glucose and xylose but severely repressed xylose uptake in the presence of glucose showing diauxic growth profile. To overcome the barrier related to transporter repression, Farwick et al. (2014) conducted homology modelling for xylose transporters to transport D-xylose without any inhibition by D-glucose. This study showed that glucose-insensitive xylose transporters could be obtained by mutations in Gal2 and Hxt7 transporters, and hence it contributed to the understanding of sugar-transport mechanisms. More specifically, single point mutation in N376-F region of Gal2 and N370-S region of Hxt7 led to higher affinity towards xylose and loss of ability to transport hexose sugars.

Nijland et al. (2017) adapted an evolutionary engineering strategy to develop a chimeric HXT36 by the fusion of functional hexose transporter Hxt3-Hxt6. An amino acid substitution at N367A of Hxt36 enabled the coconsumption of glucose and xylose. The genome sequence analysis showed that co-repressors such as CYC8 and SSN6 were responsible for phenotypic characteristics of the non-evolved strain. Inactivation of CYC8 showed a higher activity of Hxt, which in turn increased the xylose transport and led to less sensitivity to D-glucose repression (Nijland et al., 2017). Wei et al (2018) found 11 transcriptional factors in glycolysis and pentose pathway of yeast that varied with the concentration of xylose and glucose/xylose in the medium. Knockout of THI2 promoted ribosome synthesis, enhanced xylose uptake rate and ethanol production by $26.8 \%$ and $32.4 \%$, respectively. Also, the over-expression of cell cycle related transcriptional factor Nrm1 further improved the xylose utilization rate by $30 \%$ and ethanol production by $76.6 \%$ in a glucose and xylose containing medium. An overview of metabolic engineering in yeast for simultaneous uptake of glucose and xylose is depicted in Figure 4.

\subsubsection{Elimination of by-products for efficient production of ethanol}

In microbial fermentation, the production of by-products is inevitable, which in turn diverts the carbon flux from the main product, thereby reducing the desired product titers (Arora et al., 2019). In order to overcome this bottleneck, appropriate rewiring of metabolic pathway is indispensable. In $S$. cerevisiae, glycerol is one of the major by-products, which accounts 
Hexose Transporter

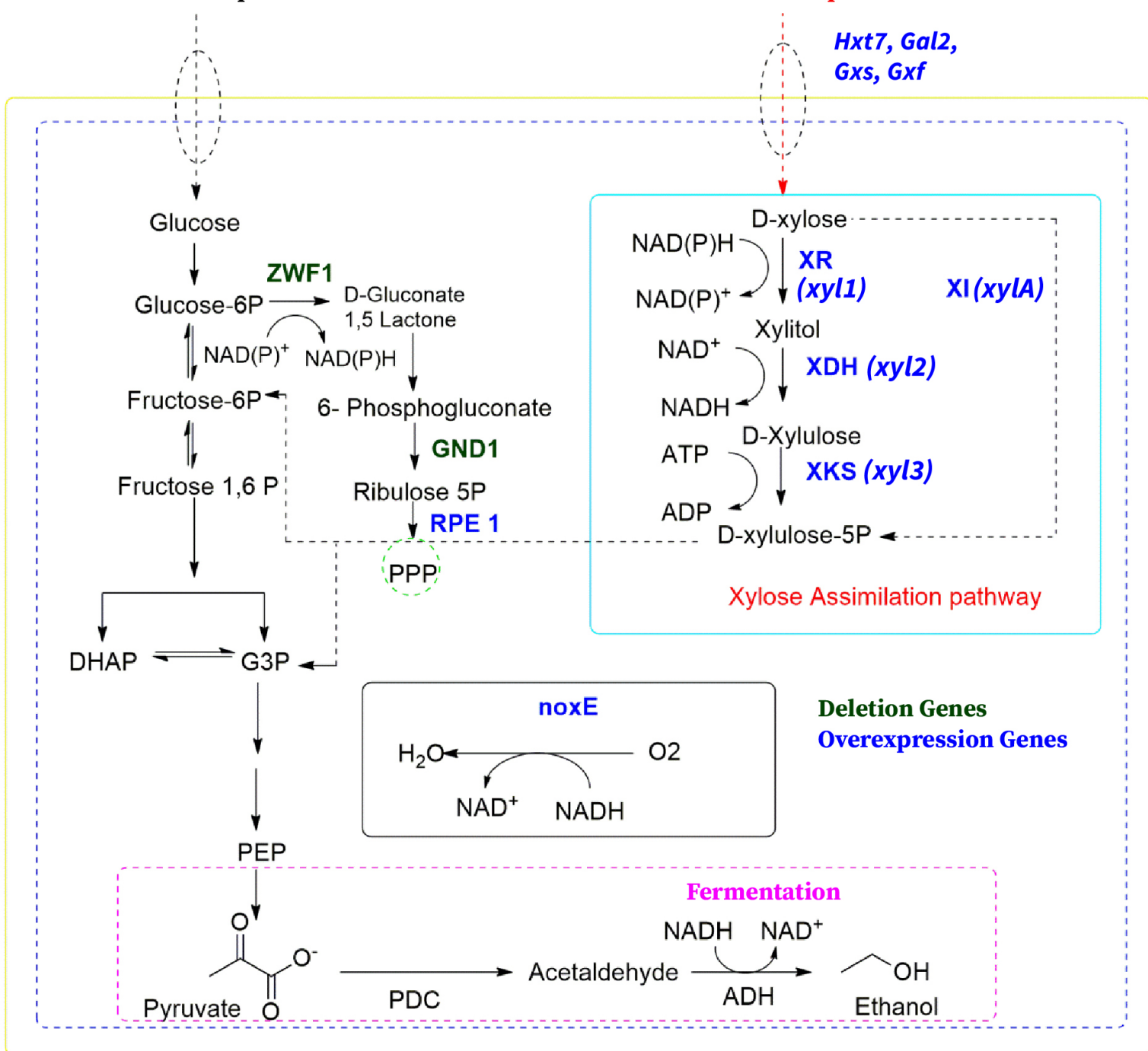

Pentose Transporter

Gxs, Gxf

Deletion Gene

Overexpression Genes

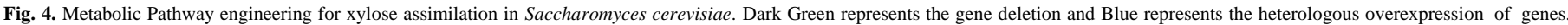

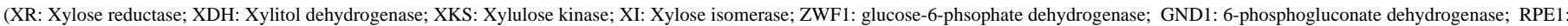

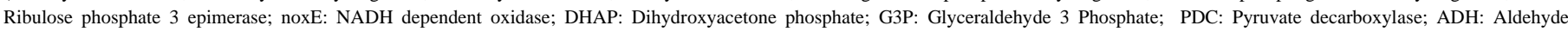
dehydrogenase; Hxt7, Gal2, Gxs, and Gxf are transporters)

for 2-3\% of sugar bioconversion. Even though glycerol is one of the platform chemicals, its separation during ethanol fermentation is not economically viable (Prior and Hohmann, 1997). In S. cerevisiae, glycerol formation is a twostep process. In the initial step, the NADH-dependent glycerol-3-phosphate dehydrogenases (GPD) catalyze the conversion of dihydroxyacetone phosphate to glycerol-3-phosphate followed by dephosphorylation of glycerol3-phosphate to glycerol (Gancedo et al., 1968; Påhlman et al., 2001). Glycerol is usually accumulated in the cell during osmotic stress condition and acts as osmolytes (Luyten, 1995). Jain et al. (2011) eliminated the gdpl (osmotically induced) and $g d p 2$ (anaerobically induced) but the growth of the strain was hindered under anaerobic conditions due to the excess accumulation of NADH. The redox imbalance was mitigated by introduction of oxido-reductase gene (which converts NADH to NAD ${ }^{+}$by production of sorbitol and propane-1,2diol) and ethanol yield was maintained at $0.48 \mathrm{~g} / \mathrm{g}$ glucose. On the similar lines, Papapetridis et al. (2017), deleted $g d p 2$ and aldehyde dehydrogenase (ALD6) genes and replaced it with native $g d p$ of an archaeal $\mathrm{NADP}^{+}$-preferring enzyme in an acetate reducing $S$. cerevisiae strain. The mutant strain was able to grow under anaerobic conditions with a high osmolarity and through the consumption of acetic acid without producing glycerol.

Acetic acid is another product usually observed in $S$. cerevisiae fermentation. It is also one of the major inhibitors present in lignocellulosic hydrolysate. Wei et al. (2013) proposed co-utilization of xylose and acetic acid for the production of ethanol by combining the NADH-producing xylose utilization pathway and NADH-consuming acetate reduction pathway. For this, they deleted $g d p 1$ and $g d p 2$ in order to reduce glycerol formation and introduced XR-XDH from $P$. stipitis, and adhE and $m p h F$ (proteins that are part of a bifunctional aldolase-dehydrogenase complex involved in 4-hydroxy-2-ketovalerate catabolism) from $E$. coli. The adhE and $m p h F$ genes aided in reduction of acetate to ethanol by generating 2 $\mathrm{NAD}^{+}$molecules. In xylose assimilation pathway, 1 mole of NADH is generated by the oxidation of xylitol to D-xylulose. The co-factor is exchanged between these two pathways showing improved ethanol production. 


\section{Integration approaches}

The most extensively used method of ethanol production using LCB is separate hydrolysis and fermentation (SHF), which involves two consecutive steps of enzymatic hydrolysis and fermentation in separate reactors. In this process, each process is optimized separately to achieve better enzymatic hydrolysis and microbial fermentation. However, some of the major limitations associated with this method are high production cost, less product yield, and high chances of contamination.

The fermentation of hexoses and pentoses are performed in different reactors during SHF, which further increases the processing time (Chandel et al., 2007; Offei et al., 2018; Tandon and Sharma, 2019). Based on the limitations associated with SHF, various integration processes such as simultaneous saccharification and fermentation/co-fermentation (SSF/SSCF) and CBP approaches have been adapted for commercial production of bioethanol (Fig. 5) (Arora et al., 2015a). CBP encompasses two strategies, i.e., engineering of wild microbial strains to improve product-related properties (titre and yield), and expression of heterologous cellulase system for cellulose utilization by high product-yielding non-cellulolytic microbes (Lynd et al., 2005). the same reactor in SSCF. In this process, the saccharification of cellulose and fermentation/co-fermentation of pentose and hexose sugars do not occur simultaneously, but in a sequential manner (Zhao et al., 2011).

These integrated approaches are less susceptible to contamination due to immediate conversion of sugars into ethanol in the same reaction vessel, which also leads to higher ethanol yields due to avoidance of feedback inhibition to enzyme. Moreover, these approaches offer easy process design and short reaction time, and are easy to operate with reduced process cost However, there are also some limitations associated with these processes One of the major challenges is the optimization of reaction conditions to make the system more efficient because separate optimal conditions are required for enzymatic hydrolysis and microbial fermentation.

SSF and SSCF processes are operated normally at $30-35^{\circ} \mathrm{C}$ to accommodate both microbial growth and ethanol fermentation (Canilha et al., 2012; Nikolić et al., 2016; Azhar et al., 2017). Moreover, the fermentation media used for bioethanol production is very viscous in nature due to presence of lignin content of LCB, and it is very difficult to separate lignin from the cellulosic part before fermentation. This results in difficulty in heat and mass transfer, and homogenous mixing of culture and media

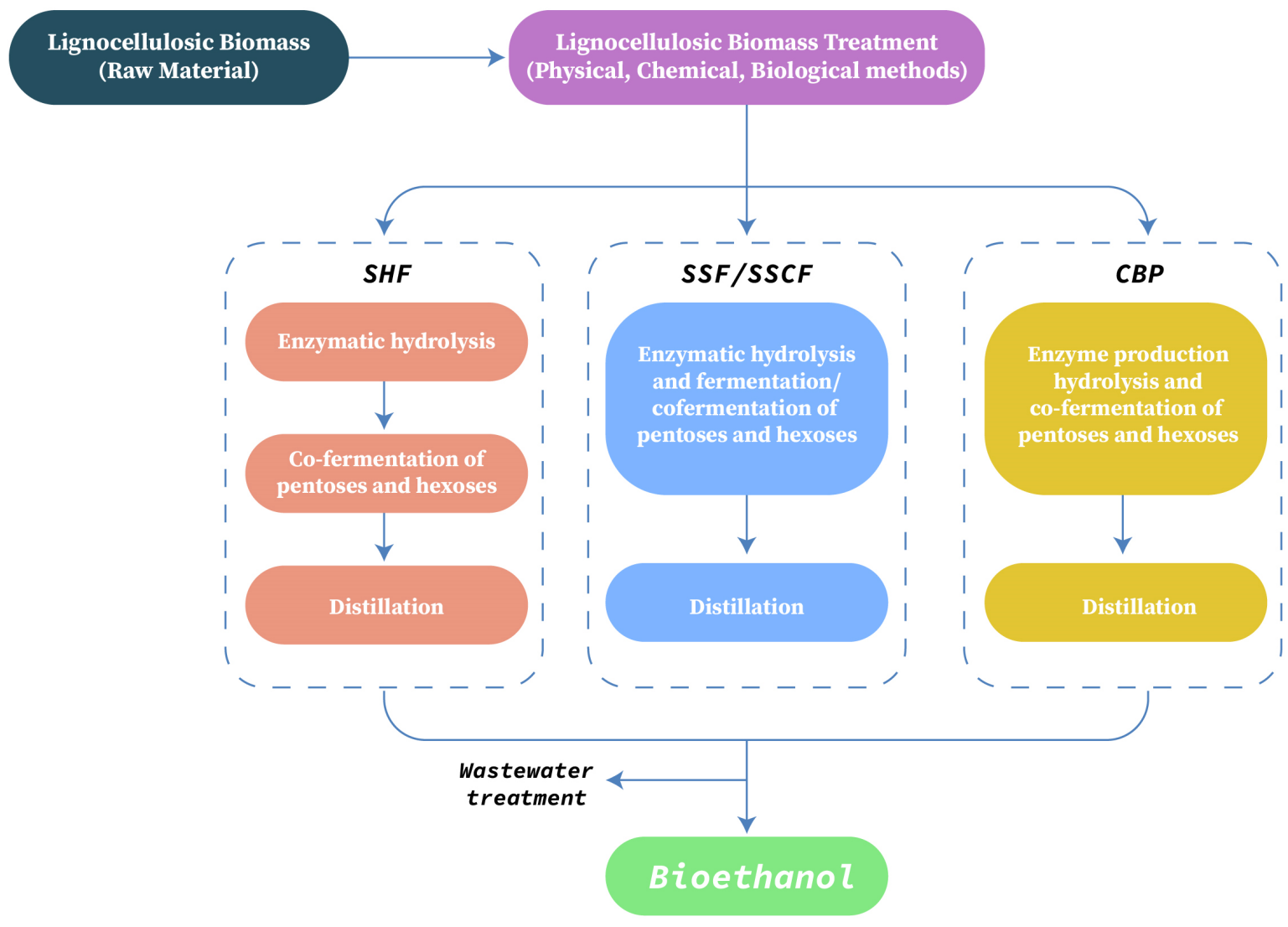

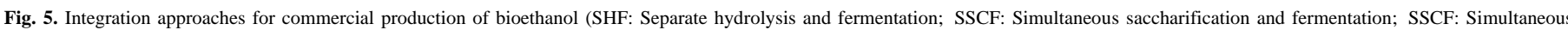
saccharification and co-fermentation; CBP: Consolidated bioprocessing).

\subsection{Simultaneous saccharification and fermentation/co-fermentation $(S S F / S S C F)$}

In SSF and SSCF processes, both enzymatic hydrolysis and fermentation processes are carried out simultaneously in the same reactor to maintain a low concentration of glucose as the accumulation of glucose inhibits the enzymatic activity. The fermentation of hexoses is performed by hexose-fermenting microorganisms in SSF whereas, both pentoses and hexoses are fermented in components. Hence, the energy consumption is high for distillation of fermentation broth and treatment of distillate (Zhao et al., 2011).

The promising microorganisms for bioethanol fermentation in SSF system are S. cerevisiae and Z. mobilis (Nigam and Singh, 1995). The other yeast strains, which have been reported for bioethanol production in SSF system are $K$. marxianus, $K$. fragilis, $P$. pastoris, and Hansenula polymorpha (Mejía-Barajas et al., 2016). It has been found that microwaveassisted liquefaction ( $80 \mathrm{~W}$ for $5 \mathrm{~min}$ ) of cornmeal (cornmeal to water ratio 
of 1:3) increased bioethanol production by $13.4 \%$ using S. cerevisiae var. ellipsoideus in SSF process (Nikolić et al., 2016). In another study, SSF system was used for bioethanol production from recycled paper sludge using $P$. stipitis CBS 5773. Celluclast ${ }^{\circledR} 1.5 \mathrm{~L}$ supplemented with Novozym ${ }^{\circledR} 188$ was used for enzymatic hydrolysis, which resulted in $100 \%$ saccharification. The ethanol concentration of $19.6 \mathrm{~g} / \mathrm{L}$ was achieved after $179 \mathrm{~h}$ of fermentation (Marques et al., 2008). Similarly, bioethanol production was reported using pretreated municipal solid waste via SSF using $S$. cerevisiae in a fed-batch mode with $25 \%(w / w)$ substrate loading and achieved an ethanol concentration of $30 \mathrm{~g} / \mathrm{L}$ (Ballesteros et al., 2010).

In a study, the thermotolerant yeast strain S. cerevisiae KNU5377 was used for ethanol production from pretreated waste newspaper $(250 \mathrm{~g} / \mathrm{L}$, solid loading) in a SSF system, and the ethanol production of $8.4 \%(\mathrm{v} / \mathrm{v})$ was obtained at $50^{\circ} \mathrm{C}$ after $72 \mathrm{~h}$ in a $5 \mathrm{~L}$ fermenter (Park et al., 2010). In another study, SSF was conducted using $S$. cerevisiae under shaking conditions $(60$ $\mathrm{rpm})$ using $1 \%(\mathrm{v} / \mathrm{v})$ inoculum under semi-anaerobic conditions for ethanol production from dates juice, and $88 \%$ of the substrate was converted into bioethanol at the end of fermentation with a product yield of $0.51 \mathrm{~g} / \mathrm{g}$ sugar (Taouda et al., 2017).

In a more recent study, bioethanol production of $82.1 \mathrm{~g} / \mathrm{L}$ was reported using sulphite-pretreated momentary pine slurry $(25 \%$, w/w) in a SSF system. Prehydrolysis was done at $50^{\circ} \mathrm{C}$ for $24 \mathrm{~h}$ and $200 \mathrm{rpm}$ followed by fermentation at $28^{\circ} \mathrm{C}$ or $35^{\circ} \mathrm{C}$ using $5 \mathrm{~g} / \mathrm{L}$ dry inoculum of $S$. cerevisiae (Dong et al., 2018). Many previous studies have also been reported on bioethanol production using SSCF fermentation (Erdei et al., 2013; Liu and Chen, 2016; Qin et al., 2018; Sharma et al., 2018b). SSCF improved ethanol production and productivity from food waste using $S$. coreanus and P. stipitis, standing at $48.63 \mathrm{~g} / \mathrm{L}$ and $2.03 \mathrm{~g} / \mathrm{L} / \mathrm{h}$, respectively (Jeong et al., 2012).

\subsection{Consolidated bioprocessing (CBP)}

The concept of CBP strategy was evolved from direct microbial conversion, but wild microbial strains are not available for commercial bioethanol production using this approach (Zhao et al., 2011). In CBP, all the steps of bioethanol production, i.e., enzymes production, cellulose hydrolysis, and fermentation, are conducted in a single vessel, and single microbial community is used for both production of cellulases and fermentation, which makes the process cost-effective. Lynd and his team have made great contributions to developing CBP systems for industrial ethanol production with high yields and titers from native and recombinant microbial strains (Laser et al., 2002; Lynd et al., 2005; Van Zyl et al., 2007; Olson et al., 2012; Holwerda et al., 2014; Izquierdo et al., 2014; Tian et al., 2017; Hon et al., 2018). In CBP, rational designs are used for production of engineered strains of bacteria and yeast with high ethanol titers (Jin et al., 2011). Filamentous fungi, Fusarium oxysporum, possesses the potential of bioethanol production from lignocelluloses in the CBP system (Ali et al., 2016). In the past few years, thermophilic anaerobic cellulolytic bacteria such as $T$. ethanolicus, C. thermohydrosulfuricum, $T$. mathranii, Thermoanaerobium brockii, and C. thermosaccharolyticum have been explored for bioethanol production using the CBP approach due to their ability for direct conversion of cheaper biomass feedstocks into bioethanol at extreme temperatures. However, these extremophiles are sensitive to ethanol concentration, which is a major hurdle for their use (Lynd et al., 2005; Vazirzadeh and Robati, 2013). The economic commercial production of bioethanol (66 million gallons at a breakeven price of $\$ 1.31$ per gallons) from pure sugarcane bagasse feed using the CBP platform has been reported by Raftery and Karim (2017). In another study, pine needle biomass was pretreated using IL followed by fermentation using $S$. cerevisiae and $P$. stipitis in a CBP system. The ethanol yield of $0.148 \mathrm{~g} / \mathrm{g}$ was obtained after $72 \mathrm{~h}$, and the fermentation efficiency of system was found at $41.39 \%$ (Vaid et al., 2018). Recently, recombinant $S$. cerevisiae ER T12 and M2n T1 strains (harboring integrated temA and temG Opt gene cassettes) simultaneously expressing $\alpha$ amylase and glucoamylase, produced $89.35 \mathrm{~g} / \mathrm{L}$ and $98.13 \mathrm{~g} / \mathrm{L}$ ethanol from starchy biomass in a single step CBP system at $30^{\circ} \mathrm{C}$ after $192 \mathrm{~h}$ with carbon conversion of $87 \%$ and $94 \%$, respectively (Cripwell et al., 2019).

Beri et al. (2020) proved the consumption of $85 \%$ recalcitrant glucuronoarabinoxylan (GAX) contained in from corn fiber by the isolated Herbinix spp. strain LL1355, and reported that six enzymes were involved in the hydrolysis of GAX linkages. They argued that the successful expression of up to four genes in Thermoanaerobacterium thermosaccharolyticum increased the GAX consumption and ethanol yield by $78 \%$ and $28 \%$, respectively.
Recently, the cell-free extract reaction (CFER) system was developed in Clostridium thermocellum to identify potential metabolic limitations and to offer potential metabolic engineering interventions to enhance ethanol titers (Cui et al., 2020). Although CBP method is much improved for ethano production compared to other existing methods due to less production cost of enzymes, yet there are some gaps concerning the commercial use of CBP systems. Future studies should be directed towards understanding the metabolic pathways of microorganisms, synergistic action between microbes and their enzymes for simultaneous pretreatment, hydrolysis and fermentation, and developing recombinant strains and bio-design strategies for enhanced ethanol production with improved yields.

\section{Concluding remarks and future prospects}

Lignocellulosic or $2 \mathrm{G}$ ethanol is being considered as one of the longterm sustainable alternative to the environmentally-degrading crude oil reserves. However, there are several technical and economic challenges associated with bioethanol refineries. Low-cost pretreatment to overcome biomass inherent recalcitrance in an eco-friendly manner is the first major hindrance that needs to be addressed. The choice of pretreatment method relies on the type of biomass selected for $2 \mathrm{G}$ sugars production at competitive prices. Thermo-mechanical extrusion method is considered one of the most efficient pretreatment methods which can be used in combination with other technologies such as particle-size reduction and green solvent pretreatment for efficient ethanol production. Pretreatment cost and chemical waste generation can also be reduced by altering lignin structure of LCB and expressing novel microbial enzymes in plants, which results in decreased molecular weight of lignin without compromising the biomass yield.

High cost associated with the commercially available cellulase/hemicellulase enzymes is another bottleneck that should be addressed by formulating indigenous tailor-made enzyme cocktails that are highly efficient against a wide range of agro-residues even at low protein loadings. On-site production of enzymes could be an effective strategy to reduce the production cost of bioethanol. The innovative technologies like protein engineering and computational protein design can be used for generation of cost-effective and industrially important novel biocatalysts. The future research should also target designing integrated approaches for simultaneous pretreatment and saccharification of biomass, and fermentation of the released sugars.

The third major challenge in $2 \mathrm{G}$ ethanol processing is the limited uptake of xylose by fermenting yeasts in the presence of glucose. The ethanol production efficiency can also be improved by using genetically modified microbes, which possess the ability to ferment pentose and hexose sugars simultaneously in the presence of fermentation inhibitors by eliminating the detoxification step. Therefore, the future research should be focused on the development of robust engineered yeast having suitable transporters for simultaneous uptake of glucose and xylose with equal assimilation rates Metabolic engineering, cell surface engineering, and synthetic biology are other promising approaches being used for the synthesis of engineered host fermentation system to improve the production of bioethanol. CRISPRCas9 is a simple but powerful gene-editing tool for safe and stable gene expression, which can be used for synthesis of engineered microbial strains. Among the various production platforms, CBP seems more efficient for economic bioethanol production because all the steps are performed in a single reactor by a single microorganism capable of producing hydrolytic enzymes and fermentation.

Finally, development of biorefineries seems critical for economical utilization of LCB. Focusing on a single product or bioethanol may not be an economically viable option. A biorefinery may be designed in such a fashion to valorize each and every component of lignocelluloses into biofuels and biochemicals for sustainable development of circular bioeconomy (Chandel et al., 2020). Therefore, a major focus should be placed on the development of such kinds of systems to reduce production cost and improve production efficiency.

Addressing the above-mentioned challenges could help to provide solutions for escalating global energy demands while mitigating the climate-related challenges as well. 


\section{Acknowledgements}

MH and SK are thankful to the Department of Biotechnology, Ministry of Science and Technology, India, for providing funds to carry out the research work via the grant no. DBT/IC-2/Indo-Brazil/2016-19/05. AKC is grateful to the CAPES-Brazil for the financial assistance (Process USP number: 15.1.1118.1.0)

\section{References}

[1] Abbott, A.P., Capper, G., Davies, D.L., Rasheed, R.K., Tambyrajah, V., 2003. Novel solvent properties of choline chloride/urea mixtures. Chem. Commun. (1), 70-71.

[2] Abdu Yusuf, A., L Inambao, F., 2019. Bioethanol production techniques from lignocellulosic biomass as alternative fuel: a review. Int. J. Mech. Eng. Technol. 10(6)

[3] Abo, B.O., Gao, M., Wang, Y., Wu, C., Ma, H., Wang, Q., 2019. Lignocellulosic biomass for bioethanol: an overview on pretreatment, hydrolysis and fermentation processes. Rev. Environ. Health. 34(1), 5768.

[4] Abreu-Cavalheiro, A., Monteiro, G., 2013. Solving ethanol production problems with genetically modified yeast strains. Braz. J. Microbiol. 44(3), 665-671.

[5] Adeleye, T., Kareem, S., Dairo, O., Atanda, O., 2019. Studies on amylase from protoplast fusants of Aspergillus species using response surface methodology. Access Microbiol. 1(1A), 19.

[6] Aden, A., Foust, T., 2009. Technoeconomic analysis of the dilute sulfuric acid and enzymatic hydrolysis process for the conversion of corn stover to ethanol. Cellulose. 16(4), 535-545.

[7] Adsul, M., Bastawde, K., Varma, A.J., Gokhale, D.V., 2007. Strain improvement of Penicillium janthinellum NCIM 1171 for increased cellulase production. Bioresour. Technol. 98(7), 1467-1473.

[8] Aeling, K.A., Salmon, K.A., Laplaza, J.M., Li, L., Headman, J.R., Hutagalung, A.H., Picataggio, S., 2012. Co-fermentation of xylose and cellobiose by an engineered Saccharomyces cerevisiae. J. Ind. Microbial. Biotechnol. 39(11), 1597-1604.

[9] Akhtar, N., Gupta, K., Goyal, D., Goyal, A., 2016. Recent advances in pretreatment technologies for efficient hydrolysis of lignocellulosic biomass. Environ. Prog. Sust. Energy. 35(2), 489-511.

[10] Al-Battashi, H.S., Annamalai, N., Sivakumar, N., Al-Bahry, S., Tripathi, B.N., Nguyen, Q.D., Gupta, V.K., 2019. Lignocellulosic biomass (LCB): a potential alternative biorefinery feedstock for polyhydroxyalkanoates production. Rev. Environ. Sci. Biotechnol. 18(1), 183-205.

[11] Ali, S.S., Nugent, B., Mullins, E., Doohan, F.M., 2013. Insights from the fungus Fusarium oxysporum point to high affinity glucose transporters as targets for enhancing ethanol production from lignocellulose. PloS one. $8(1)$, e54701

[12] Ali, S.S., Nugent, B., Mullins, E., Doohan, F.M., 2016. Fungal-mediated consolidated bioprocessing: the potential of Fusarium oxysporum for the lignocellulosic ethanol industry. AMB Express. 6(1), 13.

[13] Allen, S.A.A., REE, A.G., Ayodeji, S.A.M., Deborah, S.A.E., 2016. Lignocelluloses: an economical and ecological resource for bio-ethanol production-a review. Management. 1(3), 128-144.

[14] Almeida, J.R., Bertilsson, M., Hahn-Hägerdal, B., Lidén, G., GorwaGrauslund, M.F., 2009. Carbon fluxes of xylose-consuming Saccharomyces cerevisiae strains are affected differently by NADH and NADPH usage in HMF reduction. Appl. Microbial. Biotechnol. 84(4), 751-761.

[15] Alonso, D.A., Baeza, A., Chinchilla, R., Guillena, G., Pastor, I.M., Ramón, D.J., 2016. Deep eutectic solvents: the organic reaction medium of the century. Eur. J. Org. Chem. 2016(4), 612-632.

[16] Amore, A., Giacobbe, S., Faraco, V., 2013. Regulation of cellulase and hemicellulase gene expression in fungi. Current genomics. 14(4), 230249.

[17] An, Y.X., Zong, M.H., Wu, H., Li, N., 2015. Pretreatment of lignocellulosic biomass with renewable cholinium ionic liquids: biomass fractionation, enzymatic digestion and ionic liquid reuse. Bioresour. Technol. 192, 165-171

[18] Apel, A.R., Ouellet, M., Szmidt-Middleton, H., Keasling, J.D., Mukhopadhyay, A., 2016. Evolved hexose transporter enhances xylose uptake and glucose/xylose co-utilization in Saccharomyces cerevisiae. Sci. Rep. 6(1), 1-10

[19] Arora, R., Behera, S., Kumar, S., 2015a. Bioprospecting thermophilic/thermotolerant microbes for production of lignocellulosic ethanol: a future perspective. Renew. Sust. Energy Rev. 51, 699-717.

[20] Arora, R., Behera, S., Sharma, N.K., Kumar, S., 2015b. Bioprospecting thermostable cellulosomes for efficient biofue production from lignocellulosic biomass. Bioresour. Bioprocess. 2(38), 1-12.

[21] Arora, R., Behera, S., Sharma, N.K., Kumar, S., 2015c. A new search for thermotolerant yeasts, its characterization and optimization using response surface methodology for ethanol production. Front Microbiol. 6, 889 .

[22] Arora, R., Behera, S., Sharma, N.K., Kumar, S., 2017. Augmentation of ethanol production through statistically designed growth and fermentation medium using novel thermotolerant yeast isolates. Renewable Energy. 109, 406-421.

[23] Arora, T., Rudenko, O., Egerod, K.L., Husted, A.S., KovatchevaDatchary, P., Akrami, R., Kristensen, M., Schwartz, T.W., Bäckhed F., 2019. Microbial fermentation of flaxseed fibers modulates the transcriptome of GPR41-expressing enteroendocrine cells and protects mice against diet-induced obesity. Am. J. Physiol Endocrinol. Metab. 316(3), E453-E463

[24] Arumugam, A., Malolan, V.V., Ponnusami, V., 2020. Contemporary pretreatment strategies for bioethanol production from corncobs: a comprehensive review. Waste Biomass Valorization. 1-36.

[25] Awoyale, A.A., Lokhat, D., 2019. Harnessing the potential of bioethanol production from lignocellulosic biomass in Nigeria-a review. Biofuels, Bioprod. Biorefin. 13(1), 192-207.

[26] Azhar, S.H.M., Abdulla, R., Jambo, S.A., Marbawi, H., Gansau, J.A. Faik, A.A.M., Rodrigues, K.F., 2017. Yeasts in sustainable bioethano production: a review. Biochem. Biophys. Rep. 10, 52-61.

[27] Ballesteros, M., Sáez, F., Ballesteros, I., Manzanares, P., Negro, M.J., Martínez, J.M., Castañeda, R., Dominguez, J.M.O., 2010. Ethano production from the organic fraction obtained after therma pretreatment of municipal solid waste. Appl. Biochem. Biotechnol. 161(1-8), 423-431

[28] Baruah, J., Nath, B.K., Sharma, R., Kumar, S., Deka, R.C., Baruah, D.C., Kalita, E., 2018. Recent trends in the pretreatment of lignocellulosic biomass for value-added products. Front. Energy Res. 6,141

[29] Basotra, N., Dhiman, S.S., Agrawal, D., Sani, R.K., Tsang, A., Chadha, B.S., 2019. Characterization of a novel lytic polysaccharide monooxygenase from Malbranchea cinnamomea exhibiting dual catalytic behavior. Carbohydr. Res. 478, 46-53

[30] Bayer, E.A., Chanzy, H., Lamed, R., Shoham, Y., 1998. Cellulose, cellulases and cellulosomes. Curr. Opin. Struct. Boil. 8(5), 548-557.

[31] Beeson, W.T., Phillips, C.M., Cate, J.H., Marletta, M.A., 2012 Oxidative cleavage of cellulose by fungal copper-dependent polysaccharide monooxygenases. J. Am. Chem. Soc. 134(2), 890 892.

[32] Behera, S., Arora, R., Nandhagopal, N., Kumar, S., 2014. Importance of chemical pretreatment for bioconversion of lignocellulosic biomass. Renew. Sust. Energy Rev. 36, 91-106.

[33] Beri, D., York, W.S., Lynd, L.R., Peña, M.J., Herring, C.D., 2020 Development of a thermophilic coculture for corn fiber conversion to ethanol. Nat. Commun. 11(1), 1-11.

[34] Berni, R., Piasecki, E., Legay, S., Hausman, J.F., Siddiqui, K.S., Cai, G., Guerriero, G., 2019. Identification of the laccase-like multicopper oxidase gene family of sweet cherry (Prunus avium L.) and expression analysis in six ancient Tuscan varieties. Sci. Rep. 9(1), 114.

[35] Bhalla, A., Bischoff, K.M., Sani, R.K., 2014a. Highly thermostable $\mathrm{GH}_{39} \beta$-xylosidase from a Geobacillus sp. strain WSUCF 1 . BMC Biotechnol. 14(1), 963

[36] Bhalla, A., Bischoff, K.M., Uppugundla, N., Balan, V., Sani, R.K., 2014b. Novel thermostable endo-xylanase cloned and expressed from bacterium Geobacillus sp. WSUCF1. Bioresour. Technol. 165, 314 318. 
[37] Bhatia, S.K., Kim, S.H., Yoon, J.J., Yang, Y.H., 2017. Current status and strategies for second generation biofuel production using microbial systems. Energy Convers. Manage. 148, 1142-1156.

[38] Bhattacharya, A.S., Bhattacharya, A., Pletschke, B.I., 2015. Synergism of fungal and bacterial cellulases and hemicellulases: a novel perspective for enhanced bio-ethanol production. Biotechnol. Lett. 37(6), 1117-1129.

[39] Bhutto, A.W., Qureshi, K., Harijan, K., Abro, R., Abbas, T., Bazmi, A.A., Karim, S., Yu, G., 2017. Insight into progress in pre-treatment of lignocellulosic biomass. Energy. 122, 724-745.

[40] Bilal, M., Nawaz, M.Z., Iqbal, H., Hou, J., Mahboob, S., Al-Ghanim, K.A., Cheng, H., 2018. Engineering ligninolytic consortium for bioconversion of lignocelluloses to ethanol and chemicals. Protein Pept. Lett. 25(2), 108-119.

[41] Binod, P., Janu, K.U., Sindhu, R., Pandey, A., 2011. Hydrolysis of lignocellulosic biomass for bioethanol production. Biofuels. 229-250.

[42] Blumer-Schuette, S.E., Brown, S.D., Sander, K.B., Bayer, E.A., Kataeva, I., Zurawski, J.V., Conway, J.M., Adams, M.W., Kelly, R.M., 2014. Thermophilic lignocellulose deconstruction. FEMS Microbiol. Rev. 38(3), 393-448.

[43] Bodenheimer, A.M., O'Dell, W.B., Oliver, R.C., Qian, S., Stanley, C.B., Meilleur, F., 2018. Structural investigation of cellobiose dehydrogenase IIA: insights from small angle scattering into intra-and intermolecular electron transfer mechanisms. Biochim. Biophys. Acta, Gen. Subj. 1862(4), 1031-1039.

[44] Borand, M.N., Karaosmanoğlu, F., 2018. Effects of organosolv pretreatment conditions for lignocellulosic biomass in biorefinery applications: a review. J. Renew. Sustain. Energy. 10(3), 033104.

[45] Branco, R.H., Serafim, L.S., Xavier, A.M., 2019. Second generation bioethanol production: on the use of pulp and paper industry wastes as feedstock. Fermentation. 5(1), 4

[46] Brandt, A., Ray, M.J., To, T.Q., Leak, D.J., Murphy, R.J., Welton, T., 2011. Ionic liquid pretreatment of lignocellulosic biomass with ionic liquid-water mixtures. Green Chem. 13(9), 2489-2499.

[47] Brat, D., Boles, E., Wiedemann, B., 2009. Functional expression of a bacterial xylose isomerase in Saccharomyces cerevisiae. Appl. Environ. Microbiol. 75(8), 2304-2311

[48] Brown, N.A., De Gouvea, P.F., Krohn, N.G., Savoldi, M., Goldman, G.H., 2013. Functional characterisation of the non-essential protein kinases and phosphatases regulating Aspergillus nidulans hydrolytic enzyme production. Biotechnol. Biofuels. 6(1), 91

[49] Bušić, A., Marđetko, N., Kundas, S., Morzak, G., Belskaya, H., Ivančić Šantek, M., Komes, D., Novak, S., Šantek, B., 2018. Bioethanol production from renewable raw materials and its separation and purification: a review. Food Technol. Biotechnol. 56(3), 289-311.

[50] Cadete, R.M., Alejandro, M., Sandström, A.G., Ferreira, C., Gírio, F. Gorwa-Grauslund, M.F., Rosa, C.A., Fonseca, C., 2016. Exploring xylose metabolism in Spathaspora species: $\mathrm{XYL}_{1.2}$ from Spathaspora passalidarum as the key for efficient anaerobic xylose fermentation in metabolic engineered Saccharomyces cerevisiae. Biotechnol. Biofuels. 9(1), 167

[51] Canilha, L., Chandel, A.K., Suzane dos Santos Milessi, T., Antunes, F.A.F., Luiz da Costa Freitas, W., das Graças Almeida Felipe, M., da Silva, S.S., 2012. Bioconversion of sugarcane biomass into ethanol: an overview about composition, pretreatment methods, detoxification of hydrolysates, enzymatic saccharification, and ethanol fermentation. BioMed Res. Int. 2012

[52] Cantarel, B.L., Coutinho, P.M., Rancurel, C., Bernard, T., Lombard, V., Henrissat, B., 2009. The Carbohydrate-Active EnZymes database (CAZy): an expert resource for glycogenomics. Nucleic Acids Res. 37(suppl_1), D233-D238.

[53] Capolupo, L., Faraco, V., 2016. Green methods of lignocellulose pretreatment for biorefinery development. Appl. Microbial. Biotechnol. 100(22), 9451-9467.

[54] Chadha, B., Rubinder, K., Saini, H., 2005. Constitutive $\alpha$-amylase producing mutant and recombinant haploid strains of thermophilic fungus Thermomyces lanuginosus. Folia Microbial. 50(2), 133.

[55] Chadha, B.S., Rai, R., Mahajan, C., 2019. Chapter 18-Hemicellulases for lignocellulosics-based bioeconomy. biofuels: alternative feedstocks and conversion processes for the production of liquid and gaseous biofuels ( $2^{\text {nd }}$ Edition). pp. 427-445.
[56] Chandel, A.K., Chan, E.S., Rudravaram, R., Narasu, M.L., Rao, L.V. Ravindra, P., 2007. Economics and environmental impact of bioethanol production technologies: an appraisal. Biotechnol. Mol. Boil. Rev. 2(1), 14-32

[57] Chandel, A.K., Garlapati, V.K., Jeevan Kumar, S., Hans, M., Singh, A.K., Kumar, S., 2020. The role of renewable chemicals and biofuels in building a bioeconomy. Biofuels, Bioprod. Biorefin. 14(4), 830844.

[58] Cheah, W.Y., Sankaran, R., Show, P.L., Ibrahim, T.N.B.T., Chew, K.W., Culaba, A., Jo-Shu, C., 2020. Pretreatment methods for lignocellulosic biofuels production: current advances, challenges and future prospects. Biofuel Res. J. 7(1), 1115-1127.

[59] Chekushina, A.V., Dotsenko, G.S., Sinitsyn, A.P., 2013. Comparing the efficiency of plant material bioconversion processes using biocatalysts based on Trichoderma and Penicillium verruculosum enzyme preparations. Catal. Ind. 5(1), 98-104

[60] Chen, H., Liu, J., Chang, X., Chen, D., Xue, Y., Liu, P., Lin, H., Han, S., 2017. A review on the pretreatment of lignocellulose for highvalue chemicals. Fuel Process. Technol. 160, 196-206.

[61] Cheng, M.H., Wang, Z., Dien, B.S., Slininger, P.J., Singh, V., 2019 Economic analysis of cellulosic ethanol production from sugarcane bagasse using a sequential deacetylation, hot water and disk-refining pretreatment. Processes. 7(10), 642

[62] Cheng, N.G., Hasan, M., Kumoro, A.C., Ling, C.F., Tham, M., 2009. Production of ethanol by fed-batch fermentation. Pertanika J. Sci. Technol. 17(2), 399-408

[63] Cho, K.M., Yoo, Y.J., Kang, H.S., 1999. $\delta$-Integration of endo/exoglucanase and $\beta$-glucosidase genes into the yeast chromosomes for direct conversion of cellulose to ethanol. Enzyme Microb. Technol. 25(1-2), 23-30

[64] Choe, D., Lee, J.H., Yoo, M., Hwang, S., Sung, B.H., Cho, S. Palsson, B., Kim, S.C., Cho, B.K., 2019. Adaptive laboratory evolution of a genome-reduced Escherichia coli. Nat. Commun. $10(1), 1-14$

[65] Chylenski, P., Petrović, D.M., Müller, G., Dahlström, M., Bengtsson, O., Lersch, M., Siika-Aho, M., Horn, S.J., Eijsink, V.G., 2017. Enzymatic degradation of sulfite-pulped softwoods and the role of LPMOs. Biotechnol. Biofuels. 10(1), 177.

[66] Cripps, R., Eley, K., Leak, D.J., Rudd, B., Taylor, M., Todd, M., Boakes, S., Martin, S., Atkinson, T., 2009. Metabolic engineering of Geobacillus thermoglucosidasius for high yield ethanol production. Metab. Eng. 11(6), 398-408

[67] Cripwell, R.A., Rose, S.H., Favaro, L., Van Zyl, W.H., 2019 Construction of industrial Saccharomyces cerevisiae strains for the efficient consolidated bioprocessing of raw starch. Biotechnol. Biofuels. 12(1), 201

[68] Cui, J., Stevenson, D., Korosh, T., Amador-Noguez, D., Olson, D.G., Lynd, L.R., 2020. Developing a cell-free extract reaction (CFER system in Clostridium thermocellum to identify metabolic limitations to ethanol production. Front. Energy Res. 8

[69] Davies, G., Henrissat, B., 1995. Structures and mechanisms of glycosyl hydrolases. Structure. 3(9), 853-859

[70] Den Haan, R., Rose, S.H., Lynd, L.R., van Zyl, W.H., 2007 Hydrolysis and fermentation of amorphous cellulose by recombinant Saccharomyces cerevisiae. Metab. Eng. 9(1), 87-94.

[71] Dey, P., Pal, P., Kevin, J.D., Das, D.B., 2020. Lignocellulosic bioethanol production: prospects of emerging membrane technologies to improve the process-a critical review. Rev. Chem. Eng. 36(3), 333 367.

[72] Dhiman, S.S., David, A., Braband, V.W., Hussein, A., Salem, D.R. Sani, R.K., 2017. Improved bioethanol production from corn stover: role of enzymes, inducers and simultaneous product recovery. Appl. Energy. 208, 1420-1429

[73] Dien, B.S., Cotta, M.A., Jeffries, T.W., 2003. Bacteria engineered for fuel ethanol production: current status. Appl. Microbial. Biotechnol. 63(3), 258-266.

[74] Ding, X., Yao, L., Hou, Y., Hou, Y., Wang, G., Fan, J., Qian, L., 2020. Optimization of culture conditions during the solid-state fermentation of tea residue using mixed strains. Waste Biomass Valorization. 1-9. 
[75] Doğan, A., Demirci, S., Aytekin, A.Ö., Şahin, F., 2014. Improvements of tolerance to stress conditions by genetic engineering in Saccharomyces cerevisiae during ethanol production. Appl. Biochem. Biotechnol. 174(1), 28-42.

[76] Doi, R.H., Kosugi, A., 2004. Cellulosomes: plant-cell-wall-degrading enzyme complexes. Nat. Rev. Microbial. 2(7), 541-551.

[77] Dong, C., Wang, Y., Zhang, H., Leu, S.Y., 2018. Feasibility of highconcentration cellulosic bioethanol production from undetoxified whole Monterey pine slurry. Bioresour. Technol. 250, 102-109.

[78] Druzhinina, I.S., Kubicek, C.P., 2017. Genetic engineering of Trichoderma reesei cellulases and their production. Microb. Biotechnol. 10(6), 1485-1499.

[79] Dutta, A., Dowe, N., Ibsen, K.N., Schell, D.J., Aden, A., 2010. An economic comparison of different fermentation configurations to convert corn stover to ethanol using Z. mobilis and Saccharomyces. Biotechnol. Prog. 26(1), 64-72.

[80] Erbeldinger, M., Ni, X., Halling, P.J., 1998. Enzymatic synthesis with mainly undissolved substrates at very high concentrations. Enzyme Microb. Technol. 23(1-2), 141-148.

[81] Erdei, B., Galbe, M., Zacchi, G., 2013. Simultaneous saccharification and co-fermentation of whole wheat in integrated ethanol production. Biomass Bioenergy. 56, 506-514.

[82] Ezeilo, U.R., Zakaria, I.I., Huyop, F., Wahab, R.A., 2017. Enzymatic breakdown of lignocellulosic biomass: the role of glycosyl hydrolases and lytic polysaccharide monooxygenases. Biotechnol. Biotechnol. Equip. 31(4), 647-662.

[83] Fang, H., Xia, L., 2015. Heterologous expression and production of Trichoderma reesei cellobiohydrolase II in Pichia pastoris and the application in the enzymatic hydrolysis of corn stover and rice straw. Biomass Bioenergy. 78, 99-109.

[84] Fang, X., Yano, S., Inoue, H., Sawayama, S., 2009. Strain improvement of Acremonium cellulolyticus for cellulase production by mutation. J. Biosci. Bioeng. 107(3), 256-261.

[85] Farwick, A., Bruder, S., Schadeweg, V., Oreb, M., Boles, E., 2014. Engineering of yeast hexose transporters to transport D-xylose without inhibition by D-glucose. Proc. Natl. Acad. Sci. 111(14), 5159-5164.

[86] Feng, B.Z., Li, P., 2014. Cloning, characterization and expression of a novel laccase gene Pclac2 from Phytophthora capsici. Braz. J. Microbiol. 45(1), 351-358.

[87] Filiatrault-Chastel, C., Navarro, D., Haon, M., Grisel, S., HerpoëlGimbert, I., Chevret, D., Fanuel, M., Henrissat, B., Heiss-Blanquet, S., Margeot, A., Berrin, J.G., 2019. AA16, a new lytic polysaccharide monooxygenase family identified in fungal secretomes. Biotechnol. Biofuels. 12(1), 55

[88] Financie, R., Moniruzzaman, M., Uemura, Y., 2016. Enhanced enzymatic delignification of oil palm biomass with ionic liquid pretreatment. Biochem. Eng. J. 110, 1-7.

[89] Fockink, D.H., Andreaus, J., Ramos, L.P., Łukasik, R.M., 2020. Pretreatment of cotton spinning residues for optimal enzymatic hydrolysis: a case study using green solvents. Renewable Energy. 145, 490-499.

[90] Fontes, C.M., Gilbert, H.J., 2010. Cellulosomes: highly efficient nanomachines designed to deconstruct plant cell wall complex carbohydrates. Annu. Rev. Biochem. 79, 655-681.

[91] Francisco, M., van den Bruinhorst, A., Kroon, M.C., 2012. New natural and renewable low transition temperature mixtures (LTTMs): screening as solvents for lignocellulosic biomass processing. Green Chem. 14(8), 2153-2157.

[92] Fujii, T., Fang, X., Inoue, H., Murakami, K., Sawayama, S., 2009. Enzymatic hydrolyzing performance of Acremonium cellulolyticus and Trichoderma reesei against three lignocellulosic materials. Biotechnol. Biofuels. 2(1), 24.

[93] Fujii, T., Inoue, H., Ishikawa, K., 2013. Enhancing cellulase and hemicellulase production by genetic modification of the carbon catabolite repressor gene, creA, in Acremonium cellulolyticus. AMB Express. 3(1), 73.

[94] Fujii, T., Inoue, H., Yano, S., Sawayama, S., 2018. Strain improvement for industrial production of lignocellulolytic enzyme by Talaromyces cellulolyticus. Fungal Cellulolytic Enzymes. Springer, Singapore. 135154.
[95] Fujita, Y., Ito, J., Ueda, M., Fukuda, H., Kondo, A., 2004. Synergistic saccharification, and direct fermentation to ethanol, of amorphous cellulose by use of an engineered yeast strain codisplaying three types of cellulolytic enzyme. Appl. Environ. Microbiol. 70(2), 1207-1212.

[96] Gabhane, J., Kumar, S., Sarma, A.K., 2020. Effect of glycerol therma and hydrothermal pretreatments on lignin degradation and enzymatic hydrolysis in paddy straw. Renewable Energy. 154, 1304-1313

[97] Gancedo, C., Gancedo, J.M., Sols, A., 1968. Glycerol metabolism in yeasts: pathways of utilization and production. Eur. J. Biochem. 5(2) $165-172$.

[98] García, A., Rodríguez-Juan, E., Rodríguez-Gutiérrez, G., Rios, J.J. Fernández-Bolaños, J., 2016. Extraction of phenolic compounds from virgin olive oil by deep eutectic solvents (DESs). Food Chem. 197, 554-561.

[99] Ge, J.P., Zhang, L.Y., Ping, W.X., Zhang, M.Y., Shen, Y., Song, G. 2014. Genetically engineered Saccharomyces cerevisiae strain that can ultilize both xylose and glucose for fermentation. Appl. Mech. Mater. Trans. Tech. Publ. 1637-1643.

[100]Geysens, S., Pakula, T., Uusitalo, J., Dewerte, I., Penttilä, M. Contreras, R., 2005. Cloning and characterization of the glucosidase II alpha subunit gene of Trichoderma reesei: a frameshift mutation results in the aberrant glycosylation profile of the hypercellulolytic strain Rut-C30. Appl. Environ. Microbiol. 71(6), 2910-2924.

[101]Gibney, E., Nolan, C., 2010. Epigenetics and gene expression. Heredity. 105(1), 4-13

[102] Gielen, D., Boshell, F., Saygin, D., Bazilian, M.D., Wagner, N., Gorini, R., 2019. The role of renewable energy in the global energy transformation. Energy Strategy Rev. 24, 38-50.

[103]Gill, I., Vulfson, E., 1994. Enzymic catalysis in heterogeneous eutectic mixtures of substrates. Trends Biotechnol. 12(4), 118-122.

[104]Goncalves, D.L., Matsushika, A., Belisa, B., Goshima, T., Bon, E.P., Stambuk, B.U., 2014. Xylose and xylose/glucose co-fermentation by recombinant Saccharomyces cerevisiae strains expressing individual hexose transporters. Enzyme Microb. Technol. 63, 13-20.

[105]Gong, Y.Y., Yin, X., Zhang, H.M., Wu, M.C., Tang, C.D., Wang, J.Q., Pang, Q.F., 2013. Cloning, expression of a feruloyl esterase from Aspergillus usamii E001 and its applicability in generating ferulic acid from wheat bran. J. Ind. Microbial. Biotechnol. 40(12), 14331441.

[106]Gusakov, A.V., 2011. Alternatives to Trichoderma reesei in biofue production. Trends Biotechnol. 29(9), 419-425.

[107]Hahn-Hägerdal, B., Karhumaa, K., Fonseca, C., Spencer-Martins, I. Gorwa-Grauslund, M.F., 2007. Towards industrial pentosefermenting yeast strains. Appl. Microbial. Biotechnol. 74(5), 937 953.

[108]Haldar, D., Purkait, M.K., 2020. Lignocellulosic conversion into value-added products: a review. Process Biochem. 89, 110-133.

[109]Hallborn, J., Meinander, N., Hahn-Hëgerdal, B., Gorwa, M.F. Pentillä, M., Keränen, S., 1994. The influence of cosubstrate and aeration on xylitol formation by recombinantSaccharomyces cerevisiae expressing theXYL1 gene. Appl. Microbial. Biotechnol. 42(2-3), 326-333.

[110]Hamacher, T., Becker, J., Gárdonyi, M., Hahn-Hägerdal, B., Boles E., 2002. Characterization of the xylose-transporting properties of yeast hexose transporters and their influence on xylose utilization. Microbiology. 148(9), 2783-2788.

[111]Hameed, A., Shahina, M., Lai, W.A., Lin, S.Y., Young, L.S., Liu, Y.C., Hsu, Y.H., Young, C.C., 2015. Oricola cellulosilytica gen. nov. sp. nov., a cellulose-degrading bacterium of the family Phyllobacteriaceae isolated from surface seashore water, and emended descriptions of Mesorhizobium loti and Phyllobacterium myrsinacearum. Antonie van Leeuwenhoek. 107(3), 759-771.

[112]Hannon, J.R., Lynd, L.R., Andrade, O., Benavides, P.T., Beckham, G.T., Biddy, M.J., Brown, N., Chagas, M.F., Davison, B.H., Foust, T., 2020. Technoeconomic and life-cycle analysis of single-step catalytic conversion of wet ethanol into fungible fuel blendstocks. Proc. Natl. Acad. Sci. 117(23), 12576-12583.

[113]Hans, M., Garg, S., Pellegrini, V.O., Filgueiras, J.G., de Azevedo, E.R., Guimaraes, F.E., Chandel, A.K., Polikarpov, I., Chadha, B.S. Kumar, S., 2020. Liquid ammonia pretreatment optimization for 
improved release of fermentable sugars from sugarcane bagasse. J. Clean. Prod. 123922.

[114]Hans, M., Kumar, S., Chandel, A.K., Polikarpov, I., 2019. A review on bioprocessing of paddy straw to ethanol using simultaneous saccharification and fermentation. Process Biochem. 85, 125-134.

[115]Haq, F., Ali, H., Shuaib, M., Badshah, M., Hassan, S.W., Munis, M.F.H., Chaudhary, H.J., 2016. Recent progress in bioethanol production from lignocellulosic materials: a review. Int. J. Green Energy. 13(14), 14131441

[116]Harmsen, P.F.H., Huijgen, W., Bermudez, L., Bakker, R., 2010. Literature review of physical and chemical pretreatment processes for lignocellulosic biomass. Wageningen UR-Food Biobased Res. 1184.

[117]Harner, N.K., Wen, X., Bajwa, P.K., Austin, G.D., Ho, C.Y., Habash, M.B., Trevors, J.T., Lee, H., 2015. Genetic improvement of native xylose-fermenting yeasts for ethanol production. J. Ind. Microbiol. Biotechnol. 42(1), 1-20.

[118] Hasunuma, T., Kondo, A., 2012. Development of yeast cell factories for consolidated bioprocessing of lignocellulose to bioethanol through cell surface engineering. Biotechnol. Adv. 30(6), 1207-1218.

[119]Henriksson, G., Johansson, G., Pettersson, G., 2000. A critical review of cellobiose dehydrogenases. J. Biotechnol. 78(2), 93-113.

[120]Ho, N.W., Chen, Z., Brainard, A.P., 1998. Genetically engineered Saccharomycesyeast capable of effective cofermentation of glucose and xylose. Appl. Environ. Microbiol. 64(5), 1852-1859

[121]Holwerda, E.K., Thorne, P.G., Olson, D.G., Amador-Noguez, D., Engle, N.L., Tschaplinski, T.J., Van Dijken, J.P., Lynd, L.R., 2014. The exometabolome of Clostridium thermocellum reveals overflow metabolism at high cellulose loading. Biotechnol. Biofuels. 7(1), 155.

[122]Hon, S., Holwerda, E.K., Worthen, R.S., Maloney, M.I., Tian, L., Cui, J., Lin, P.P., Lynd, L.R., Olson, D.G., 2018. Expressing the Thermoanaerobacterium saccharolyticum pforA in engineered Clostridium thermocellum improves ethanol production. Biotechnol. Biofuels. 11(1), 242.

[123]Hou, X.D., Feng, G.J., Ye, M., Huang, C.M., Zhang, Y., 2017. Significantly enhanced enzymatic hydrolysis of rice straw via a highperformance two-stage deep eutectic solvents synergistic pretreatment. Bioresour. Technol. 238, 139-146.

[124]Hou, X.D., Li, N., Zong, M.H., 2013. Facile and simple pretreatment of sugar cane bagasse without size reduction using renewable ionic liquidswater mixtures. ACS Sust. Chem. Eng. 1(5), 519-526.

[125]Hou, X.D., Smith, T.J., Li, N., Zong, M.H., 2012. Novel renewable ionic liquids as highly effective solvents for pretreatment of rice straw biomass by selective removal of lignin. Biotechnol. Bioeng. 109(10), 2484-2493.

[126]Huang, Y., Qin, X., Luo, X.M., Nong, Q., Yang, Q., Zhang, Z., Gao, Y., Lv, F., Chen, Y., Yu, Z., Liu, J.L., 2015. Efficient enzymatic hydrolysis and simultaneous saccharification and fermentation of sugarcane bagasse pulp for ethanol production by cellulase from Penicillium oxalicum EU2106 and thermotolerant Saccharomyces cerevisiae ZM1-5. Biomass Bioenergy. 77, 53-63.

[127]Ilmén, M., Thrane, C., Penttilä, M., 1996. The glucose repressor genecre1 of Trichoderma: isolation and expression of a full-length and a truncated mutant form. Mol. Gen. Genet. MGG. 251(4), 451-460.

[128]Ingale, S., Joshi, S.J., Gupte, A., 2014. Production of bioethanol using agricultural waste: banana pseudo stem. Braz. J. Microbiol. 45(3), 885892

[129]Isikgor, F.H., Becer, C.R., 2015. Lignocellulosic biomass: a sustainable platform for the production of bio-based chemicals and polymers. Polym. Chem. 6(25), 4497-4559

[130]Islam, F., Roy, N., 2019. Isolation and characterization of cellulaseproducing bacteria from sugar industry waste. Am. J. BioSci. 7(1), 16-24.

[131]Izquierdo, J.A., Pattathil, S., Guseva, A., Hahn, M.G., Lynd, L.R., 2014. Comparative analysis of the ability of Clostridium clariflavum strains and Clostridium thermocellum to utilize hemicellulose and unpretreated plant material. Biotechnol. Biofuels. 7(1), 1-8.

[132]Jahid, M., Gupta, A., Sharma, D.K., 2018. Production of bioethanol from fruit wastes (banana, papaya, pineapple and mango peels) under milder conditions. J. Bioprocess. Biotech. 8(3), 327.

[133]Jain, V.K., Divol, B., Prior, B.A. and Bauer, F.F., 2012. Effect of alternative NAD+-regenerating pathways on the formation of primary and secondary aroma compounds in a Saccharomyces cerevisiae glycerol-defective mutant. Appl. Microbiol. Biotechnol. 93(1), 131141.

[134]Jain, A., Chaurasia, S.P., 2014. Bioethanol production in membrane bioreactor (MBR) system: a review. Int. J. Environ. Res. Dev. 4(4) 387-394.

[135]Janusz, G., Pawlik, A., Sulej, J., Świderska-Burek, U., JaroszWilkołazka, A., Paszczyński, A., 2017. Lignin degradation: microorganisms, enzymes involved, genomes analysis and evolution. FEMS Microbiol. Rev. 41(6), 941-962.

[136]Jatinder, K.A.U.R., Chadha, B.S., Saini, H.S., 2006. Optimization of medium components for production of cellulases by Melanocarpus sp. MTCC 3922 under solid-state fermentation. World J. Microbiol. Biotechnol. 22(1), 15-22.

[137]Jayasekara, S., Ratnayake, R., 2019. Microbial Cellulases: an overview and applications. In Cellulose. Intechopen.

[138]Jeffries, T.W., Jin, Y.S., 2004. Metabolic engineering for improved fermentation of pentoses by yeasts. Appl. Microbiol. Biotechnol. 63(5), 495-509.

[139]Jenkin, G.R., Al-Bassam, A.Z., Harris, R.C., Abbott, A.P., Smith, D.J., Holwell, D.A., Chapman, R.J., Stanley, C.J., 2016. The application of deep eutectic solvent ionic liquids for environmentallyfriendly dissolution and recovery of precious metals. Miner. Eng. 87, 18-24.

[140]Jeong, S.M., Kim, Y.J., Lee, D.H., 2012. Ethanol production by cofermentation of hexose and pentose from food wastes using Saccharomyces coreanus and Pichia stipitis. Korean J. Chem. Eng. 29(8), 1038-1043.

[141]Jeya, M., Thiagarajan, S., Lee, J.K., Gunasekaran, P., 2009. Cloning and expression of GH11 xylanase gene from Aspergillus fumigatus MKU1 in Pichia pastoris. J. Biosci. Bioeng. 108(1), 24-29.

[142]Jhong, H.R., Wong, D.S.H., Wan, C.C., Wang, Y.Y., Wei, T.C., 2009 A novel deep eutectic solvent-based ionic liquid used as electrolyte for dye-sensitized solar cells. Electrochem. Commun. 11(1), 209-211.

[143]Jin, M., Balan, V., Gunawan, C., Dale, B.E., 2011. Consolidated bioprocessing (CBP) performance of Clostridium phytofermentans on AFEX-treated corn stover for ethanol production. Biotechnol. Bioeng. 108(6), 1290-1297.

[144]Jo, J.H., Park, Y.C., Jin, Y.S., Seo, J.H., 2017. Construction of efficient xylose-fermenting Saccharomyces cerevisiae through a synthetic isozyme system of xylose reductase from Scheffersomyces stipitis. Bioresour. Technol. 241, 88-94.

[145]Juturu, V., Wu, J.C., 2013. Insight into microbial hemicellulases other than xylanases: a review. J. Chem. Technol. Biotechnol. 88(3), 353 363.

[146]Kandanelli, R., Thulluri, C., Mangala, R., Rao, P.V., Gandham, S., Velankar, H.R., 2018. A novel ternary combination of deep eutectic solvent-alcohol (DES-OL) system for synergistic and efficient delignification of biomass. Bioresour. Technol. 265, 573-576.

[147]Karhumaa, K., Sanchez, R.G., Hahn-Hägerdal, B., Gorwa-Grauslund, M.F., 2007. Comparison of the xylose reductase-xylitol dehydrogenase and the xylose isomerase pathways for xylose fermentation by recombinant Saccharomyces cerevisiae. Microb. cell Fact. 6(1), 5 .

[148]Kassaye, S., Pant, K.K., Jain, S., 2017. Hydrolysis of cellulosic bamboo biomass into reducing sugars via a combined alkaline solution and ionic liquid pretreament steps. Renewable Energy. 104, $177-184$

[149]Katahira, S., Ito, M., Takema, H., Fujita, Y., Tanino, T., Tanaka, T., Fukuda, H., Kondo, A., 2008. Improvement of ethanol productivity during xylose and glucose co-fermentation by xylose-assimilating S cerevisiae via expression of glucose transporter Sut1. Enzyme Microb. Technol. 43(2), 115-119.

[150]Kaur, B., Oberoi, H.S., Chadha, B.S., 2014. Enhanced cellulase producing mutants developed from heterokaryotic Aspergillus strain. Bioresour. Technol. 156, 100-107.

[151]Kaur, B., Sharma, M., Soni, R., Oberoi, H.S., Chadha, B.S., 2013 Proteome-based profiling of hypercellulase-producing strains developed through interspecific protoplast fusion between 
Aspergillus nidulans and Aspergillus tubingensis. Appl. Biochem. Biotechnol. 169(2), 393-407.

[152]Kazi, F.K., Fortman, J.A., Anex, R.P., Hsu, D.D., Aden, A., Dutta, A., Kothandaraman, G., 2010. Techno-economic comparison of process technologies for biochemical ethanol production from corn stover. Fuel. 89, S20-S28.

[153]Khaliq, A.D., Chafidz, A., Lukman, M.A., Kholil, I., 2020. Making of bioethanol banana weevil as renewable energy. IOP Conf. Ser.: Mater. Sci. Eng. IOP Publishing. 722(1), 012080.

[154]Kim, K.H., Dutta, T., Sun, J., Simmons, B., Singh, S., 2018. Biomass pretreatment using deep eutectic solvents from lignin derived phenols. Green Chem. 20(4), 809-815.

[155]Kim, S.R., Ha, S.J., Wei, N., Oh, E.J., Jin, Y.S., 2012. Simultaneous cofermentation of mixed sugars: a promising strategy for producing cellulosic ethanol. Trends Biotechnol. 30(5), 274-282.

[156]Kim, S.R., Skerker, J.M., Kang, W., Lesmana, A., Wei, N., Arkin, A.P., Jin, Y.S., 2013. Rational and evolutionary engineering approaches uncover a small set of genetic changes efficient for rapid xylose fermentation in Saccharomyces cerevisiae. PloS one. 8(2), e57048.

[157]Kiran, B., Kumar, R., Deshmukh, D., 2014. Perspectives of microalgal biofuels as a renewable source of energy. Energy Convers. Manage. 88, 1228-1244.

[158]Knob, A., Carmona, E.C., 2009. Cell-associated acid $\beta$-xylosidase production by Penicillium sclerotiorum. New Biotechnol. 26(1-2), 60-67.

[159]Ko, J.K., Jung, J.H., Altpeter, F., Kannan, B., Kim, H.E., Kim, K.H., Alper, H.S., Um, Y., Lee, S.M., 2018. Largely enhanced bioethanol production through the combined use of lignin-modified sugarcane and xylose fermenting yeast strain. Bioresour. Technol. 256, 312-320.

[160]Kordowska-Wiater, M., Polak-Berecka, M., Wasko, A., Targonski, Z., 2012. Protoplast fusion of Rhizopus oryzae and Rhizopus microsporus for enhanced fumaric acid production from glycerol. BioTechnologia. J. Biotechnol. Comput. Biol. Bionanotechnol. 93(4).

[161]Kötter, P., Amore, R., Hollenberg, C.P., Ciriacy, M., 1990. Isolation and characterization of the Pichia stipitis xylitol dehydrogenase gene, $\mathrm{XYL}_{2}$, and construction of a xylose-utilizing Saccharomyces cerevisiae transformant. Curr. Genet. 18(6), 493-500.

[162]Kratzel, A., Todt, D., V'kovski, P., Steiner, S., Gultom, M., Thao, T.T.N., Ebert, N., Holwerda, M., Steinmann, J., Niemeyer, D., 2020. Inactivation of severe acute respiratory syndrome coronavirus 2 by WHOrecommended hand rub formulations and alcohols. Emerging Infect. Dis. 26(7), 1592.

[163]Kremer, T.A., LaSarre, B., Posto, A.L., McKinlay, J.B., 2015. N2 gas is an effective fertilizer for bioethanol production by Zymomonas mobilis. Proc. Natl. Acad. Sci. 112(7), 2222-2226.

[164]Kricka, W., Fitzpatrick, J., Bond, U., 2014. Metabolic engineering of yeasts by heterologous enzyme production for degradation of cellulose and hemicellulose from biomass: a perspective. Front. Microbial. 5, 174.

[165]Kucharska, K., Słupek, E., Cieśliński, H., Kamiński, M., 2020. Advantageous conditions of saccharification of lignocellulosic biomass for biofuels generation via fermentation processes. Chem. Pap. 74(4), 1199-1209.

[166]Kuila, A., Sharma, V., Garlapati, V.K., Singh, A., Roy, L., Banerjee, R., 2016. Present statu s on enzymatic hydrolysis of lignocellulosic biomass for bioethanol production. Adv Biofeedstocks Biofuels. 1, 85 .

[167]Kumar, A.K., Parikh, B.S., Pravakar, M., 2016. Natural deep eutectic solvent mediated pretreatment of rice straw: bioanalytical characterization of lignin extract and enzymatic hydrolysis of pretreated biomass residue. Environ. Sci. Pollut. Res. 23(10), 9265-9275.

[168]Kumar, A.K., Sharma, S., 2017. Recent updates on different methods of pretreatment of lignocellulosic feedstocks: a review. Bioresour. Bioprocess. 4(1), 7.

[169]Kumar, R., Singh, S., Singh, O.V., 2008. Bioconversion of lignocellulosic biomass: biochemical and molecular perspectives. J. Ind. Microbial. Biotechnol. 35(5), 377-391.

[170]Kumar, S., Dheeran, P., Singh, S.P., Mishra, I.M., Adhikari, D.K., 2015. Continuous ethanol production from sugarcane bagasse hydrolysate at high temperature with cell recycle and in-situ recovery of ethanol. Chem. Eng. Sci. 138, 524-530.

[171]Kuyper, M., Hartog, M.M., Toirkens, M.J., Almering, M.J., Winkler, A.A., van Dijken, J.P., Pronk, J.T., 2005. Metabolic engineering of a xylose-isomerase-expressing Saccharomyces cerevisiae strain for rapid anaerobic xylose fermentation. FEMS Yeast res. 5(4-5), 399409.

[172]Kwak, S., Jin, Y.S., 2017. Production of fuels and chemicals from xylose by engineered Saccharomyces cerevisiae: a review and perspective. Microb. cell Fact. 16(1), 82.

[173]Langston, J.A., Shaghasi, T., Abbate, E., Xu, F., Vlasenko, E. Sweeney, M.D., 2011. Oxidoreductive cellulose depolymerization by the enzymes cellobiose dehydrogenase and glycoside hydrolase 61 . Appl. Environ. Microbiol. 77(19), 7007-7015.

[174]Lara-Serrano, M., Sáez Angulo, F., Negro, M.a.J., Morales-delaRosa, S., Campos-Martin, J.M., Fierro, J.L., 2018. Second-generation bioethanol production combining simultaneous fermentation and saccharification of IL-pretreated barley straw. ACS Sust. Chem. Eng. 6(5), 7086-7095

[175]Laser, M., Schulman, D., Allen, S.G., Lichwa, J., Antal Jr, M.J., Lynd, L.R., 2002. A comparison of liquid hot water and steam pretreatments of sugar cane bagasse for bioconversion to ethanol. Bioresour. Technol. 81(1), 33-44.

[176]Leandro, M.J., Gonçalves, P., Spencer-Martins, I., 2006. Two glucose/xylose transporter genes from the yeast Candida intermedia: first molecular characterization of a yeast xylose- $\mathrm{H}^{+}$symporter. Biochem. J. 395(3), 543-549.

[177]Lee, M., Rozeboom, H.J., de Waal, P.P., de Jong, R.M., Dudek, H.M. Janssen, D.B., 2017. Metal dependence of the xylose isomerase from Piromyces sp. E2 explored by activity profiling and protein crystallography. Biochemistry. 56(45), 5991-6005.

[178]Lee, S.M., Jellison, T., Alper, H.S., 2014. Systematic and evolutionary engineering of a xylose isomerase-based pathway in Saccharomyces cerevisiae for efficient conversion yields. Biotechnol. Biofuels. 7(1), 122.

[179]Levasseur, A., Drula, E., Lombard, V., Coutinho, P.M., Henrissat, B., 2013. Expansion of the enzymatic repertoire of the CAZy database to integrate auxiliary redox enzymes. Biotechnol. Biofuels. 6(1), 41.

[180]Li, C., Knierim, B., Manisseri, C., Arora, R., Scheller, H.V., Auer, M., Vogel, K.P., Simmons, B.A., Singh, S., 2010. Comparison of dilute acid and ionic liquid pretreatment of switchgrass: biomass recalcitrance, delignification and enzymatic saccharification. Bioresour. Technol. 101(13), 4900-4906.

[181]Li, X., Park, A., Estrela, R., Kim, S.R., Jin, Y.S., Cate, J.H., 2016. Comparison of xylose fermentation by two high-performance engineered strains of Saccharomyces cerevisiae. Biotechnol. Rep. 9, 53-56.

[182]Li, Y.J., Lu, Y.Y., Zhang, Z.J., Mei, S., Tan, T.W., Fan, L.H., 2017. Co-fermentation of cellulose and sucrose/xylose by engineered yeasts for bioethanol production. Energy Fuels. 31(4), 4061-4067.

[183]Lim, W.L., Gunny, A.A.N., Kasim, F.H., AlNashef, I.M., Arbain, D., 2019a. Alkaline deep eutectic solvent: a novel green solvent for lignocellulose pulping. Cellulose. 26(6), 4085-4098.

[184]Lim, J., Choi, Y.H., Hurh, B.S., Lee, I., 2019b. Strain improvement of Aspergillus sojae for increased 1-leucine aminopeptidase and protease production. Food Sci. Biotechnol. 28(1), 121-128.

[185]Liu, D., Li, J., Zhao, S., Zhang, R., Wang, M., Miao, Y., Shen, Y., Shen, Q., 2013. Secretome diversity and quantitative analysis of cellulolytic Aspergillus fumigatus $Z_{5}$ in the presence of different carbon sources. Biotechnol. Biofuels. 6(1), 149.

[186]Liu, R., Chen, L., Jiang, Y., Zhou, Z., Zou, G., 2015. Efficient genome editing in filamentous fungus Trichoderma reesei using the CRISPR/Cas9 system. Cell Discovery. 1, 15007.

[187]Liu, Z.H., Chen, H.Z., 2016. Simultaneous saccharification and cofermentation for improving the xylose utilization of steam exploded corn stover at high solid loading. Bioresour. Technol. 201, 15-26.

[188]Lombard, V., Golaconda Ramulu, H., Drula, E., Coutinho, P.M., Henrissat, B., 2014. The carbohydrate-active enzymes database (CAZy) in 2013. Nucleic Acids Res. 42(D1), D490-D495.

[189]Lönn, A., Träff-Bjerre, K., Otero, R.C., Van Zyl, W.H., HahnHägerdal, B., 2003. Xylose isomerase activity influences xylose fermentation with recombinant Saccharomyces cerevisiae strains expressing mutated xylA from Thermus thermophilus. Enzyme Microb. Technol. 32(5), 567-573. 
[190]Loose, J.S., Forsberg, Z., Kracher, D., Scheiblbrandner, S., Ludwig, R., Eijsink, V.G., Vaaje-Kolstad, G., 2016. Activation of bacterial lytic polysaccharide monooxygenases with cellobiose dehydrogenase. Protein Sci. 25(12), 2175-2186.

[191]Loow, Y.L., Wu, T.Y., Yang, G.H., Ang, L.Y., New, E.K., Siow, L.F., Jahim, J.M., Mohammad, A.W., Teoh, W.H., 2018. Deep eutectic solvent and inorganic salt pretreatment of lignocellulosic biomass for improving xylose recovery. Bioresour. Technol. 249, 818-825.

[192]Lu, L., Wang, T.N., Xu, T.F., Wang, J.Y., Wang, C.L., Zhao, M., 2013. Cloning and expression of thermo-alkali-stable laccase of Bacillus licheniformis in Pichia pastoris and its characterization. Bioresour. Technol. 134, 81-86.

[193]Lugani, Y., Sooch, B.S., 2018. Insights into fungal xylose reductases and its application in xylitol production. Fungal Biorefineries. Springer. 121144.

[194]Luyten, K., Albertyn, J., Skibbe, W.F., Prior, B.A., Ramos, J., Thevelein, J.M. and Hohmann, S., 1995. Fps1, a yeast member of the MIP family of channel proteins, is a facilitator for glycerol uptake and efflux and is inactive under osmotic stress. EMBO J. 14(7), 1360-1371.

[195]Lynd, L.R., Laser, M.S., Bransby, D., Dale, B.E., Davison, B., Hamilton, R., Himmel, M., Keller, M., McMillan, J.D., Sheehan, J., 2008. How biotech can transform biofuels. Nat. Biotechnol. 26(2), 169-172.

[196]Lynd, L.R., Van Zyl, W.H., McBride, J.E., Laser, M., 2005. Consolidated bioprocessing of cellulosic biomass: an update. Curr. Opin. Biotechnol. 16(5), 577-583

[197]Ma, S., Preims, M., Piumi, F., Kappel, L., Seiboth, B., Record, E., Kracher, D., Ludwig, R., 2017. Molecular and catalytic properties of fungal extracellular cellobiose dehydrogenase produced in prokaryotic and eukaryotic expression systems. Microb. cell Factor. 16(1), 37.

[198]Madadi, M., Tu, Y., Abbas, A., 2017. Recent status on enzymatic saccharification of lignocellulosic biomass for bioethanol production. Electron. J. Biol. 13(2), 135-143.

[199]Madhavan, A., Tamalampudi, S., Srivastava, A., Fukuda, H., Bisaria, V.S., Kondo, A., 2009. Alcoholic fermentation of xylose and mixed sugars using recombinant Saccharomyces cerevisiae engineered for xylose utilization. Appl. Microbiol. Biotechnol. 82(6), 1037.

[200]Mandels, M., Weber, J., 1969. The production of cellulases. ACS Publications.

[201]Marjamaa, K., Toth, K., Bromann, P.A., Szakacs, G., Kruus, K., 2013. Novel Penicillium cellulases for total hydrolysis of lignocellulosics. Enzyme Microb. Technol. 52(6-7), 358-369.

[202]Marques, S., Alves, L., Roseiro, J., Gírio, F., 2008. Conversion of recycled paper sludge to ethanol by SHF and SSF using Pichia stipitis. Biomass Bioenergy. 32(5), 400-406.

[203]Mathew, G.M., Sukumaran, R.K., Singhania, R.R., Pandey, A., 2008. Progress in research on fungal cellulases for lignocellulose degradation.

[204]McDonald, J.E., Houghton, J.N., Rooks, D.J., Allison, H.E., McCarthy, A.J., 2012. The microbial ecology of anaerobic cellulose degradation in municipal waste landfill sites: evidence of a role for fibrobacters. Environ. Microbial. 14(4), 1077-1087.

[205]McEwen, J.T., Atsumi, S., 2012. Alternative biofuel production in nonnatural hosts. Curr. Opin. Biotechnol. 23(5), 744-750.

[206]McMillan, J.D., 1994. Pretreatment of lignocellulosic biomass. ACS Publications.

[207]Meher, L.C., Sagar, D.V., Naik, S., 2006. Technical aspects of biodiesel production by transesterification-a review. Renew. Sust. Energy Rev. $10(3), 248-268$

[208]Mejía-Barajas, J.A., Montoya-Pérez, R., Cortés-Rojo, C., SaavedraMolina, A., 2016. Levaduras termotolerantes: aplicaciones industriales, estrés oxidativo y respuesta Antioxidante. Información Tecnológica. 27(4), 03-16.

[209]Mello-de-Sousa, T.M., Rassinger, A., Derntl, C., J Poças-Fonseca, M., L Mach, R., R Mach-Aigner, A., 2016. The relation between promoter chromatin status, Xyrl and cellulase expression in Trichoderma reesei. Curr. Genomics. 17(2), 145-152.

[210]Mingardon, F., Chanal, A., López-Contreras, A.M., Dray, C., Bayer, E.A., Fierobe, H.P., 2007. Incorporation of fungal cellulases in bacterial minicellulosomes yields viable, synergistically acting cellulolytic complexes. Appl. Environ. Microbiol. 73(12), 3822-3832.
[211]Miotto, L.S., de Rezende, C.A., Bernardes, A., Serpa, V.I., Tsang, A., Polikarpov, I., 2014. The characterization of the endoglucanase Cel12A from Gloeophyllum trabeum reveals an enzyme highly active on $\beta$-glucan. PloS One. 9(9), e108393.

[212]Misra, P., Shukla, P.K., Rao, K.P., Ramteke, P., 2019. Genetic engineering applications to improve cellulase production and efficiency: part II. New Future Dev. Microb. Biotechnol. Bioeng. Elsevier. 227-260.

[213]Mohammadi, M., Shafiei, M., Karimi, K., Abdolmaleki, A., Mikkola, J.P., Larsson, C., 2019. Improvement of ethanol production from birch and spruce pretreated with 1-H-3-methylmorpholinium chloride. Electron. J. Biotechnol. 41, 95-99.

[214]Mohanty, B., Abdullahi, I.I., 2016. Bioethanol production from lignocellulosic waste-a review. Biosci. Biotechnol. Res. Asia. 13(2), $1153-1161$

[215]Morgenstern, I., Powlowski, J., Tsang, A., 2014. Fungal cellulose degradation by oxidative enzymes: from dysfunctional GH61 family to powerful lytic polysaccharide monooxygenase family. Briefings Funct. Genomics. 13(6), 471-481.

[216]Moysés, D.N., Reis, V.C.B., Almeida, J.R.M.d., Moraes, L.M.P.d., Torres, F.A.G., 2016. Xylose fermentation by Saccharomyces cerevisiae: challenges and prospects. Int. J. Mol. Sci. 17(3), 207.

[217]Müller, G., Kalyani, D.C., Horn, S.J., 2017. LPMOs in cellulase mixtures affect fermentation strategies for lactic acid production from lignocellulosic biomass. Biotechnol. Bioeng. 114(3), 552-559.

[218]Myat, L., Ryu, G., 2016. Pretreatments and factors affecting saccharification and fermentation for lignocellulosic ethanol production. Cellulose Chem. Technol. 50(2), 177-188.

[219]Nagoor Gunny, A., Arbain, D., Mohamed Daud, M., Jamal, P., 2014 Synergistic action of deep eutectic solvents and cellulases for lignocellulosic biomass hydrolysis. Mater. Res. Innovations. 18(sup6), S6-65-S66-67.

[220]Nakamura, A.M., Nascimento, A.S., Polikarpov, I., 2017. Structural diversity of carbohydrate esterases. Biotechnol. Res. Innovation. 1(1), 35-51.

[221]Nigam, P., Singh, D., 1995. Enzyme and microbial systems involved in starch processing. Enzyme Microb. Technol. 17(9), 770-778.

[222]Nijland, J.G., Shin, H.Y., Boender, L.G., de Waal, P.P., Klaassen, P., Driessen, A.J., 2017. Improved xylose metabolism by a CYC8 mutant of Saccharomyces cerevisiae. Appl. Environ. Microbiol. 83(11), e00095-00017.

[223]Nikolić, S., Pejin, J., Mojović, L., 2016. Challenges in bioethano production: utilization of cotton fabrics as a feedstock. Chem. Ind. Chem. Eng. Q. 22(4), 375-390.

[224]Nitta, M., Furukawa, T., Shida, Y., Mori, K., Kuhara, S., Morikawa, Y., Ogasawara, W., 2012. A new Zn (II) $)_{2}$ Cys $_{6}$-type transcription factor BgIR regulates $\beta$-glucosidase expression in Trichoderma reesei. Fungal Genet. Biol. 49(5), 388-397.

[225]Nor, N.A.M., Mustapha, W.A.W., Hassan, O., 2015. Deep eutectic solvent (DES) as a pretreatment for oil palm empty fruit bunch (OPEFB) in production of sugar. AIP Publishing LLC. AIP Conf. Proc. 1678(1), 050044

[226]Numan, M.T., Bhosle, N.B., 2006. $\alpha$-L-Arabinofuranosidases: the potential applications in biotechnology. J. Ind. Microbiol. Biotechnol. $33(4), 247-260$.

[227]Nwosu-Obieogu, K., Chiemenem, L., Adekunle, K., 2016. Utilization of agricultural waste for bioethanol production-a review. Int. J. Curr. Res. Rev. 8(19), 1

[228]Offei, F., Mensah, M., Thygesen, A., Kemausuor, F., 2018. Seaweed bioethanol production: a process selection review on hydrolysis and fermentation. Fermentation. 4(4), 99.

[229]Olson, D.G., McBride, J.E., Shaw, A.J., Lynd, L.R., 2012. Recent progress in consolidated bioprocessing. Curr. Opin. Biotechnol. 23(3), 396-405.

[230]Olsson, L., Hahn-Hägerdal, B., 1996. Fermentation of lignocellulosic hydrolysates for ethanol production. Enzyme Microb. Technol. 18(5), 312-331.

[231]Ota, M., Sakuragi, H., Morisaka, H., Kuroda, K., Miyake, H., Tamaru, Y., Ueda, M., 2013. Display of Clostridium cellulovorans xylose isomerase on the cell surface of Saccharomyces cerevisiae and its 
direct application to xylose fermentation. Biotechnol. Prog. 29(2), 346351.

[232] Ottenheim, C., Werner, K.A., Zimmermann, W., Wu, J.C., 2015. Improved endoxylanase production and colony morphology of Aspergillus niger DSM 26641 by $\gamma$-ray induced mutagenesis. Biochem. Eng. J. 94, 9-14.

[233]Påhlman, A.K., Granath, K., Ansell, R., Hohmann, S. and Adler, L., 2001. The yeast glycerol 3-phosphatases Gpp1p and Gpp2p are required for glycerol biosynthesis and differentially involved in the cellular responses to osmotic, anaerobic, and oxidative stress. J. Biol. Chem. 276(5), 35553563.

[234]Pang, J., Liu, Z.Y., Hao, M., Zhang, Y.F., Qi, Q.S., 2017. An isolated cellulolytic Escherichia coli from bovine rumen produces ethanol and hydrogen from corn straw. Biotechnol. Biofuels. 10(1), 165.

[235]Papapetridis, I., van Dijk, M., van Maris, A.J., Pronk, J.T., 2017. Metabolic engineering strategies for optimizing acetate reduction, ethanol yield and osmotolerance in Saccharomyces cerevisiae. Biotechnol. Biofuels 10(1), 107.

[236]Parambil, L.K., Sarkar, D., 2015. In silico analysis of bioethanol overproduction by genetically modified microorganisms in coculture fermentation. Biotechnol. Res. Int. 2015.

[237]Park, I., Kim, I., Kang, K., Sohn, H., Rhee, I., Jin, I., Jang, H., 2010. Cellulose ethanol production from waste newsprint by simultaneous saccharification and fermentation using Saccharomyces cerevisiae KNU5377. Process. Biochem. 45(4), 487-492.

[238]Patel, A.K., Singhania, R.R., Sim, S.J., Pandey, A., 2019. Thermostable cellulases: current status and perspectives. Bioresour. Technol. 279, 385392

[239]Peng, B., Huang, S., Liu, T., Geng, A., 2015. Bacterial xylose isomerases from the mammal gut Bacteroidetes cluster function in Saccharomyces cerevisiae for effective xylose fermentation. Microb. cell Fact. 14(1), 70.

[240]Pérez-Pimienta, J.A., Papa, G., Gladden, J.M., Simmons, B.A., Sanchez, A., 2020. The effect of continuous tubular reactor technologies on the pretreatment of lignocellulosic biomass at pilot-scale for bioethanol production. RSC Adv. 10(31), 18147-18159.

[241]Phillips, C.M., Iavarone, A.T., Marletta, M.A., 2011. Quantitative proteomic approach for cellulose degradation by Neurospora crassa. J. proteome Res. 10(9), 4177-4185.

[242]Phillips, E., 2019. Genetic engineering applications to improve cellulase production and efficiency: part I. New Future Dev. microb. Biotechnol. Bioeng. 209-225.

[243]Phitsuwan, P., Laohakunjit, N., Kerdchoechuen, O., Kyu, K.L., Ratanakhanokchai, K., 2013. Present and potential applications of cellulases in agriculture, biotechnology, and bioenergy. Folia Microbial. 58(2), 163-176

[244]Poidevin, L., Feliu, J., Doan, A., Berrin, J.G., Bey, M., Coutinho, P.M., Henrissat, B., Record, E., Heiss-Blanquet, S., 2013. Insights into exo-and endoglucanase activities of family 6 glycoside hydrolases from Podospora anserina. Appl. Environ. Microbiol. 79(14), 4220-4229.

[245] Prabavathy, V.R., Mathivanan, N., Sagadevan, E., Murugesan, K., Lalithakumari, D., 2006. Self-fusion of protoplasts enhances chitinase production and biocontrol activity in Trichoderma harzianum. Bioresour. Technol. 97(18), 2330-2334.

[246]Prasoulas, G., Gentikis, A., Konti, A., Kalantzi, S., Kekos, D., Mamma, D., 2020. Bioethanol production from food waste applying the multienzyme system produced on-site by Fusarium oxysporum $\mathrm{F} 3$ and mixed microbial cultures. Fermentation. 6(2), 39.

[247]Prior, B.A., Hohmann, S., 1997. Glycerol production and osmoregulation, in: Zimmermann, F.K., Entian, K.-D. (Eds.), Yeast sugar metabolism, Technomic Publishing Co., INC. Lancaster . Basel pp.313337.

[248]Procentese, A., Johnson, E., Orr, V., Campanile, A.G., Wood, J.A., Marzocchella, A., Rehmann, L., 2015. Deep eutectic solvent pretreatment and subsequent saccharification of corncob. Bioresour. Technol. 192, 3136.

[249]Procentese, A., Raganati, F., Olivieri, G., Russo, M.E., Rehmann, L., Marzocchella, A., 2017. Low-energy biomass pretreatment with deep eutectic solvents for bio-butanol production. Bioresour. Technol. 243, 464-473.
[250]Procentese, A., Raganati, F., Olivieri, G., Russo, M.E., Rehmann, L. Marzocchella, A., 2018. Deep eutectic solvents pretreatment of agroindustrial food waste. Biotechnol. Biofuels. 11(1), 37

[251]Qin, L., Zhao, X., Li, W.C., Zhu, J. Q., Liu, L., Li, B.Z., Yuan, Y.J., 2018. Process analysis and optimization of simultaneous saccharification and co-fermentation of ethylenediamine-pretreated corn stover for ethanol production. Biotechnol. Biofuels. 11(1), 118.

[252]Quinlan, R.J., Sweeney, M.D., Leggio, L.L., Otten, H., Poulsen, J.C.N., Johansen, K.S., Krogh, K.B., Jørgensen, C.I., Tovborg, M. Anthonsen, A., 2011. Insights into the oxidative degradation of cellulose by a copper metalloenzyme that exploits biomass components. Proc. Natl. Acad. Sci. 108(37), 15079-15084.

[253]Raftery, J.P., Karim, M.N., 2017. Economic viability of consolidated bioprocessing utilizing multiple biomass substrates for commercialscale cellulosic bioethanol production. Biomass Bioenergy. 103, 35 46.

[254]Rai, R., Kaur, B., Chadha, B.S., 2016a. A method for rapid purification and evaluation of catalytically distinct lignocellulolytic glycosyl hydrolases from thermotolerant fungus Acrophialophora sp. Renewable Energy. 98, 254-263

[255]Rai, R., Kaur, B., Singh, S., Di Falco, M., Tsang, A., Chadha, B., 2016b. Evaluation of secretome of highly efficient lignocellulolytic Penicillium sp. Dal 5 isolated from rhizosphere of conifers. Bioresour. Technol. 216, 958-967.

[256]Rai, M., Ingle, A.P., Pandit, R., Paralikar, P., Biswas, J.K., da Silva, S.S., 2019a. Emerging role of nanobiocatalysts in hydrolysis of lignocellulosic biomass leading to sustainable bioethanol production. Catal. Rev. 61(1), 1-26.

[257]Rai, R., Bibra, M., Chadha, B.S., Sani, R.K., 2019b. Enhanced hydrolysis of lignocellulosic biomass with doping of a highly thermostable recombinant laccase. Int. J. boil. Macromol. 137, 232 237.

[258]Rai, R., Basotra, N., Kaur, B., Di Falco, M., Tsang, A., Chadha, B., 2020. Exoproteome profile reveals thermophilic fungus Crassicarpon thermophilum (strain 6GKB; syn. Corynascus thermophilus) as a rich source of cellobiose dehydrogenase for enhanced saccharification of bagasse. Biomass Bioenergy. 132, 105438.

[259]Rastogi, M., Shrivastava, S., 2018. Current methodologies anc advances in bio-ethanol production. J. Biotechnol. Biores. 1(1), 1-8.

[260]Ravindran, R., Jaiswal, S., Abu-Ghannam, N., Jaiswal, A.K., 2018. A comparative analysis of pretreatment strategies on the properties and hydrolysis of brewers' spent grain. Bioresour. Technol. 248, 272-279.

[261]Rehman, L., Su, X., Guo, H., Qi, X., Cheng, H., 2016. Protoplast transformation as a potential platform for exploring gene function in Verticillium dahliae. BMC Biotechnol. 16(1), 57.

[262]Rezania, S., Din, M.F.M., Mohamad, S.E., Sohaili, J., Taib, S.M., Yusof, M.B.M., Kamyab, H., Darajeh, N., Ahsan, A., 2017. Review on pretreatment methods and ethanol production from cellulosic water hyacinth. BioResources. 12(1), 2108-2124

[263]Rezania, S., Oryani, B., Cho, J., Talaiekhozani, A., Sabbagh, F. Hashemi, B., Rupani, P.F., Mohammadi, A.A., 2020. Different pretreatment technologies of lignocellulosic biomass for bioethanol production: an overview. Energy. 117457

[264]Richard, P., Toivari, M.H., Penttilä, M., 2000. The role of xylulokinase in Saccharomyces cerevisiae xylulose catabolism. FEMS Microbial. Let. 190(1), 39-43.

[265]Robak, K., Balcerek, M., 2018. Review of second generation bioethanol production from residual biomass. Food Technol. Biotechnol. 56(2), 174-187.

[266]Robak, K., Balcerek, M., 2020. Current state-of-the-art in ethanol production from lignocellulosic feedstocks. Microbiol. Res. 240, 126534.

[267]Roca, C., Nielsen, J., Olsson, L., 2003. Metabolic engineering of ammonium assimilation in xylose-fermenting Saccharomyces cerevisiae improves ethanol production. Appl. Environ. Microbiol. 69(8), 4732-4736.

[268]Rosales-Calderon, O., Arantes, V., 2019. A review on commercialscale high-value products that can be produced alongside cellulosic ethanol. Biotechnol. Biofuels. 12(1), 240. 
[269]Runquist, D., Fonseca, C., Rådström, P., Spencer-Martins, I., HahnHägerdal, B., 2009. Expression of the Gxf1 transporter from Candida intermedia improves fermentation performance in recombinant xyloseutilizing Saccharomyces cerevisiae. Appl. Microb. Biotechnol. 82, 123130.

[270]Sadhu, S., Maiti, T.K., 2013. Cellulase production by bacteria: a review. Microb. Res. J. Int. 3(3), 235-258.

[271]Saha, B.C., Qureshi, N., Kennedy, G.J., Cotta, M.A., 2015. Enhancement of xylose utilization from corn stover by a recombinant Escherichia coli strain for ethanol production. Bioresour. Technol. 190, 182-188.

[272] Saini, J.K., Saini, R., Tewari, L., 2015. Lignocellulosic agriculture wastes as biomass feedstocks for second-generation bioethanol production: concepts and recent developments. 3 Biotech. 5(4), 337-353.

[273] Saini, J.K., Singhania, R.R., Satlewal, A., Saini, R., Gupta, R., Tuli, D., Mathur, A., Adsul, M., 2016. Improvement of wheat straw hydrolysis by cellulolytic blends of two Penicillium spp. Renewable Energy. 98, 43-50,

[274]Sakuragi, H., Kuroda, K., Ueda, M., 2011. Molecular breeding of advanced microorganisms for biofuel production. BioMed. Res. Int. 2011.

[275]Saloheimo, A., Rauta, J., Stasyk, V., Sibirny, A.A., Penttilä, M., Ruohonen, L., 2007. Xylose transport studies with xylose-utilizing Saccharomyces cerevisiae strains expressing heterologous and homologous permeases. Appl. Microbial. Biotechnol. 74, 1041-1052.

[276]Sanchez, O.J., Cardona, C.A., 2008. Trends in biotechnological production of fuel ethanol from different feedstocks. Bioresour. Technol. 99(13), 5270-5295.

[277]Sar, T., Stark, B.C., Yesilcimen Akbas, M., 2017. Effective ethanol production from whey powder through immobilized E. coli expressing Vitreoscilla hemoglobin. Bioengineered. 8(2), 171-181.

[278]Satari, B., Karimi, K., Kumar, R., 2019. Cellulose solvent-based pretreatment for enhanced second-generation biofuel production: a review. Sustainable Energy fuels. 3, 11-62

[279]Sathya, T., Khan, M., 2014. Diversity of glycosyl hydrolase enzymes from metagenome and their application in food industry. J. Food Sci. 79(11), R2149-R2156.

[280]Savitha, S., Sadhasivam, S., Swaminathan, K., 2010. Regeneration and molecular characterization of an intergeneric hybrid between Graphium putredinis and Trichoderma harzianum by protoplasmic fusion. Biotechnol. Adv. 28(3), 285-292.

[281]Sebayang, A.H., Masjuki, H.H., Ong, H.C., Dharma, S., Silitonga, A.S., Mahlia, T.M.I., Aditiya, H.B., 2016. A perspective on bioethanol production from biomass as alternative fuel for spark ignition engine. Rsc Adv. 6(18), 14964-14992.

[282]Selim, K.A., El-Ghwas, D.E., Easa, S.M., Hassan, A., Mohamed, I., 2018. Bioethanol a microbial biofuel metabolite; new insights of yeasts metabolic engineering. Fermentation. 4(1), 16.

[283] Shallom, D., Shoham, Y., 2003. Microbial hemicellulases. Curr. Opin. Microbial. 6(3), 219-228

[284] Sharma, N.K., Behera, S., Arora, R., Kumar, S., 2016a. Enhancement in xylose utilization using Kluyveromyces marxianus NIRE-K1 through evolutionary adaptation approach. Bioprocess. Biosyst. Eng. 39(5), 835843

[285]Sharma, V., Sharma, S., Kuila, A., 2016b. A review on current technological advancement of lignocellulosic bioethanol production. J. Appl. Biotechnol. Bioeng. 1(2), 11

[286] Sharma, N.K., Behera, S., Arora, R., Kumar, S., 2017. Evolutionary adaptation of Kluyveromyces marxianus NIRE-K3 for enhanced xylose utilization. Front. Energy Res. 5, 32.

[287] Sharma, N.K., Behera, S., Arora, R., Kumar, S., Sani, R.K., 2018 a. Xylose transport in yeast for lignocellulosic ethanol production: current status. J. Biosci. Bioeng. 125(3), 259-267.

[288]Sharma, S., Sharma, V., Kuila, A., 2018b. Simultaneous saccharification and fermentation of corn husk by co-culture strategy. J. Pet. Environ. Biotechnol. 9(1), 360.

[289]Shen, X.J., Wen, J.L., Mei, Q.Q., Chen, X., Sun, D., Yuan, T.Q., Sun, R.C., 2019. Facile fractionation of lignocelluloses by biomass-derived deep eutectic solvent (DES) pretreatment for cellulose enzymatic hydrolysis and lignin valorization. Green Chem. 21(2), 275-283.

[290]Shi, S., Liang, Y., Zhang, M.M., Ang, E.L., Zhao, H., 2016. A highly efficient single-step, markerless strategy for multi-copy chromosomal integration of large biochemical pathways in Saccharomyces cerevisiae. Metab. Eng. 33, 19-27.

[291]Shinoda, S., Kanamasa, S., Arai, M., 2012. Cloning of an endoglycanase gene from Paenibacillus cookii and characterization of the recombinant enzyme. Biotechnol. Lett. 34(2), 281-286.

[292]Silva, C.E.d.F., Bertucco, A., 2019. Bioethanol from Microalgal Biomass: A Promising Approach in Biorefinery. Braz. Arch. Biol. Technol. 62

[293]Singh, A., Patel, A.K., Adsul, M., Mathur, A., Singhania, R.R., 2017 Genetic modification: a tool for enhancing cellulase secretion. Biofue Res. J. 4(2), 600-610.

[294]Singh, Y.D., Satapathy, K.B., 2018. Conversion of lignocellulosic biomass to bioethanol: an overview with a focus on pretreatment. Int J. Eng. Technol. 15, 17-43.

[295] Singhania, R.R., Patel, A.K., Sukumaran, R.K., Larroche, C., Pandey, A., 2013. Role and significance of beta-glucosidases in the hydrolysis of cellulose for bioethanol production. Bioresour. Technol. 127, 500507.

[296] Socha, A.M., Parthasarathi, R., Shi, J., Pattathil, S., Whyte, D. Bergeron, M., George, A., Tran, K., Stavila, V., Venkatachalam, S., 2014. Efficient biomass pretreatment using ionic liquids derived from lignin and hemicellulose. Proc. Natl. Acad. Sci. 111(35), E3587E3595.

[297]Sonderegger, M., Schümperli, M., Sauer, U., 2004. Metabolic engineering of a phosphoketolase pathway for pentose catabolism in Saccharomyces cerevisiae. Appl. Environ. Microbiol. 70(5), 28922897

[298]Souza, G.M., Ballester, M.V.R., de Brito Cruz, C.H., Chum, H., Dale, B., Dale, V.H., Fernandes, E.C., Foust, T., Karp, A., Lynd, L., 2017. The role of bioenergy in a climate-changing world. Environ. Dev. 23, 57-64.

[299]Spyridon, A., Willem Euverink, G.J., 2016. Consolidated briefing of biochemical ethanol production from lignocellulosic biomass Electron. J. Biotechnol. 19(5), 44-53.

[300]Stanley, D., Fraser, S., Chambers, P.J., Rogers, P., Stanley, G.A. 2010. Generation and characterisation of stable ethanol-tolerant mutants of Saccharomyces cerevisiae. J. Ind. Microbial. Biotechnol. 37, 139-149.

[301]Sun, K., Li, S., Yu, J., Gong, R., Si, Y., Liu, X., Chu, G., 2019. Cu²+ assisted laccase from Trametes versicolor enhanced self-polyreaction of triclosan. Chemosphere. 225, 745-754.

[302]Sun, Y., Cheng, J., 2002. Hydrolysis of lignocellulosic materials for ethanol production: a review. Bioresour. Technol. 83(1), 1-11.

[303] Sweeney, M.D., Xu, F., 2012. Biomass converting enzymes as industrial biocatalysts for fuels and chemicals: recent developments Catalysts. 2(2), 244-263

[304]Tandon, D., Sharma, N., 2019. Ethanol from Softwood Biomass. Int. J. Curr. Microbiol. App. Sci. 8(2), 2915-2927.

[305]Taouda, H., Chabir, R., Aarab, L., Miyah, Y., Errachich, F., 2017. Biomass and bioethanol production from date extract. J. Mater Environ. Sci. 8(9), 3391-3396

[306]Tayyab, M., Noman, A., Islam, W., Waheed, S., Arafat, Y., Ali, F., Zaynab, M., Lin, S., Zhang, H., Lin, W., 2018. Bioethanol production from lignocellulosic biomass by environment-friendly pretreatment methods: a review. Appl. Ecol. Env. Res 16(1), 225-249.

[307]Teixeira, A.C.R., Sodré, J.R., Guarieiro, L.L.N., Vieira, E.D., de Medeiros, F.F., Alves, C.T., 2016. A Review on Second and Third Generation Bioethanol Production. SAE Technical Paper.

[308]Teixeira, M.C., Raposo, L.R., Mira, N.P., Lourenço, A.B., SáCorreia, I., 2009. Genome-wide identification of Saccharomyces cerevisiae genes required for maximal tolerance to ethanol. Appl. Environ. Microbiol. 75(18), 5761-5772.

[309]Temer, B., dos Santos, L.V., Negri, V.A., Galhardo, J.P., Magalhães, P.H.M., José, J., Marschalk, C., Corrêa, T.L.R., Carazzolle, M.F., Pereira, G.A.G., 2017. Conversion of an inactive xylose isomerase into a functional enzyme by co-expression of GroEL-GroES chaperonins in Saccharomyces cerevisiae. BMC Biotechnol. 17, 71.

[310]Thi, S., Lee, K.M., 2019. Comparison of deep eutectic solvents (DES) on pretreatment of oil palm empty fruit bunch (OPEFB): cellulose 
digestibility, structural and morphology changes. Bioresour. Technol. 282, 525-529.

[311]Tian, L., Perot, S.J., Stevenson, D., Jacobson, T., Lanahan, A.A., Amador-Noguez, D., Olson, D.G., Lynd, L.R., 2017. Metabolome analysis reveals a role for glyceraldehyde 3-phosphate dehydrogenase in the inhibition of C. thermocellum by ethanol. Biotechnol. Biofuels. 10.

[312]Toivari, M.H., Aristidou, A., Ruohonen, L., Penttilä, M., 2001. Conversion of xylose to ethanol by recombinant Saccharomyces cerevisiae: importance of xylulokinase (XKS1) and oxygen availability. Metab. Eng. 3(3), 236-249.

[313]Toor, M., Kumar, S.S., Malyan, S.K., Bishnoi, N.R., Mathimani, T., Rajendran, K., Pugazhendhi, A., 2020. An overview on bioethanol production from lignocellulosic feedstocks. Chemosphere. 242, 125080.

[314]Tsegaye, B., Balomajumder, C., Roy, P., 2019. Microbial delignification and hydrolysis of lignocellulosic biomass to enhance biofuel production: an overview and future prospect. Bull. Natl. Res. Centre. 43, 51

[315]Ulaganathan, K., S Goud, B., M Reddy, M., P Kumar, V., Balsingh, J., Radhakrishna, S., 2015. Proteins for breaking barriers in lignocellulosic bioethanol production. Curr. Protein Pept. Sci. 16(2), 100-134.

[316]Ummalyma, S.B., Supriya, R.D., Sindhu, R., Binod, P., Nair, R.B., Pandey, A., Gnansounou, E., 2019. Biological pretreatment of lignocellulosic biomass-current trends and future perspectives. Second Third Gener. Feedstocks. Elsevier. 197-212.

[317]Vaaje-Kolstad, G., Westereng, B., Horn, S.J., Liu, Z., Zhai, H., Sørlie, M., Eijsink, V.G., 2010. An oxidative enzyme boosting the enzymatic conversion of recalcitrant polysaccharides. Science. 330(6001), 219-222.

[318]Vaid, S., Nargotra, P., Bajaj, B.K., 2018. Consolidated bioprocessing for biofuel-ethanol production from pine needle biomass. Environ. Progr. Sust. Energy. 37(1), 546-552.

[319]Van Zyl, W.H., Lynd, L.R., den Haan, R., McBride, J.E., 2007. Consolidated bioprocessing for bioethanol production using Saccharomyces cerevisiae. Biofuels. Springer, Berlin, Heidelberg. 205235.

[320] Vazirzadeh, M., Robati, R., 2013. Investigation of bio-ethanol production from waste potatoes. Ann. Biol. Res. 4(1), 104-106.

[321]Verho, R., Londesborough, J., Penttilä, M., Richard, P., 2003. Engineering redox cofactor regeneration for improved pentose fermentation in Saccharomyces cerevisiae. Appl. Environ. Microbiol. 69(10), 5892-5897.

[322]Vermaas, J.V., Crowley, M.F., Beckham, G.T., Payne, C.M., 2015. Effects of lytic polysaccharide monooxygenase oxidation on cellulose structure and binding of oxidized cellulose oligomers to cellulases. J. Phys. Chem. B. 119(20), 6129-6143.

[323]Vu, V.H., Kim, K., 2012. Improvement of cellulase activity using errorprone rolling circle amplification and site-directed mutagenesis. J. Microbiol. Biotechnol. 22(5), 607-613

[324]Wahlbom, C.F., Hahn-Hägerdal, B., 2002. Furfural, 5-hydroxymethyl furfural, and acetoin act as external electron acceptors during anaerobic fermentation of xylose in recombinant Saccharomyces cerevisiae. Biotechnol. Bioeng. 78(2), 172-178.

[325]Wahlström, R., Suurnäkki, A., 2015. Enzymatic hydrolysis of lignocellulosic polysaccharides in the presence of ionic liquids. Green Chem. 17, 694-714.

[326]Walfridsson, M., Anderlund, M., Bao, X., Hahn-Hägerdal, B., 1997. Expression of different levels of enzymes from the Pichia stipitis XYL and $\mathrm{XYL}_{2}$ genes in Saccharomyces cerevisiae and its effects on product formation during xylose utilisation. Appl. Microbial. Biotechnol. 48(2), 218-224.

[327]Walfridsson, M., Bao, X., Anderlund, M., Lilius, G., Bülow, L., HahnHägerdal, B., 1996. Ethanolic fermentation of xylose with Saccharomyces cerevisiae harboring the Thermus thermophilus xylA gene, which expresses an active xylose (glucose) isomerase. Appl. Environ. Microbiol. 62(12), 4648-4651.

[328]Walton, P.H., Davies, G.J., 2016. On the catalytic mechanisms of 1ytic polysaccharide monooxygenases. Curr. Opin. Chem. Boil. 31, 195-207.

[329]Wang, M., Lu, X., 2016. Exploring the synergy between cellobiose dehydrogenase from Phanerochaete chrysosporium and cellulase from Trichoderma reesei. Front. Microbial. 7, 620.
[330]Wang, T., Liu, X., Yu, Q., Zhang, X., Qu, Y., Gao, P., Wang, T., 2005. Directed evolution for engineering $\mathrm{pH}$ profile of endoglucanase III from Trichoderma reesei. Biomol. Eng. 22(1-3), 89-94.

[331]Wang, Z., Hou, X., Sun, J., Li, M., Chen, Z., Gao, Z., 2018. Comparison of ultrasound-assisted ionic liquid and alkaline pretreatment of Eucalyptus for enhancing enzymatic saccharification. Bioresour. Technol. 254, 145-150

[332]Watanabe, M., Watanabe, D., Akao, T., Shimoi, H., 2009. Overexpression of MSN2 in a sake yeast strain promotes ethanol tolerance and increases ethanol production in sake brewing. J. Biosci. Bioeng. 107(5), 516-518.

[333]Wati, L., Dhamija, S.S., Singh, D., Nigam, P.S.N., Marchant, R., 1996. Characterisation of genetic control of thermotolerance in mutants of Saccharomyces cerevisiae. New Genet. Soc. 16(1), 19-26.

[334]Wei, N., Quarterman, J., Kim, S.R., Cate, J.H., Jin, Y.S., 2013. Enhanced biofuel production through coupled acetic acid and xylose consumption by engineered yeast. Nat. Commun. 4(1), 1-8.

[335]Wei, S., Liu, Y., Wu, M., Ma, T., Bai, X., Hou, J., Shen, Y., Bao, X., 2018. Disruption of the transcription factors $\mathrm{Thi}_{2} \mathrm{p}$ and $\mathrm{Nrmlp}$ alleviates the post-glucose effect on xylose utilization in Saccharomyces cerevisiae. Biotechnol. Biofuels. 11, 112.

[336]Wen, Z., Li, Q., Liu, J., Jin, M., Yang, S., 2020. Consolidated bioprocessing for butanol production of cellulolytic Clostridia: development and optimization. Microb. Biotechnol. 13(2), 410-422.

[337]Wong, Y., Sanggari, V., 2014. Bioethanol production from sugarcane bagasse using fermentation process. Orient. J. Chem. 30(2), 507-513.

[338]Woon, J.S.K., Murad, A.M.A., Abu Bakar, F., 2015. Isolation, molecular cloning and expression of cellobiohydrolase B (CbhB) from Aspergillus niger in Escherichia coli. AIP Conf. Proc. AIP Publishing LLC. 1678(1), 030004

[339]Wu, H., Mora-Pale, M., Miao, J., Doherty, T.V., Linhardt, R.J., Dordick, J.S., 2011. Facile pretreatment of lignocellulosic biomass at high loadings in room temperature ionic liquids. Biotechnol. Bioeng. 108(12), 2865-2875.

[340]Wu, R., Chen, D., Cao, S., Lu, Z., Huang, J., Lu, Q., Chen, Y., Chen, X., Guan, N., Wei, Y., 2020. Enhanced ethanol production from sugarcane molasses by industrially engineered Saccharomyces cerevisiae via replacement of the $\mathrm{PHO}_{4}$ gene. RSC Adv. 10, $2267-$ 2276.

[341]Wu, W., Wang, Z., Jin, Y., Matsumoto, Y., Zhai, H., 2014. Effects of $\mathrm{LiCl} / \mathrm{DMSO}$ dissolution and enzymatic hydrolysis on the chemical composition and lignin structure of rice straw. Biomass Bioenergy. 71, 357-362.

[342]Wymelenberg, A.V., Gaskell, J., Mozuch, M., Sabat, G., Ralph, J., Skyba, O., Mansfield, S.D., Blanchette, R.A., Martinez, D. Grigoriev, I., 2010. Comparative transcriptome and secretome analysis of wood decay fungi Postia placenta and Phanerochaete chrysosporium. Appl. Environ. Microbiol. 76(11), 3599-3610.

[343]Xia, S., Baker, G.A., Li, H., Ravula, S., Zhao, H., 2014. Aqueous ionic liquids and deep eutectic solvents for cellulosic biomass pretreatment and saccharification. RSC Adv. 4(21), 10586-10596.

[344]Xu, G.C., Ding, J.C., Han, R.Z., Dong, J.J., Ni, Y., 2016. Enhancing cellulose accessibility of corn stover by deep eutectic solvent pretreatment for butanol fermentation. Bioresour. Technol. 203, 364369.

[345] Yakovlev, I., Vaaje-Kolstad, G., Hietala, A.M., Stefańczyk, E. Solheim, H., Fossdal, C.G., 2012. Substrate-specific transcription of the enigmatic GH61 family of the pathogenic white-rot fungus Heterobasidion irregulare during growth on lignocellulose. Appl. Microbial. Biotechnol. 95, 979-990

[346]Yang, F., Gong, Y., Liu, G., Zhao, S., Wang, J., 2015. Enhancing cellulase production in thermophilic fungus Myceliophthora thermophila ATCC42464 by RNA interference of cre1 gene expression. J. Microbiol. Biotechnol. 25(7), 1101-1107.

[347]Yang, J., Bae, J.Y., Lee, Y.M., Kwon, H., Moon, H.Y., Kang, H.A., Yee, S.B., Kim, W., Choi, W., 2011. Construction of Saccharomyces cerevisiae strains with enhanced ethanol tolerance by mutagenesis of the TATA-binding protein gene and identification of novel genes associated with ethanol tolerance. Biotechnol. Bioeng. 108(8), 17761787. 
[348] Yang, P., Wu, Y., Zheng, Z., Cao, L., Zhu, X., Mu, D., Jiang, S., 2018. CRISPR-Cas9 approach constructing cellulase sestc-engineered Saccharomyces cerevisiae for the production of orange peel ethanol. Front. Microbial. 9, 2436.

[349]Yao, G., Li, Z., Gao, L., Wu, R., Kan, Q., Liu, G., Qu, Y., 2015. Redesigning the regulatory pathway to enhance cellulase production in Penicillium oxalicum. Biotechnol. Biofuels. 8, 71.

[350]Yazawa, H., Iwahashi, H., Uemura, H., 2007. Disruption of URA7 and GAL6 improves the ethanol tolerance and fermentation capacity of Saccharomyces cerevisiae. Yeast. 24(7), 551-560.

[351] Young, E., Poucher, A., Comer, A., Bailey, A., Alper, H., 2011. Functional survey for heterologous sugar transport proteins, using Saccharomyces cerevisiae as a host. Appl. Environ. Microbiol. 77(10), 3311-3319.

[352] Young, E.M., Tong, A., Bui, H., Spofford, C., Alper, H.S., 2014. Rewiring yeast sugar transporter preference through modifying a conserved protein motif. Proc. Natl. Acad. Sci. 111(1), 131-136.

[353]Zabed, H., Sahu, J., Boyce, A.N., Faruq, G., 2016. Fuel ethanol production from lignocellulosic biomass: an overview on feedstocks and technological approaches. Renew. Sust. Energy Rev. 66, 751-774.

[354]Zakir, H., Hasan, M., Shahriar, S., Ara, T., Hossain, M., 2016. Production of biofuel from agricultural plant wastes: corn stover and sugarcane bagasse. Chem. Eng. Sci. 4(1), 5-11.

[355]Zambare, V., Christopher, L.P., 2010. Solid state fermentation and characterization of a cellulase enzyme system from Aspergillus niger SB2. Int. J. Biol. Sci. Technol. 2(3), 22

[356]Zeng, R., Hu, Q., Yin, X.Y., Huang, H., Yan, J.B., Gong, Z.W., Yang, Z.H., 2016. Cloning a novel endo-1, 4- $\beta$-d-glucanase gene from Trichoderma virens and heterologous expression in E. coli. AMB Express. 6(1), 108

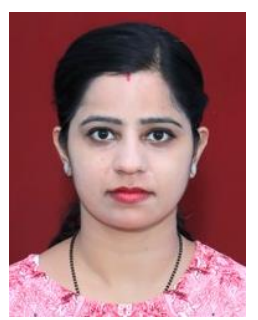

Dr. Yogita Lugani received her PhD in Biotechnology from the Punjabi University (India). She has worked as Research Associate at the Microbial Type Culture Collection and Gene Bank (MTCC), Council of Scientific and Industrial Research- Institute of Microbial Technology (CSIR-IMTech) (Chandigarh, India). She has received numerous prestigious awards, including Young Researcher Award, Women Achiever Award, and Rashtriya Gaurav Award. She is a member of the American Society of Microbiology (ASM), Association of Microbiologists of India (AMI), Biotech Research Society of India (BRSI), Proteomics Society of India (PSI), Indian Science Congress, Indian Network for Soil Contamination Research (INSCR), and Electron Microscope Society of India (EMSI). Her research interests include microbial diversity, microbial taxonomy, enzyme and fermentation technology, and production of industrial important metabolites.

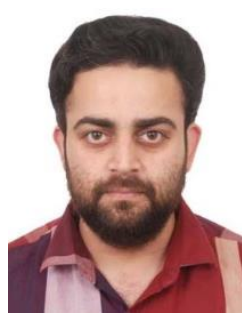

Dr. Rohit Rai is a Faculty of Applied Medical Sciences at Lovely Professional University (India). He received his $\mathrm{PhD}$ from the Department of Microbiology, Guru Nanak Dev University (Punjab, India). $\mathrm{He}$ is a recipient of a prestigious Bio-Energy Award for Cutting Edge Research (BACER) conferred by the Indo-US Science \& Technology Forum and Department of Biotechnology, Gov. of India. He was also selected as a Young Scientist of India by the Department of Science \& Technology, Gov. of India, to participate in the $4^{\text {th }}$ BRICS Young Scientist Conclave. His research interests include the development of indigenous enzyme cocktails for efficient bioconversion of lignocellulosic biomass into monomeric sugars that can be subsequently fermented into $2 \mathrm{G}$ ethanol and other value-added products.
[357]Zhang, CW., Xia, S.Q., Ma, P.S., 2016. Facile pretreatment of lignocellulosic biomass using deep eutectic solvents. Bioresour. Technol. 219, 1-5.

[358]Zhang, G.C., Liu, J.J., Ding, W.T., 2012. Decreased xylitol formation during xylose fermentation in Saccharomyces cerevisiae due to overexpression of water-forming NADH oxidase. Appl. Environ. Microbiol. 78(4), 1081-1086.

[359]Zhang, M., Jiang, Z., Yang, S., Hua, C., Li, L., 2010. Cloning and expression of a Paecilomyces thermophila xylanase gene in E. coli and characterization of the recombinant xylanase. Bioresour. Technol. 101(2), 688-695

[360]Zhang, R., Fan, Z., Kasuga, T., 2011. Expression of cellobiose dehydrogenase from Neurospora crassa in Pichia pastoris and its purification and characterization. Protein expression purify. 75(1), 63-69.

[361]Zhao, X.Q., Zi, L.H., Bai, F.W., Lin, H.L., Hao, X.M., Yue, G.J., Ho, N.W., 2011. Bioethanol from lignocellulosic biomass. Biotechnol. China III: Biofuels Bioenergy. Springer, Berlin, Heidelberg. 128, 25 51.

[362]Zheng, D.Q., Wu, X.C., Tao, X.L., Wang, P.M., Li, P., Chi, X.Q., Li, Y.D., Yan, Q.F., Zhao, Y.H., 2011. Screening and construction of Saccharomyces cerevisiae strains with improved multi-tolerance and bioethanol fermentation performance. Bioresour. Technol. 102(3), 3020-3027

[363]Zhou, H., Cheng, J.s., Wang, B.L., Fink, G.R., Stephanopoulos, G. 2012. Xylose isomerase overexpression along with engineering of the pentose phosphate pathway and evolutionary engineering enable rapid xylose utilization and ethanol production by Saccharomyces cerevisiae. Metab. Eng. 14(6), 611-622.

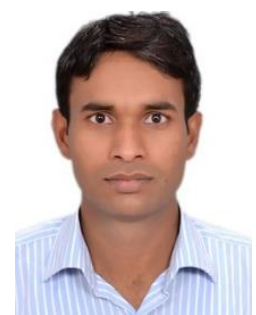

Dr. Sachin Kumar is a Deputy Director in the Biochemical Conversion Division at the Sardar Swaran Singh National Institute of Bio-Energy (Kapurthala, India). He was as a Visiting Professor in the Department of Chemical and Biological Engineering at South Dakota School of Mines and Technology (Rapid City, USA) for a year. He has more than fifteen years of research experience in Biochemical Conversion of Biomass to Biofuels including lignocellulosic ethanol, biogas, biohydrogen, etc. He is a recipient of the 2016 ASM-IUSSTF Indo-US Research Professorship and was presented with the Bioenergy-Awards for Cutting Edge Research (B-ACER) Fellow 2016 by DBT and IUSSTF.

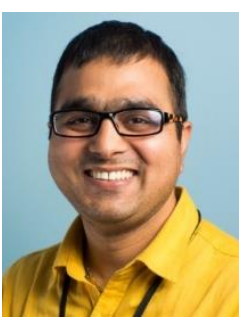

Dr. Vinod Kumar (VK) is a Lecturer in Bioenergy/Biomass Systems at the Cranfield University (CU) (UK) since 2017. Before joining the $\mathrm{CU}$, he was a Marie Curie Fellow at the Synthetic Biology Research Centre at the University of Nottingham, UK. He received his $\mathrm{PhD}$ in Biochemical Engineering \& Biotechnology and MSc. In Chemistry from the Indian Institute of Technology Delhi, India. VK has longstanding skills in microbial fermentation (fungal, yeast, and bacterial) and extensive experiences in the 'state-of-the-art' techniques of bioprocess optimization, metabolic engineering, and synthetic biology. His current research focuses on designing microbial chassis as cell factories to overproduce industrially-important compounds from waste streams rich in renewable carbon, bridging the agro-industrial waste streams such as lignocellulosic biomass, food waste, crude glycerol, etc. to valuable products. He serves as Subject Editor for "Food and Bioproducts Processing", Associate Editor for "3Biotech" and is a member of the Editorial Board of "Microbial Biotechnology" Journal. 

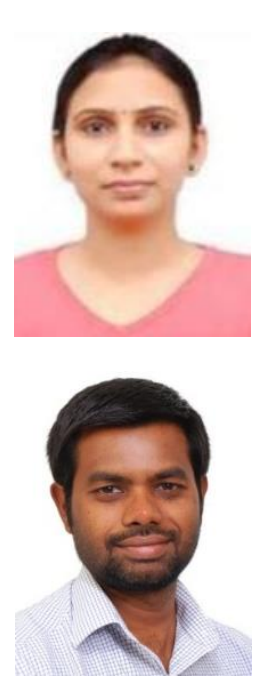

Dr. Poonam Maan is a Post-Doctoral Fellow at the Department of Biotechnology, College of Agriculture, Sardar Vallabhbhai Patel University of Agriculture and Technology (Meerut, India) under the scheme of UGC, New Delhi. Her research interests include bioenergy, biorefinery, and bioethanol production from lignocellulosic biomass.

Dr. Anuj K. Chandel is an Assistant Professor in the Department of Biotechnology, Engineering School of Lorena, University of São Paulo (Brazil). His primary research interest is to develop sustainable processes for bioconversion of renewable feedstock into renewable fuels and biochemicals by bridging the gap between research laboratories and industries.

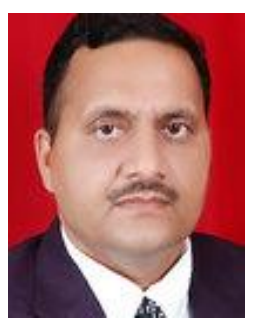

Dr. R.S. Sengar is a Professor in the Department of Biotechnology, College of Agriculture, Sardar Vallabhbhai Patel University of Agriculture and Technology (Meerut, India). His research interest is on biofuel, biodiesel, bioethanol, and tissue culture.

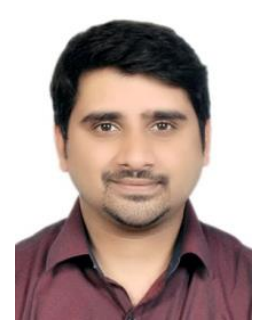

Dr. Ashish A Prabhu is an Assistant Professor in the Department of Biotechnology, National Institute of Technology Warangal (India). He received his $\mathrm{PhD}$ in Biochemical Engineering in 2018 from the Department of biosciences and bioengineering, Indian Institute of Technology (Guwahati, India). Then, he joined the Tata Institute of Genetics and Society (TIGS) (Bangalore, India) as a research associate and later worked as a research fellow in metabolic engineering at the Centre for Climate and Environmental Protection at the Cranfield University (UK). His research area includes metabolic engineering, conversion of waste to value-added products and bioprocessing of therapeutic proteins/enzymes.

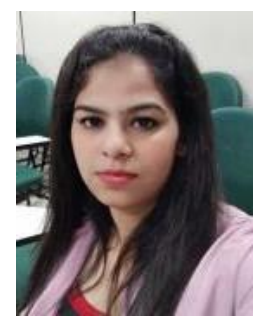

Meenu Hans is working as a Research Fellow at the Sardar Swaran Singh National Institute of BioEnergy (Kapurthala, India) while pursuing her Ph.D. at the Guru Nanak Dev University (Amritsar, India). She has also worked as a Visiting Scientist at the Institute of Physics in São Carlos (IFSC), University of São Paulo (São Paulo, Brazil) for 18 months. She has experience in fermentation technology, bioprocess optimization, biomass pretreatment and integrated biorefinery of biomass, and has research interests in converting biomass to renewable fuels and chemicals. 